\title{
مراسم تشييع جنازة الإمبراطور المغولي الهندي شاه جهان في ضوء نماذج من المنارئ المنمنمات الهندية والمصني المصادر التاريخية
}

\author{
تحمل علي عحم علي فداوي \\ دكتوراه في الآثار الإسلامية/تصوير إسلامي
}

ملخص البحث

تظل الأبام الأخيرة في حياة شاه جهان وطريقة تشييع جنازته موضع خلاف, للإلك وقع اختيار

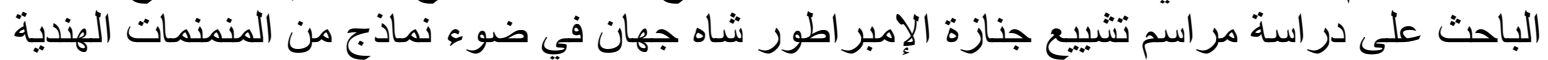

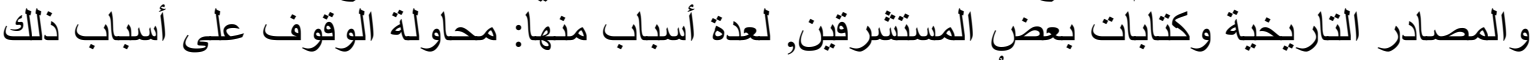

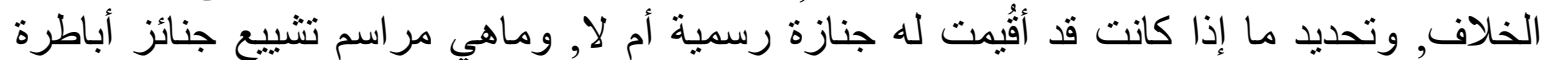

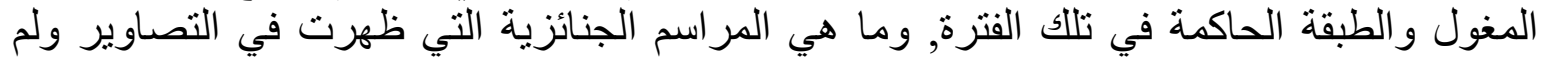

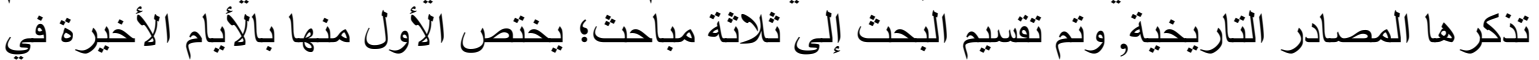

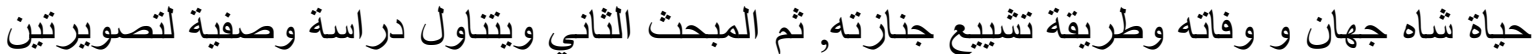

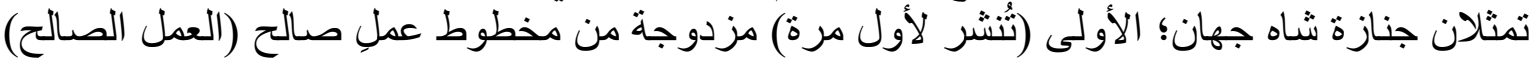

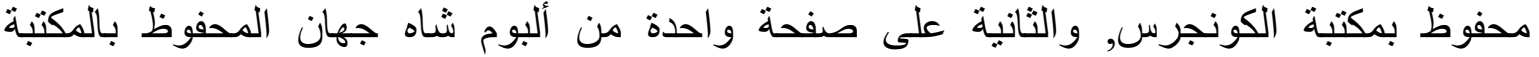

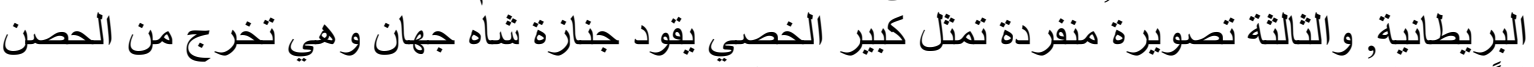

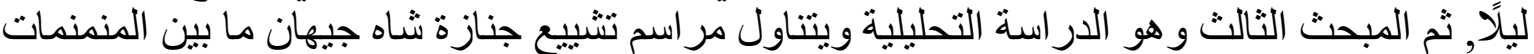
والمصادر التاريخية. الكلمات الدالة :شاه جهان - مر اسم جنائزيةــ عملِ صالح - مخطوطـ مصادر تاريخيةـ الهند.

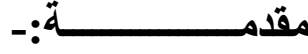
ارتبط في الغالب اسم الإمبر اطور المغولي الهندي شاه جهان بإنشائه لضريح تاج محل (ممتاز محل) الذي أنشأه لتخليد ذكرى زوجته المحبوبة ممتاز بيجوم وقصة الحب التب التي جمعت بينهما, ويُعلم الكثير حول حياة شاه جهان, وسياسته في حكم الهند, و إنجاز اته الحربية و ولئه الاقتصنادية و المعمارية و الفنية, كما

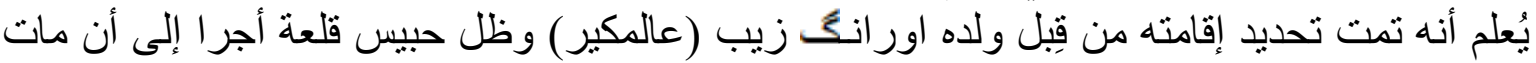

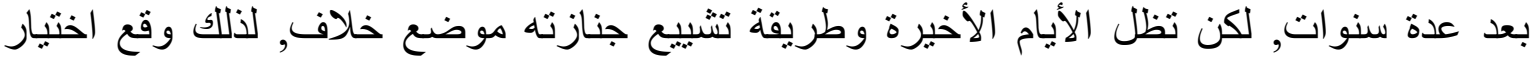

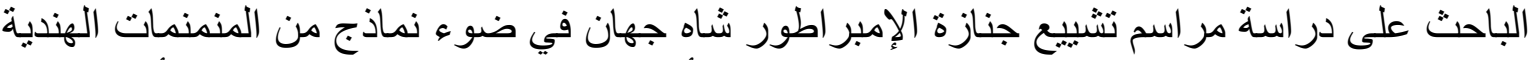

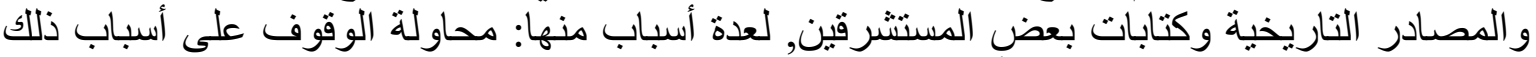

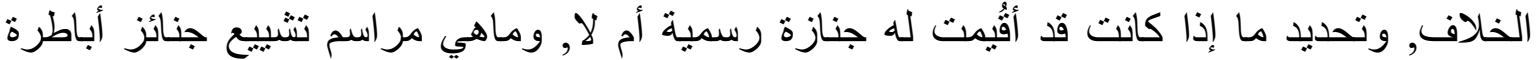

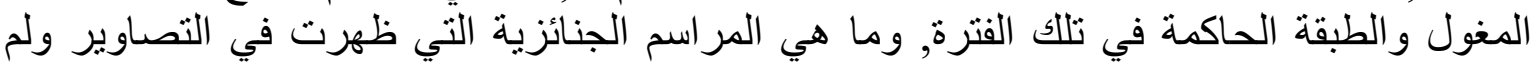
تذكر ها المصادر التاريخية, وتم تقسيم البحث إلى ثنلاثة مباحث؛ يختص الأول منها بالأيام الأخيرة في

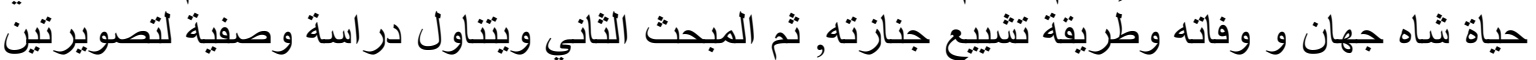

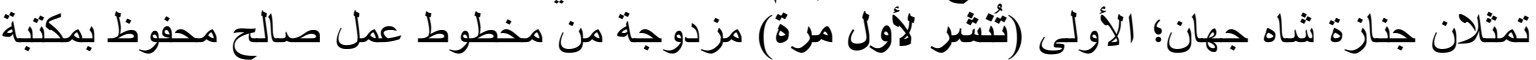

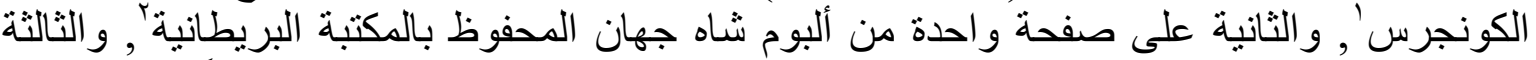

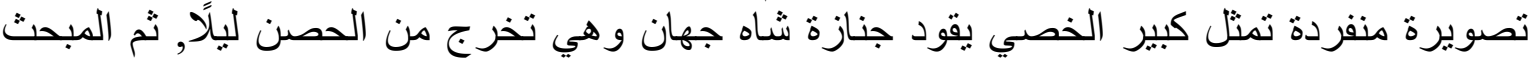

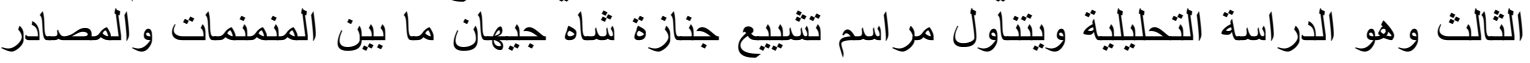




\section{المبحث الأول: الأيام الأخيرة في حياة شاه جهان و وفئه وفاته:-}

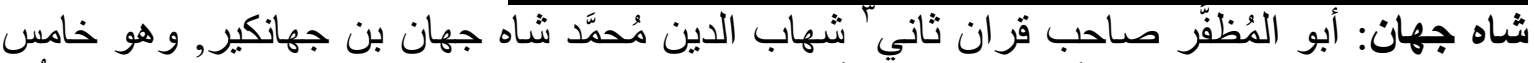

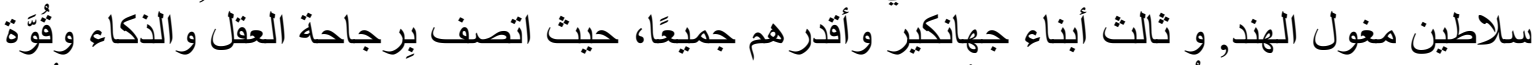

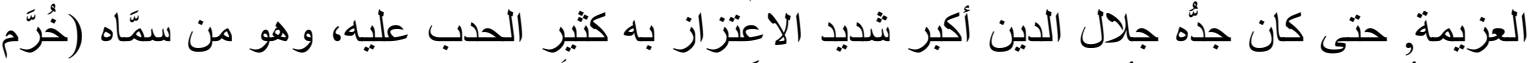

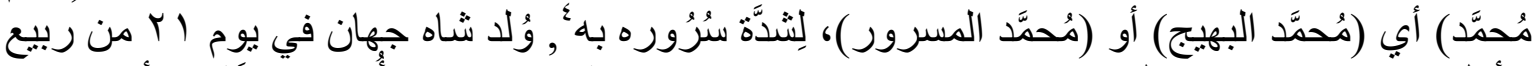

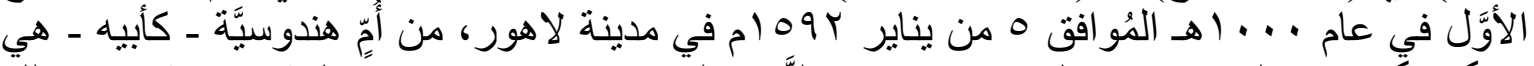

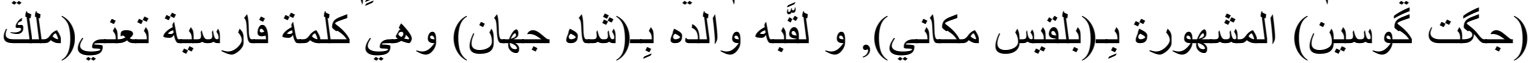

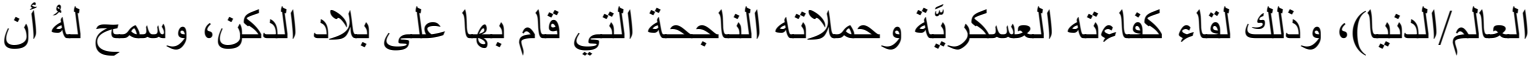

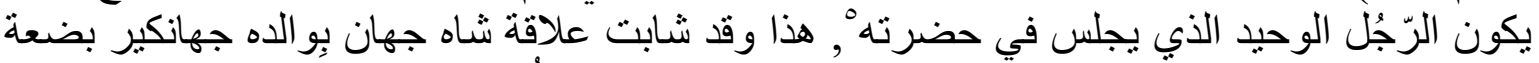

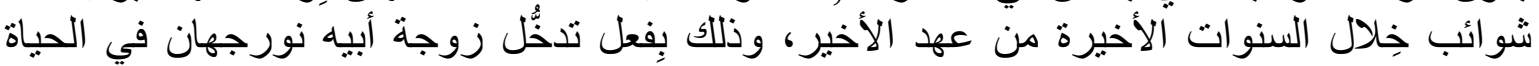

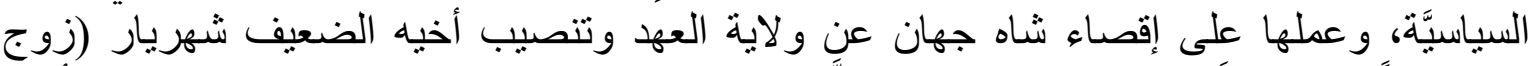

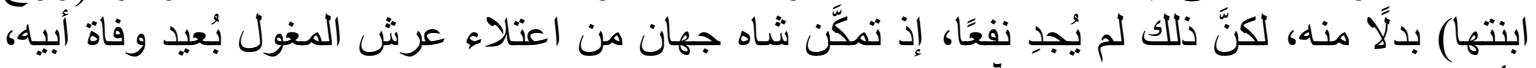

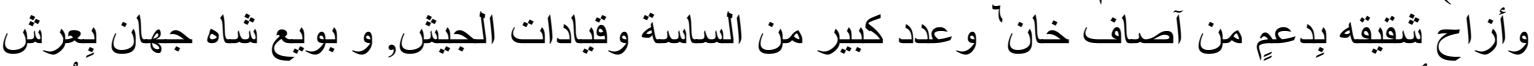

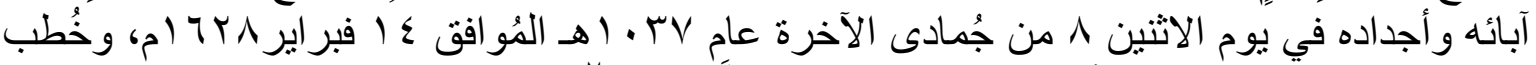

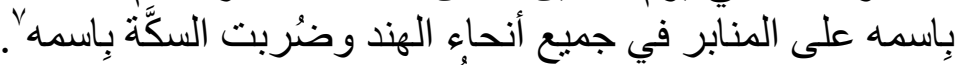

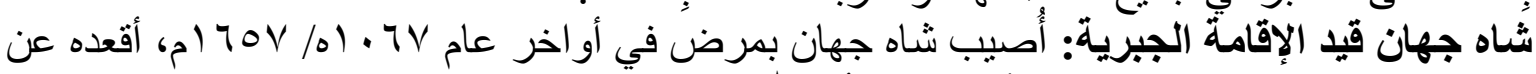

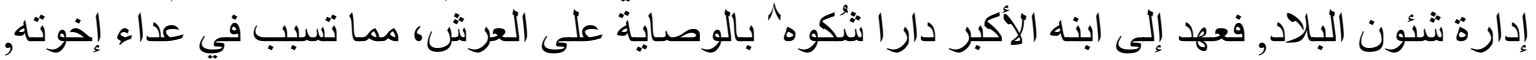

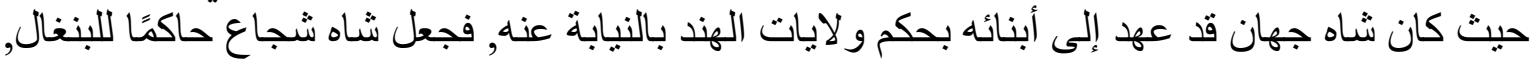

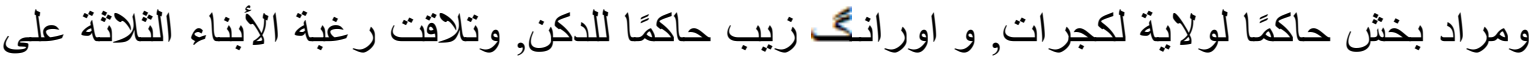

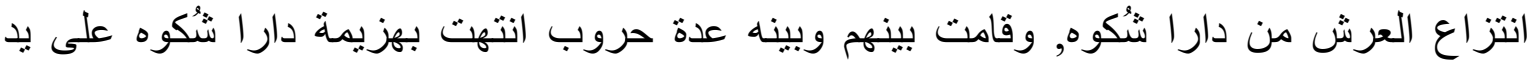

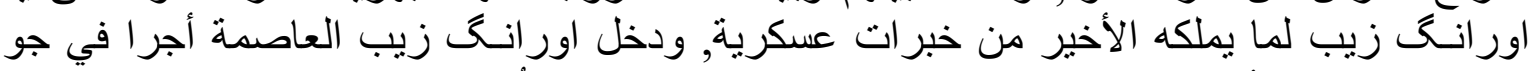

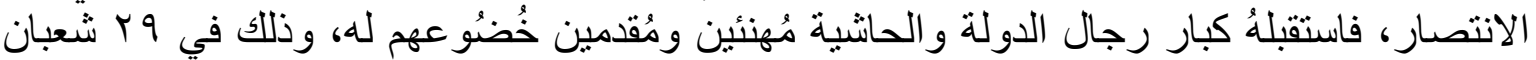

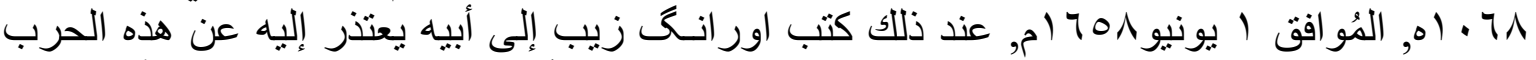

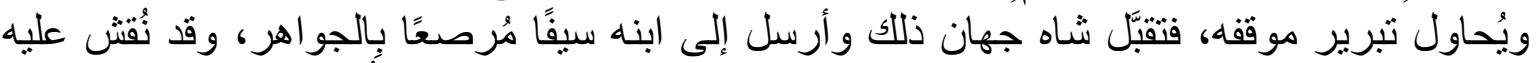

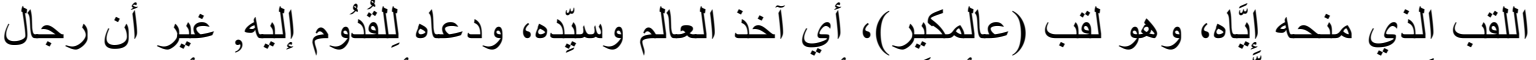

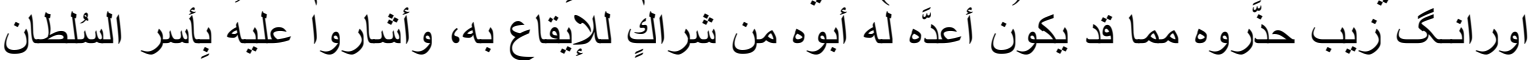

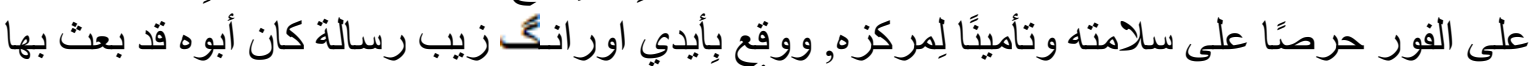

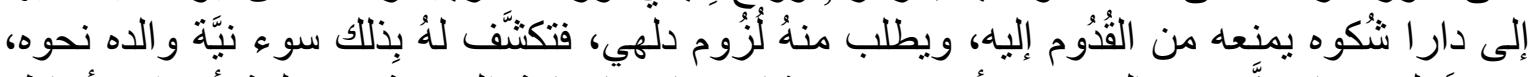

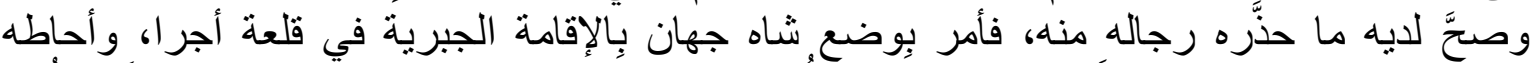

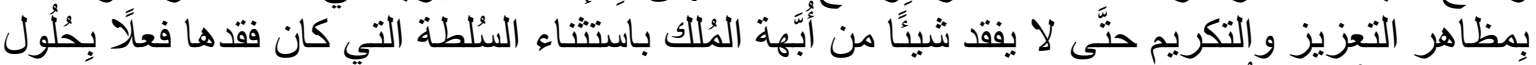

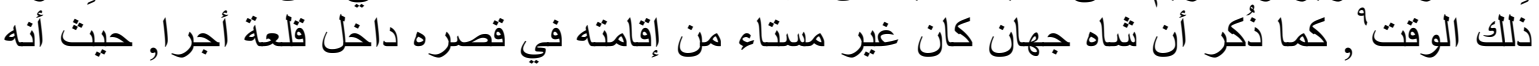

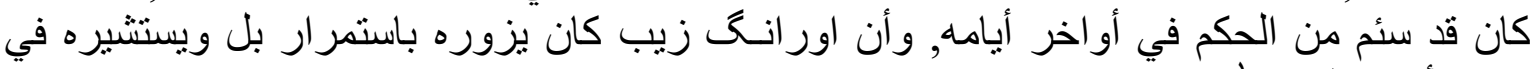
بعض أمور الحكم '.

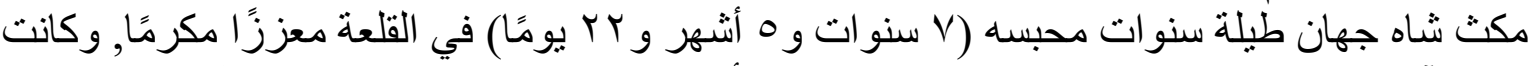

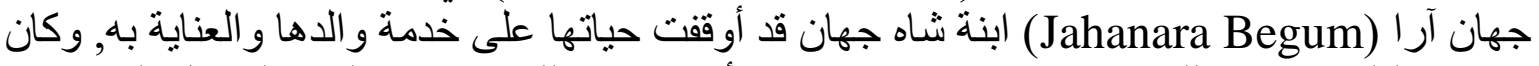

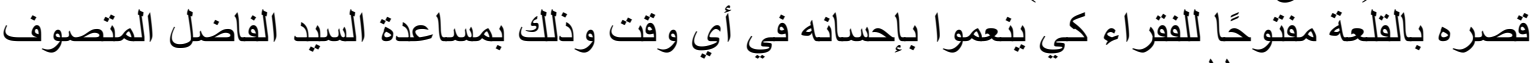
مير سيد حمد قنوجي" , حيث كان قنوجي يجلس في المجلس الثريف في القلعة وكان دائمًا ما يتلو آيات

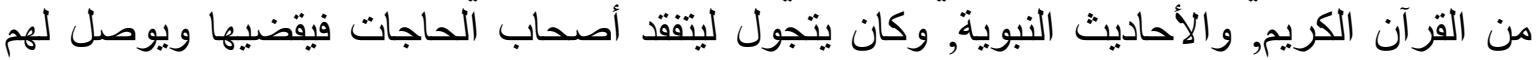

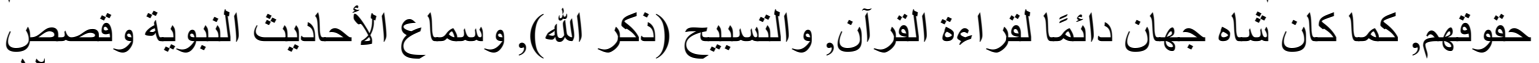

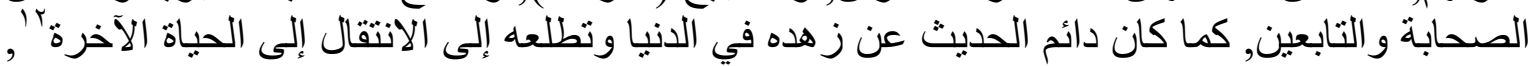




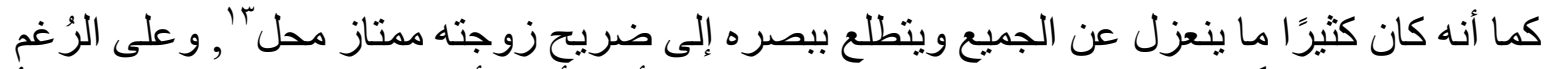

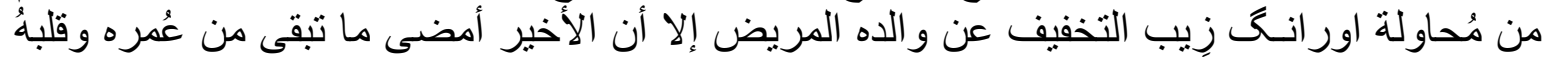

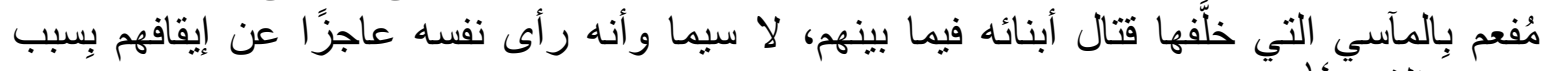
الأيسام الأخيرة: الثديد: قبيل وفاة شاه جهان بحوالي أسبو عين اشتد عليه المرض, فقد أُصيب فيما سبق بالفشل الكلوي, وفي تللك الأيام أصابته حمى شديدة و احتباه احتباس في البول, مما تسبب له في آلام شديدة لم يكن

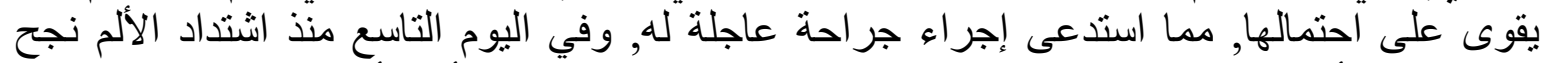

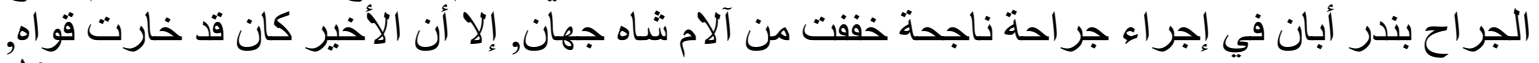

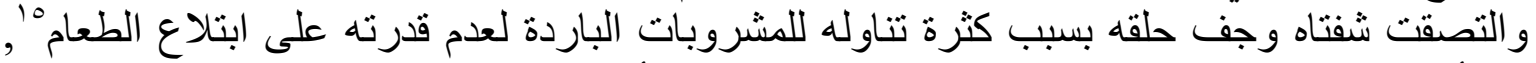

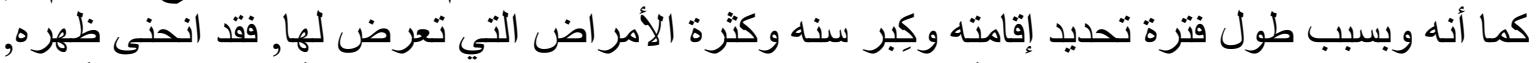

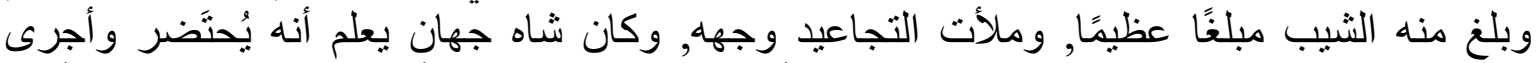

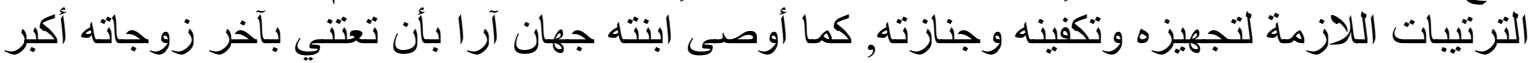

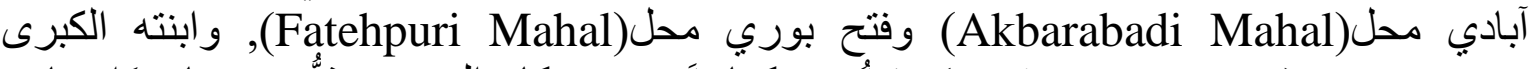

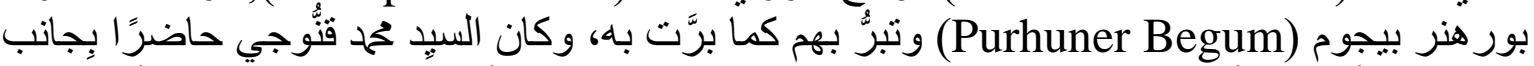

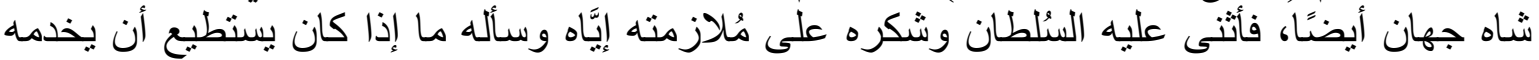

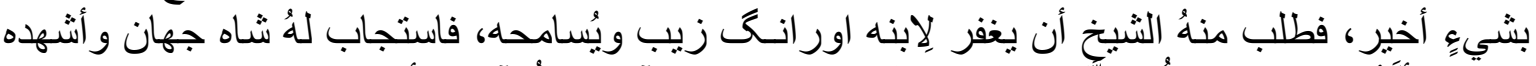

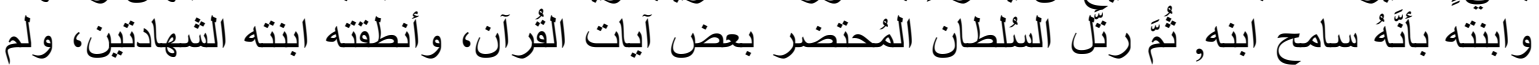

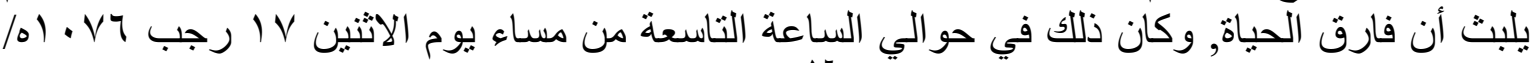

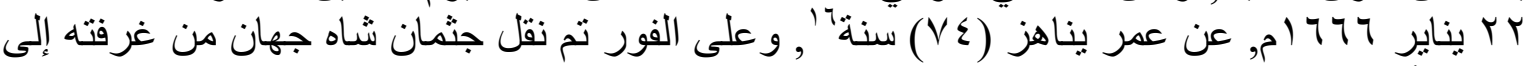

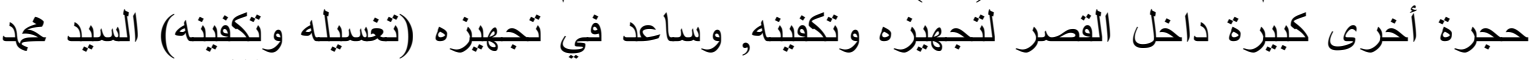

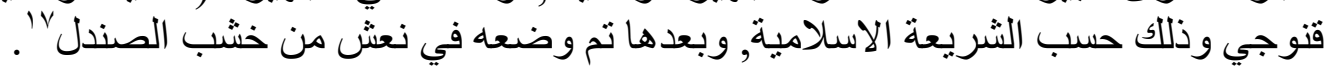

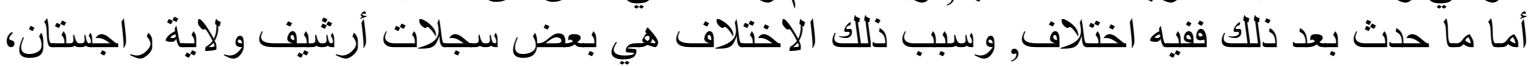

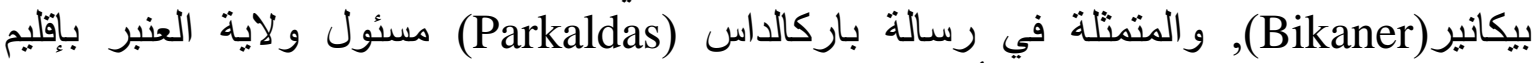

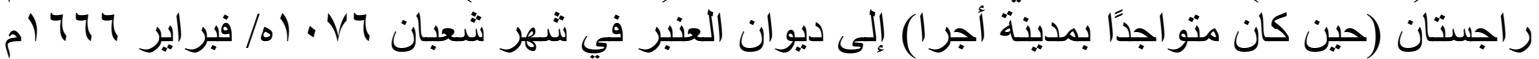

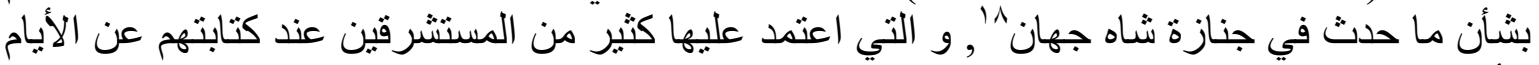

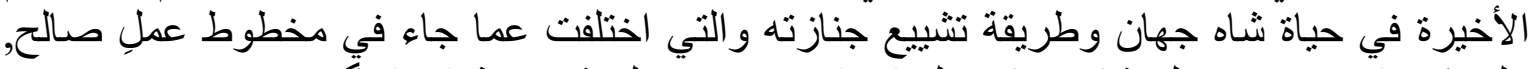

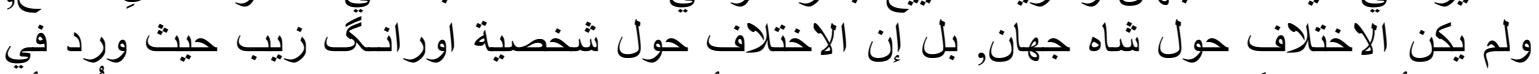

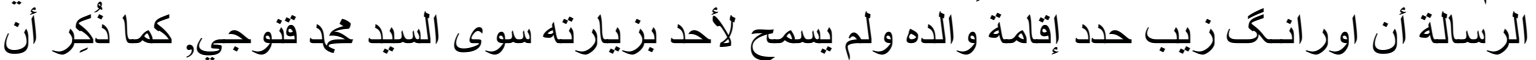

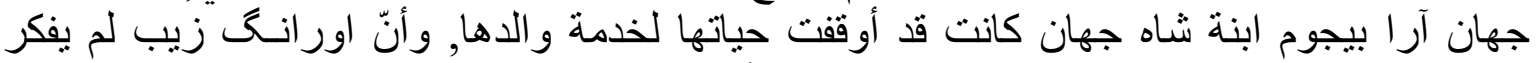

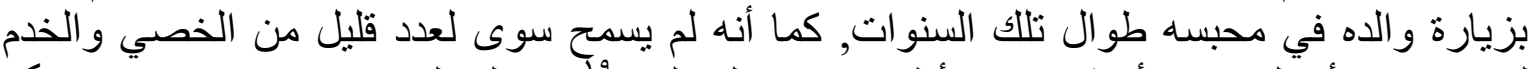

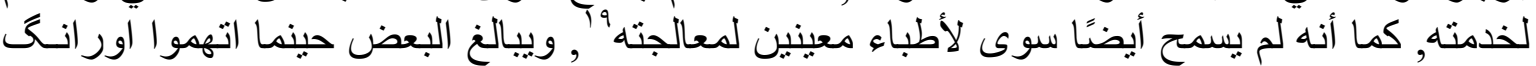
زيب بأنه دبّر لقتل و الده شاه جهان وذلك عن طريق كبير الخصي و المعروف ب بـ (Khaujo khan),

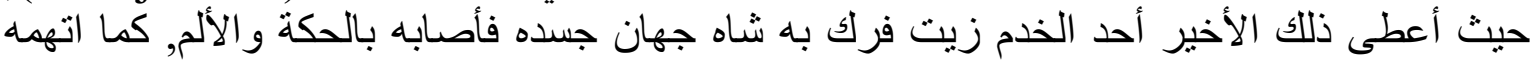

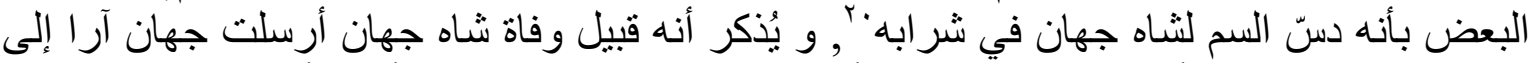

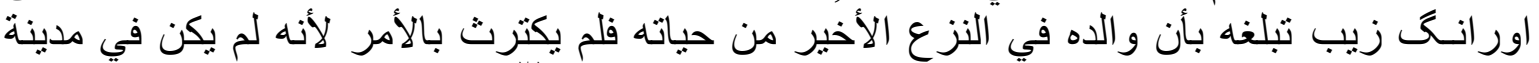

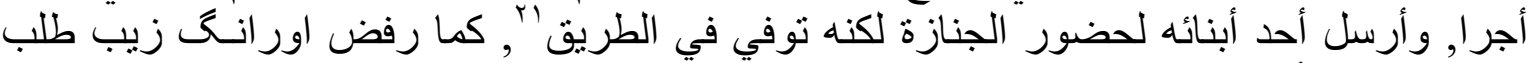

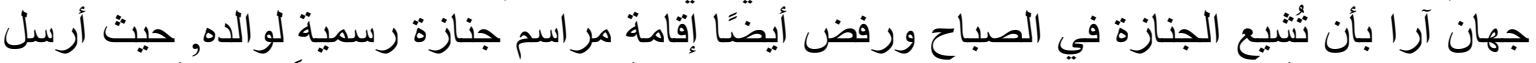

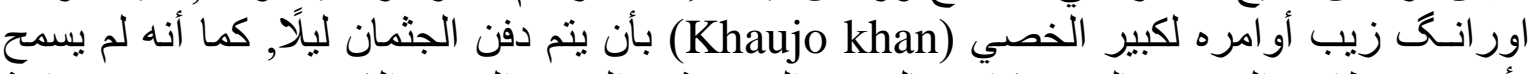

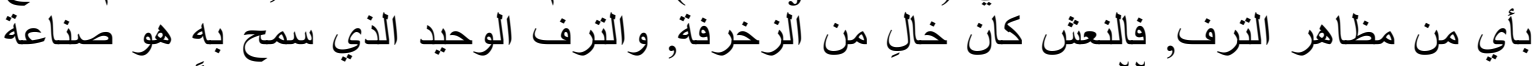

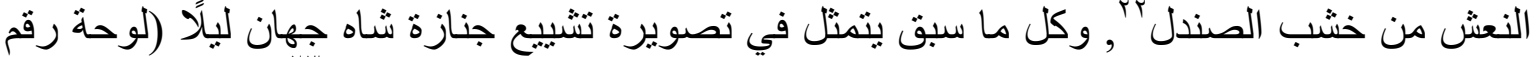

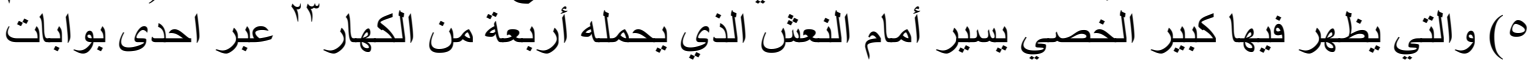


الحصن متجهين صوب قارب في نهر جمنة لبدفنوه بضريح ممتاز محل على الجهة الأخرى من النهر وكان ذللك أثناء الليل.

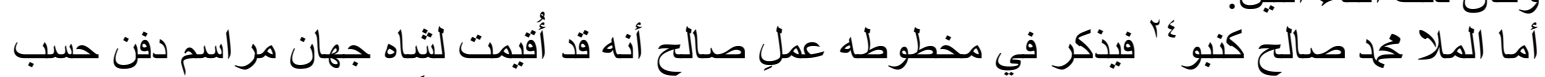

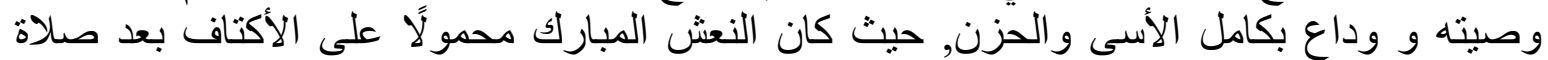

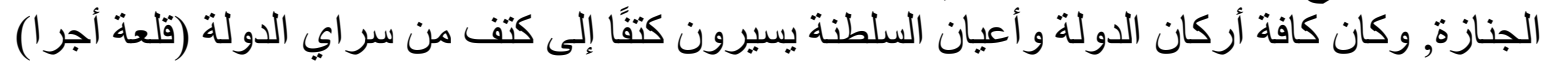

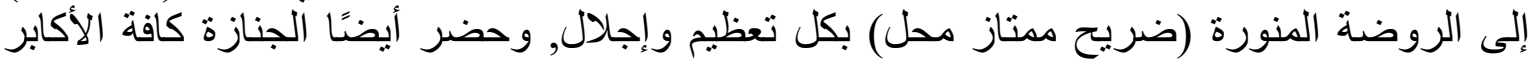

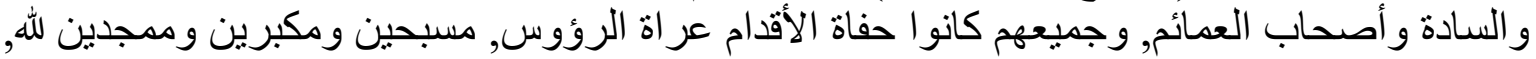

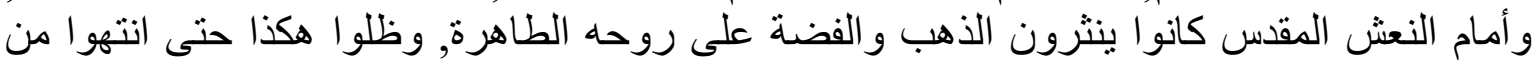

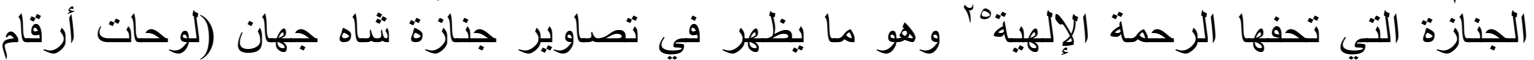
. $(\varepsilon, r, Y, 1$

وبالنظر فيما سبق يتبين مدى الاختلاف حول شخصية اور انح زيب وكيف تعامل مع و الده شاه جهان

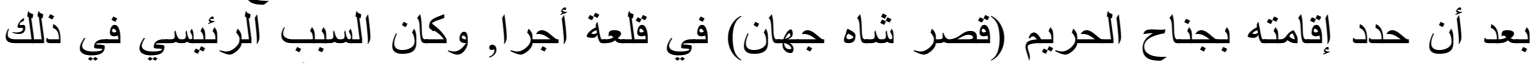

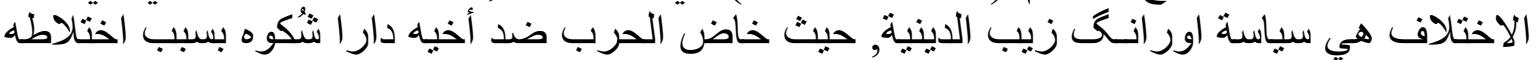

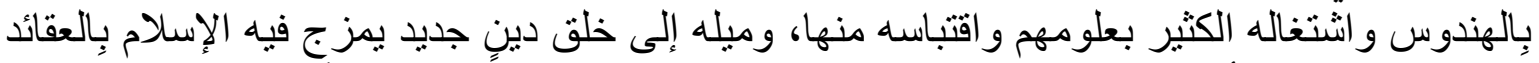

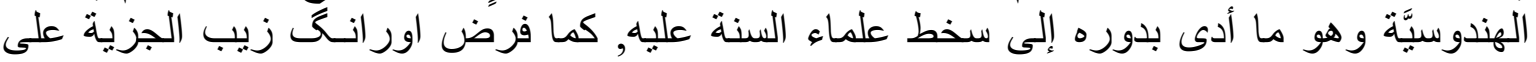

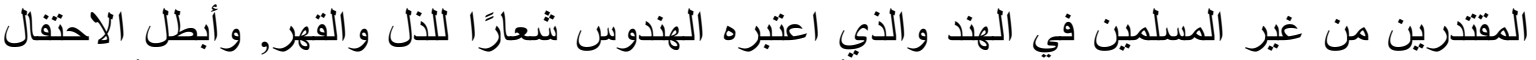

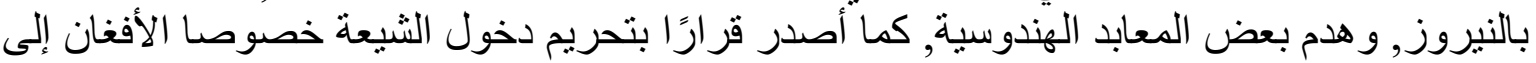

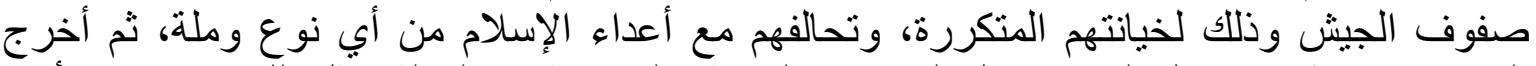

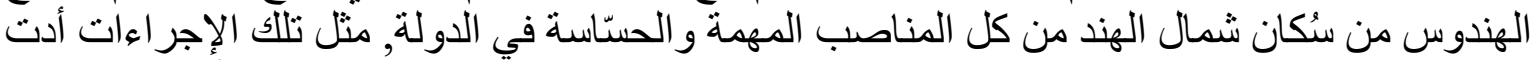

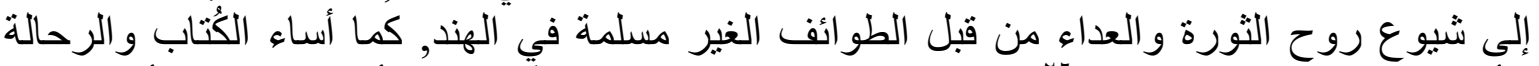

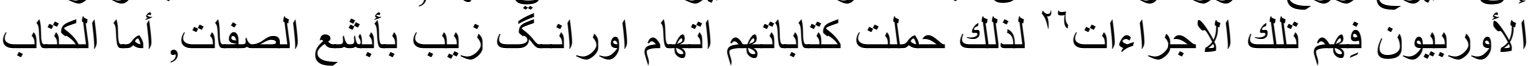
المسلمون فيرون أنه امتداد للخلفاء الر اشدين في حياته الثخصية وفي سياسته في حكم البلاد وذلته

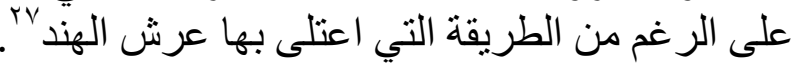

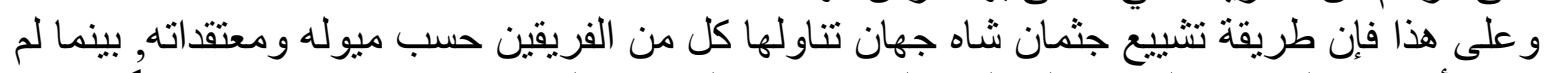

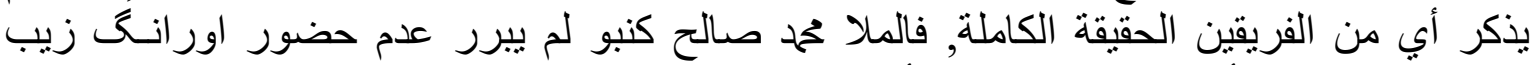

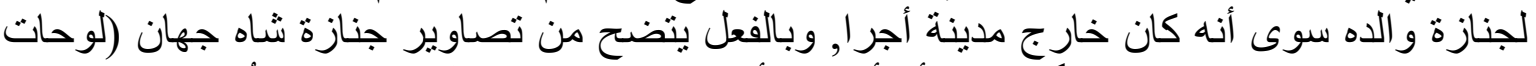

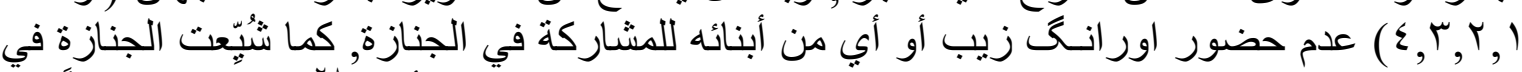

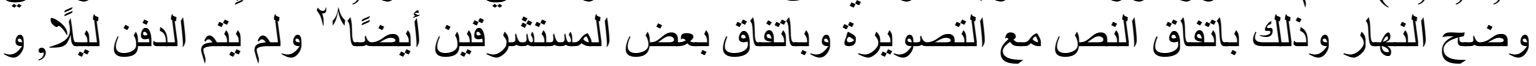

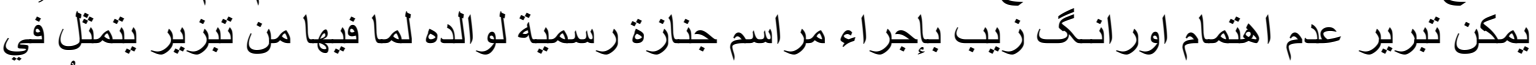

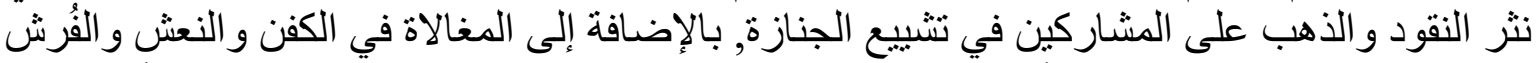

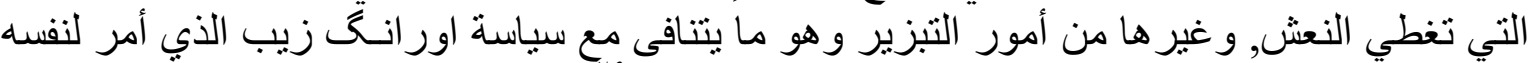

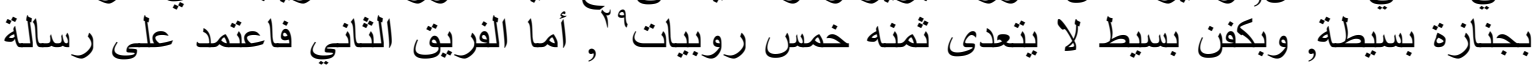

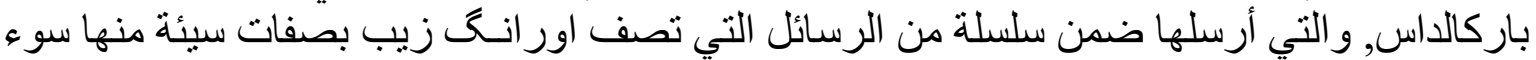

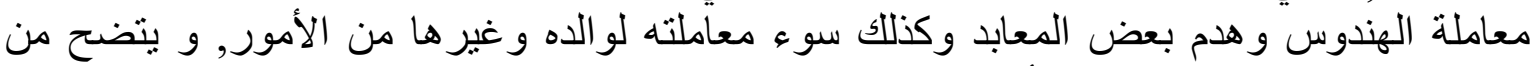

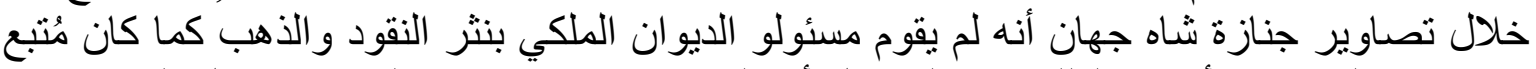

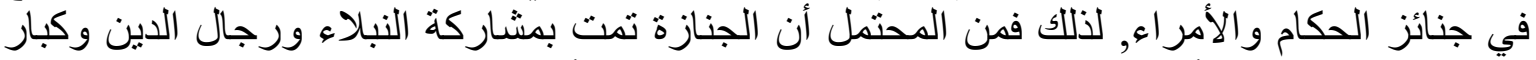

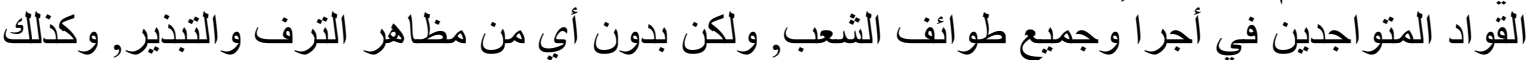
بدون حضور أي من أبناء شاه جهان أو أو أحفادهاه

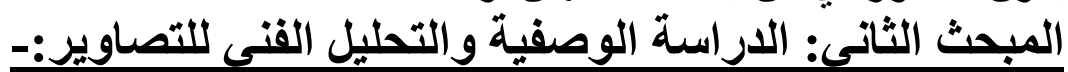

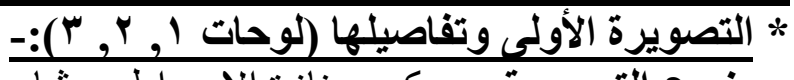

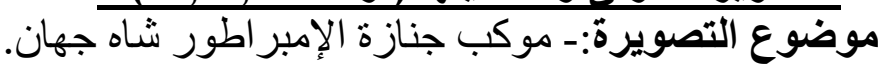




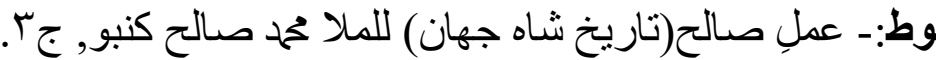
المخط

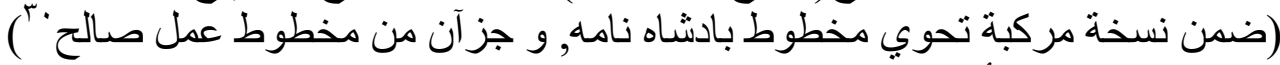

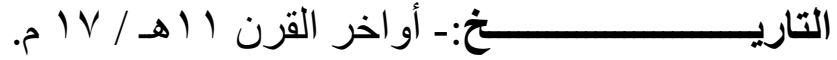

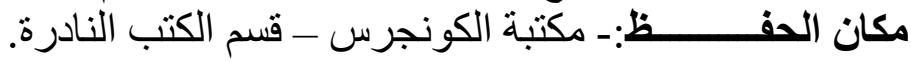

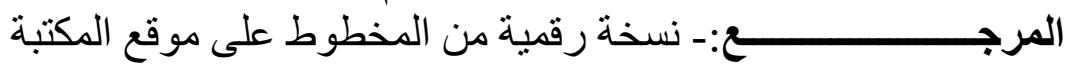

https://www.loc.gov/resource/rbc0001.2015rosen1791/?st=gallery (Last visit 20/5/2021)

تلتبع هذه التصويرة الوصفية:

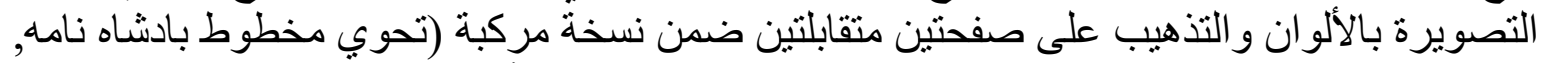

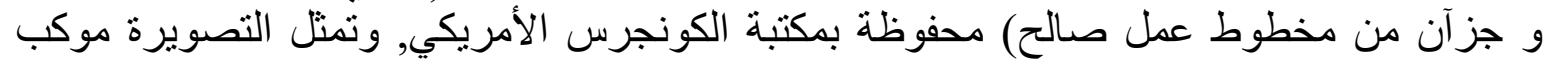

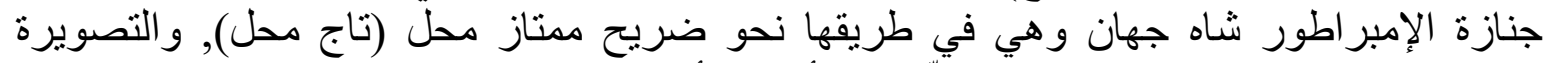

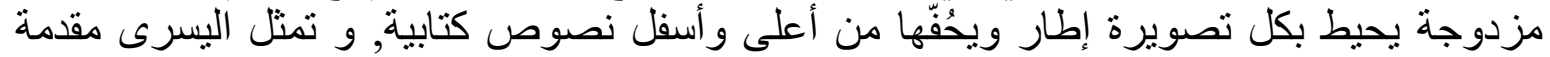

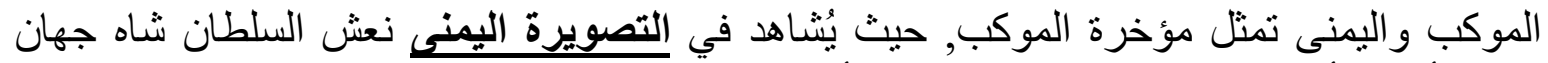

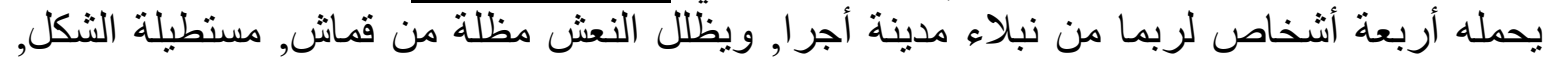

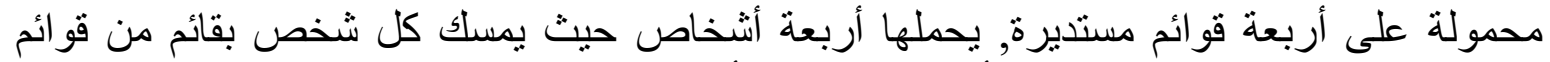

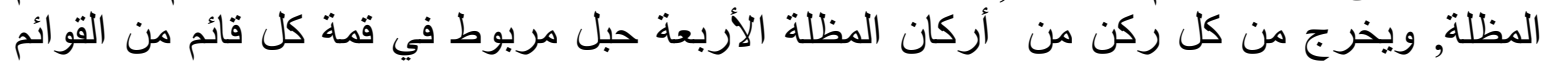

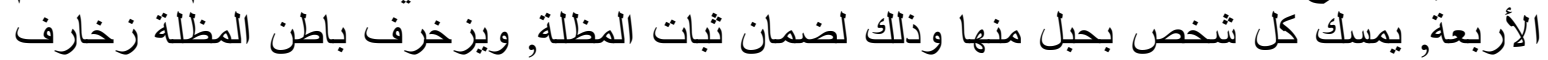

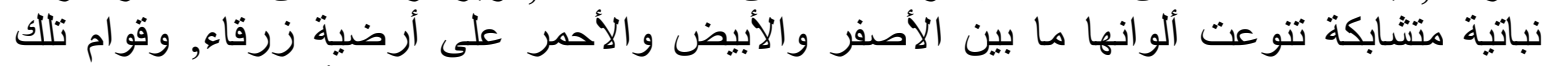

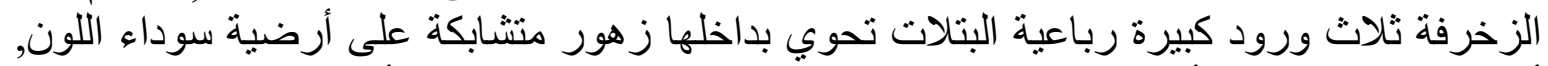

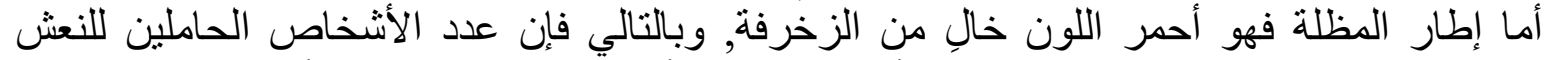

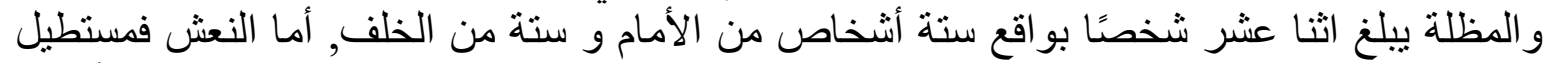

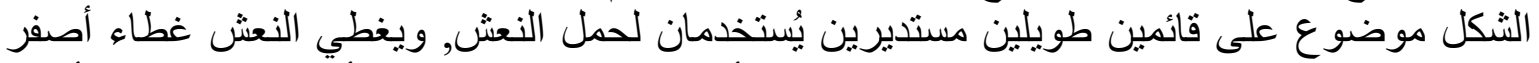

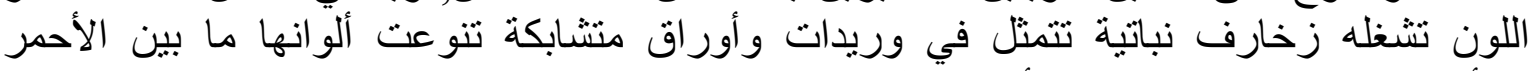

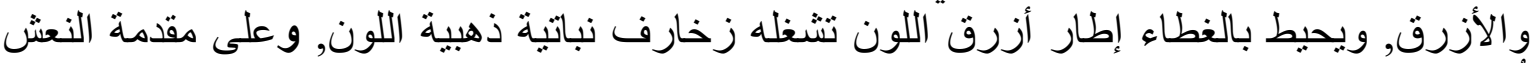

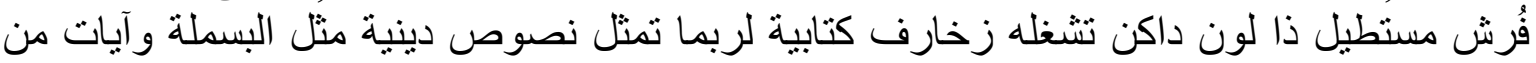

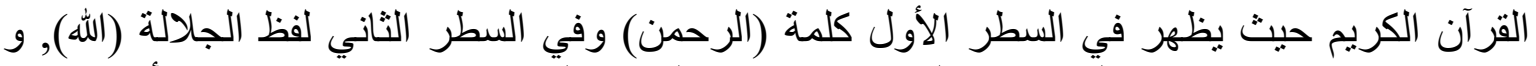

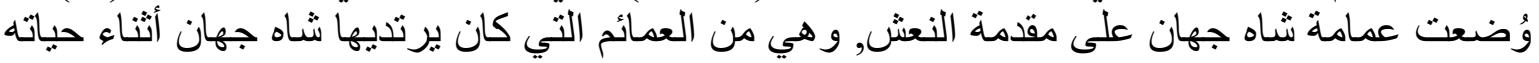

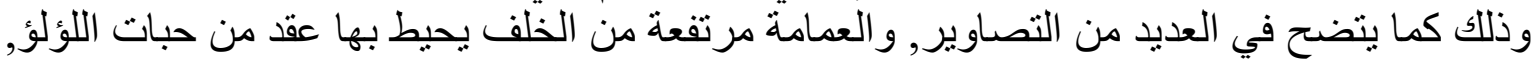

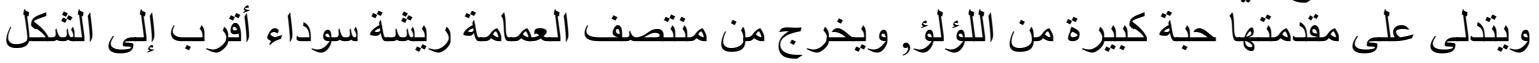

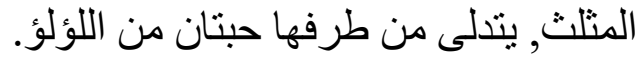

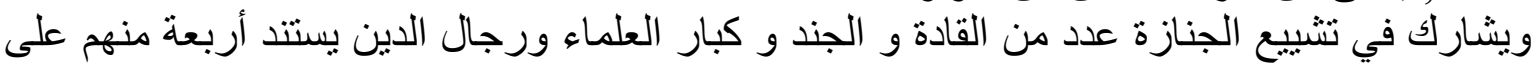

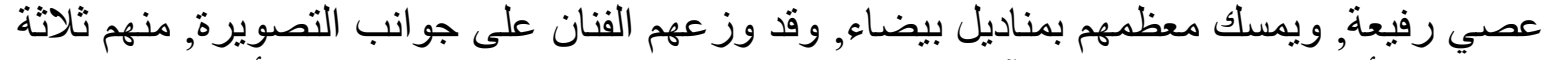

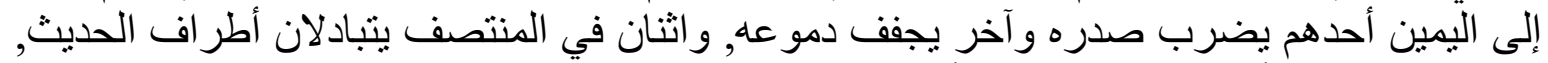

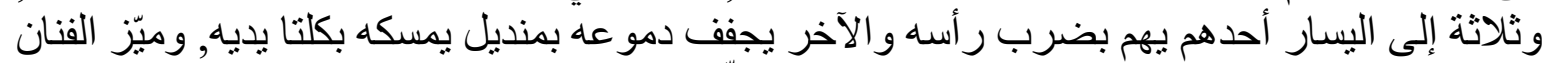

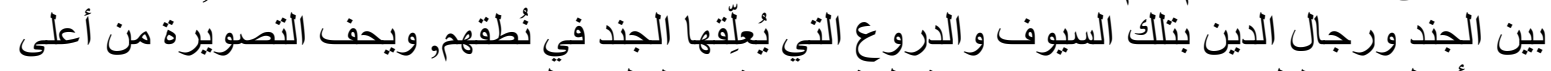

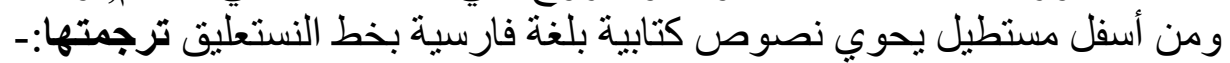

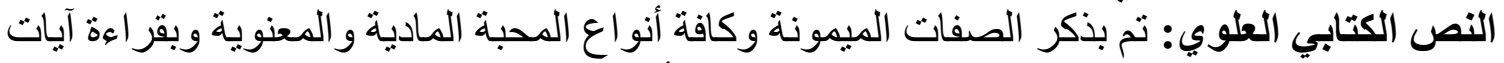

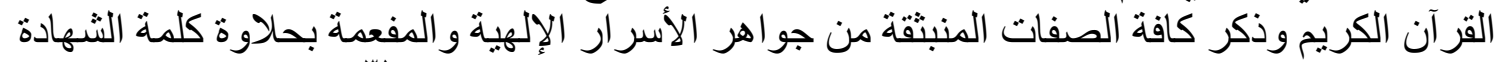

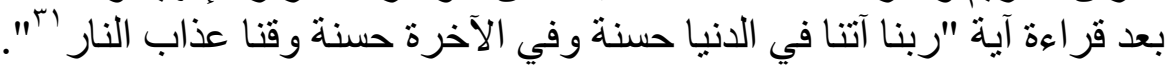


النص الكتابي السفلي: تم مع الثوق لنيل السعادة بعد مرور ثنلاث ساعات من ليلة الاثثين في السادس

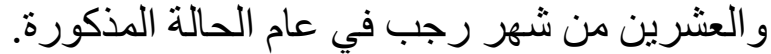

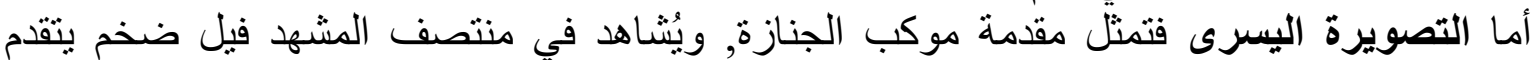

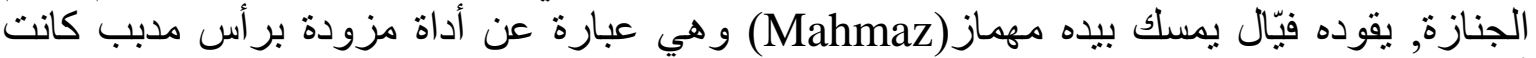

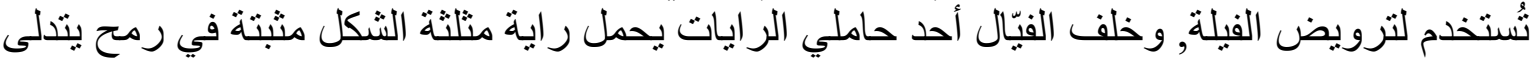

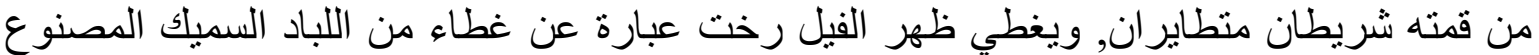

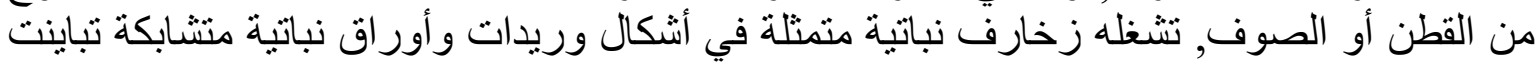

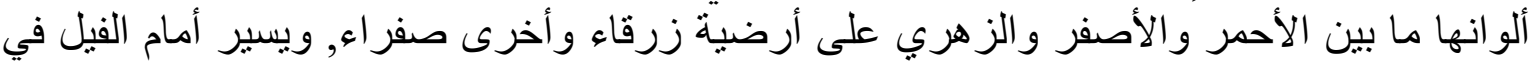

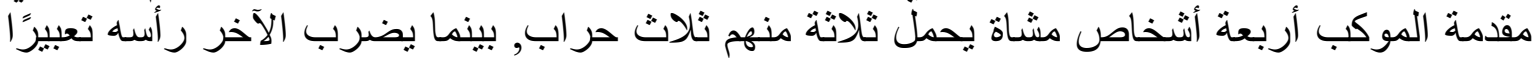

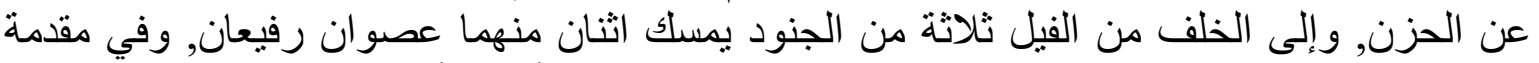

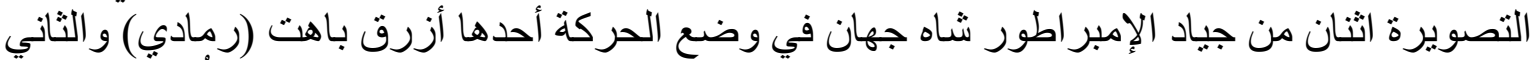

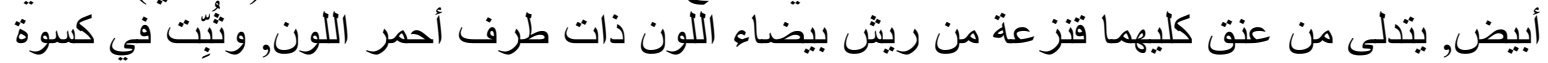

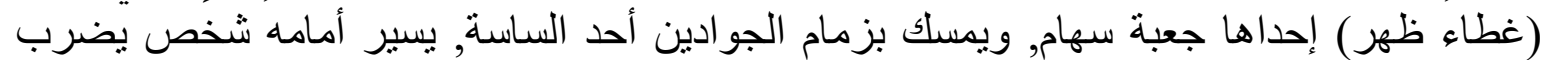

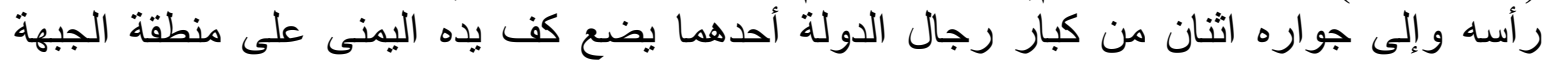

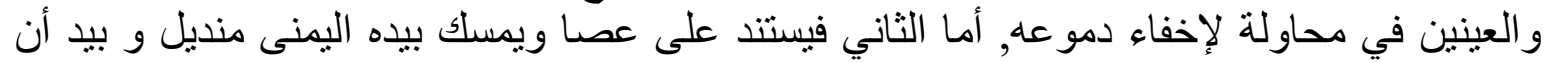

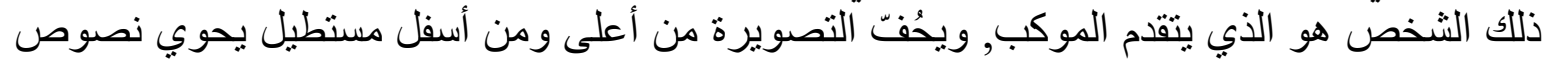
كتابية بلغة فارسية بخط النستعليق ترجمتها:-

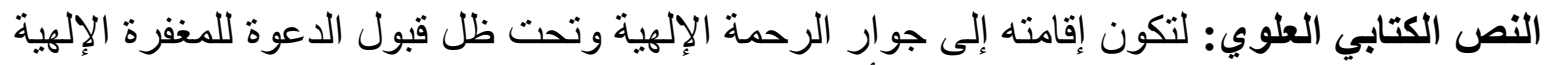

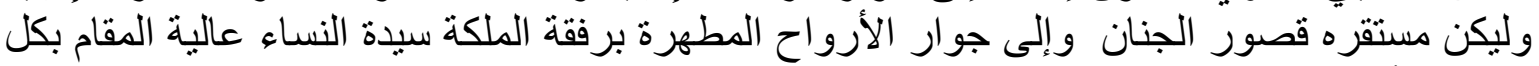

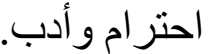

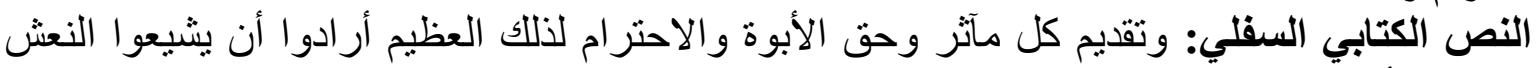

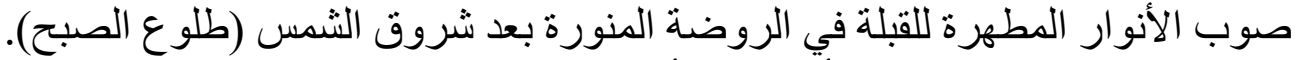

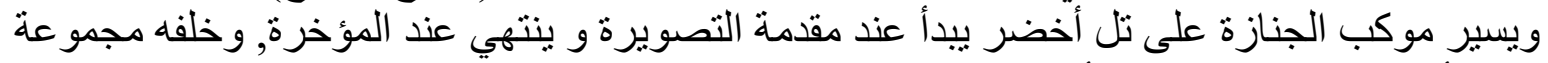

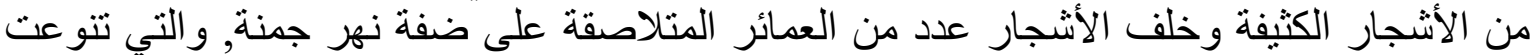

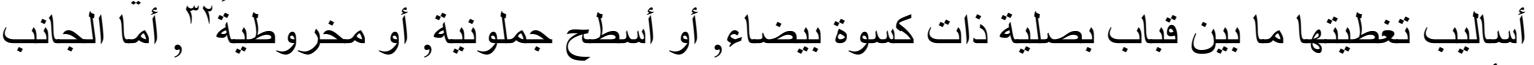

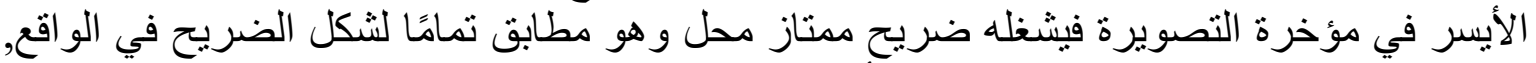

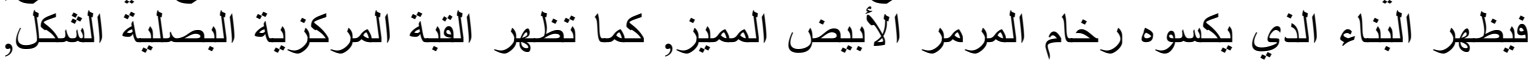

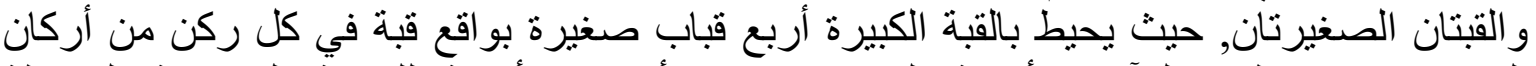

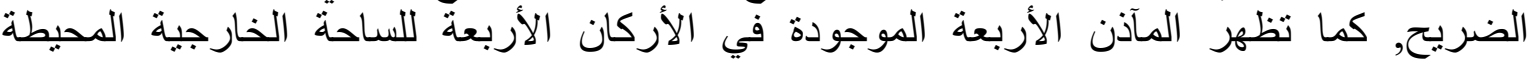

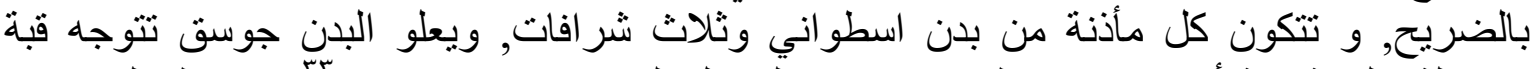

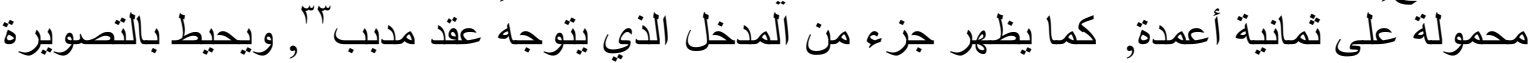

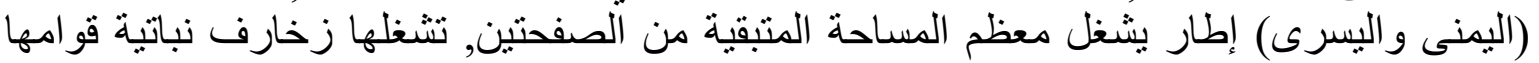

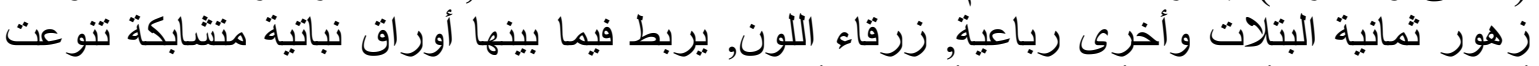

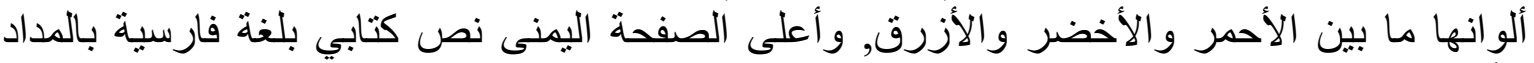

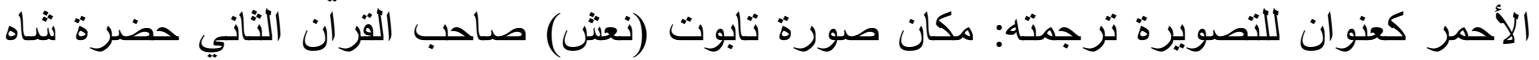

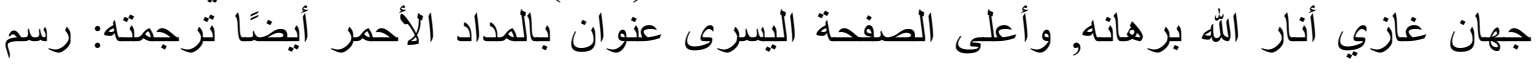
روضة ملكة التاج.

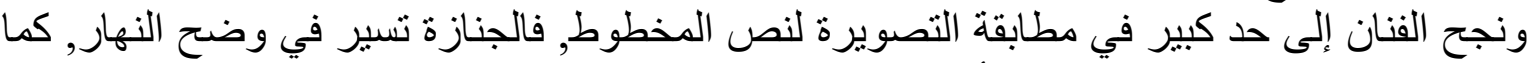

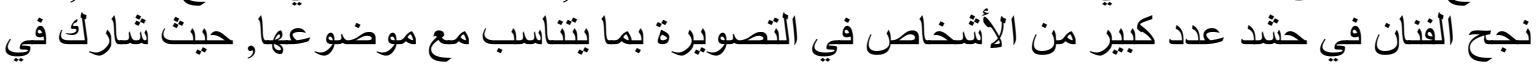

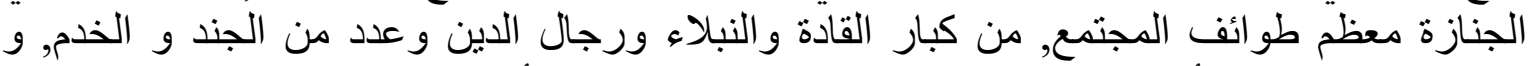
يُلاحظ في التصويرة أنه لا يوجد شخص مميز في التصويرة من أبناء البيت الحاكم يسير مسنِّا كتفه 


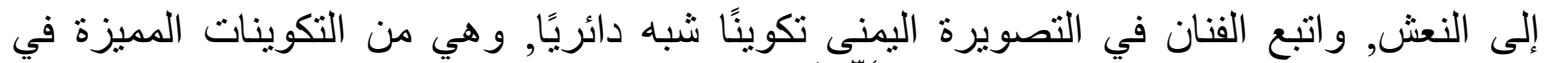

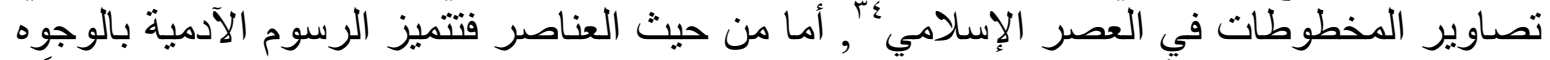

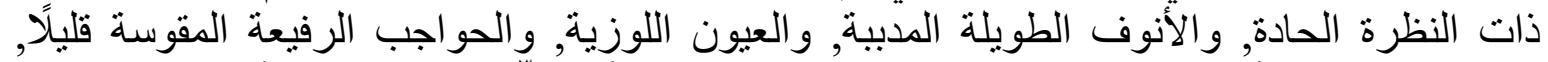

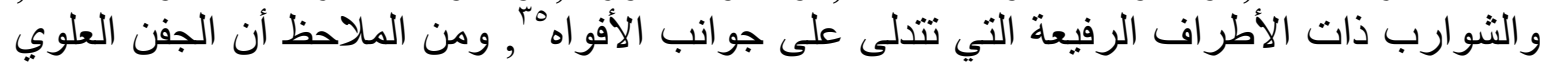

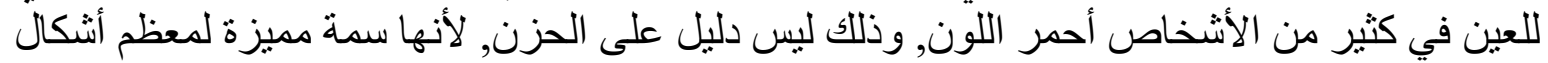

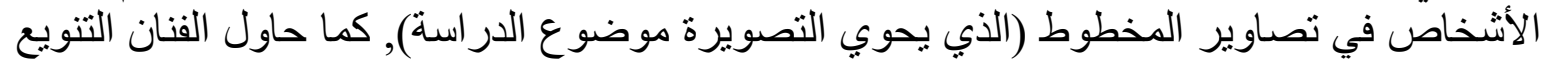

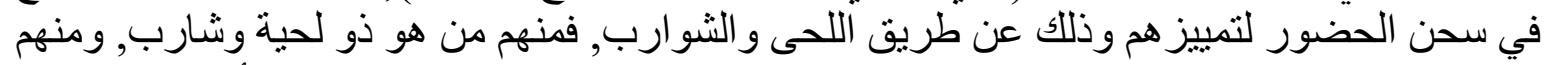

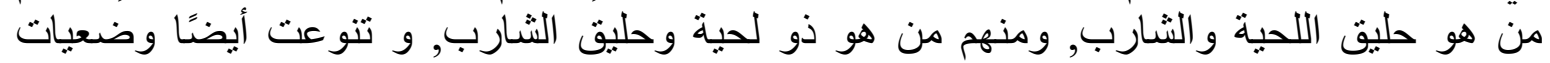

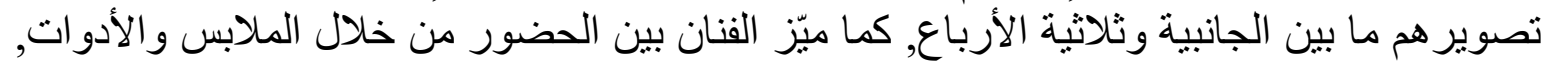

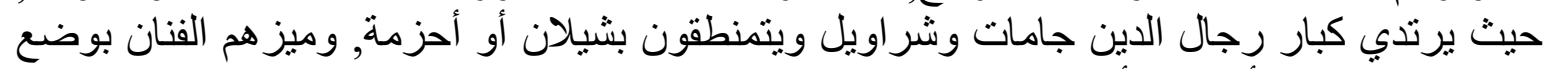

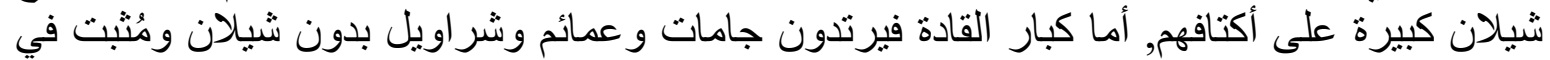

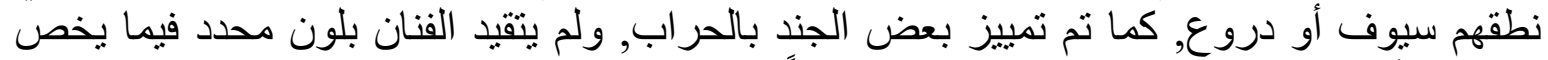

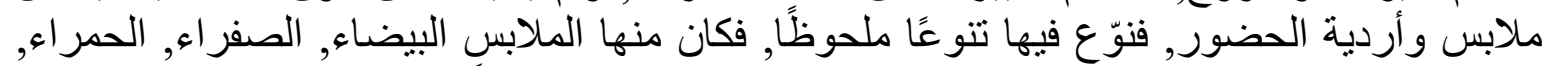

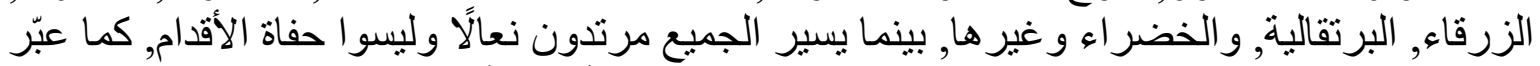

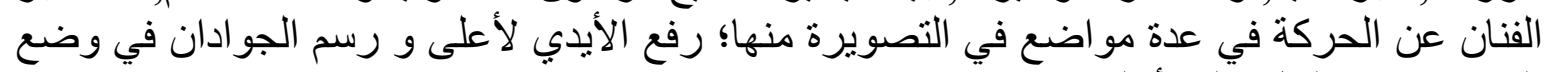
السير, و رفع الفيل ذيله لأعلى.

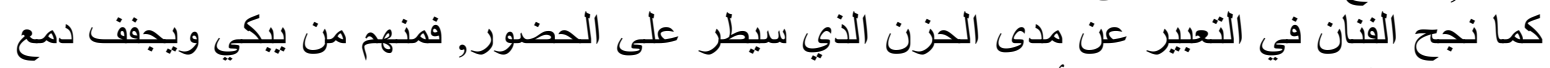

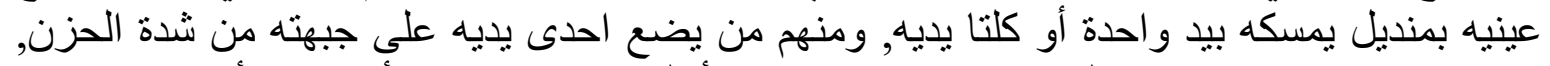

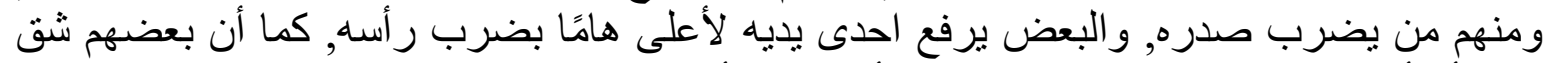

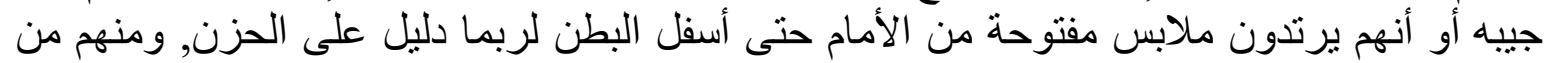

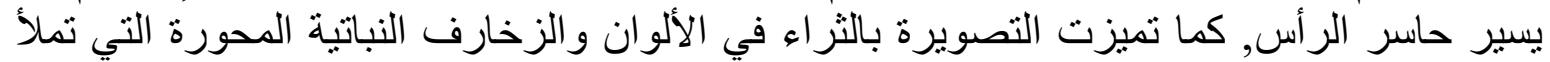

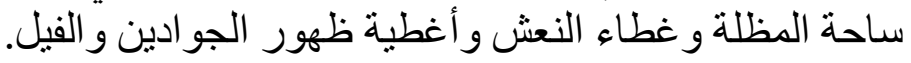

$$
\begin{aligned}
& \text { التصويرة الثانية (لوحسة رقم ؛):- } \\
& \text { موضوع التصويرة:- جنازة شاه جهان فئن في أجر ا. }
\end{aligned}
$$

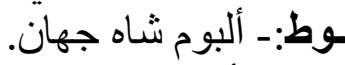

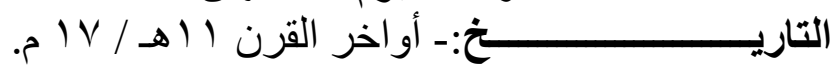

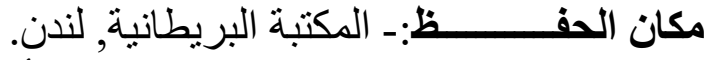

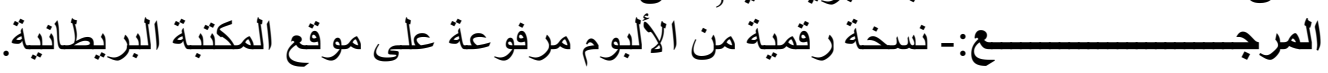
https://imagesonline.bl.uk/asset/10978

الار تاسة الوصفية:توجد تلك التصويرة ضمن ألبوم شاه جهان المحفوظ بالمكتبة البريطانية بلندن, وتُفْذت التصويرة

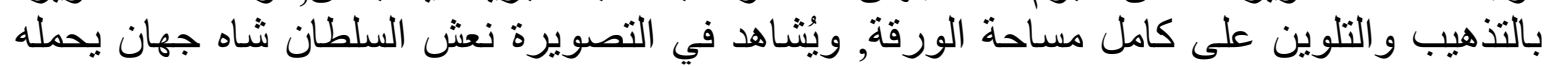

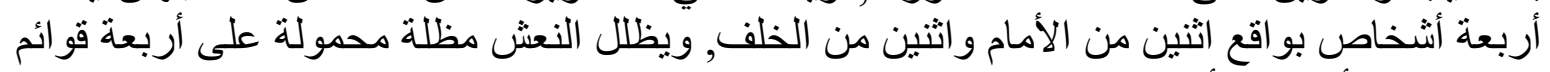

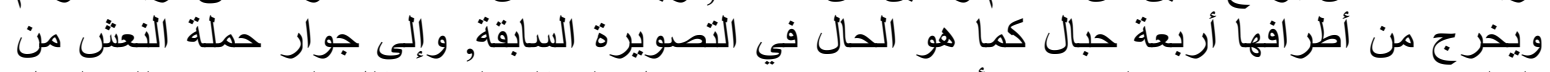

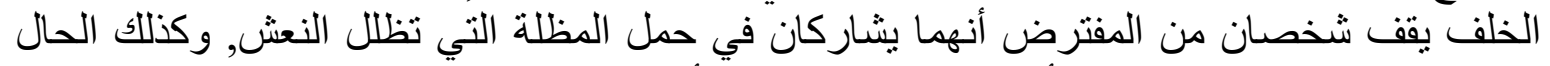

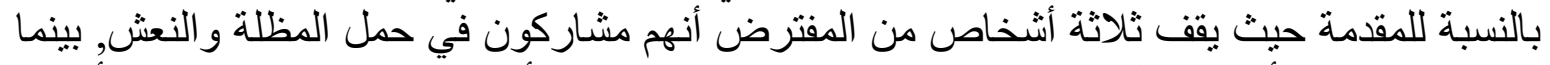

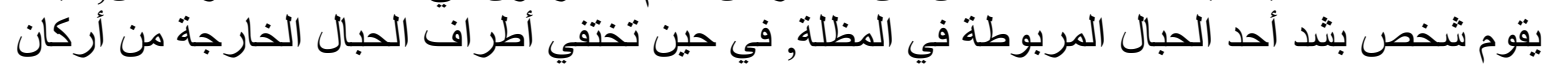

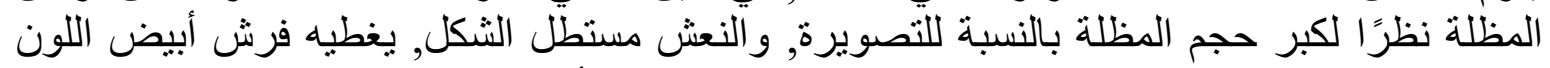

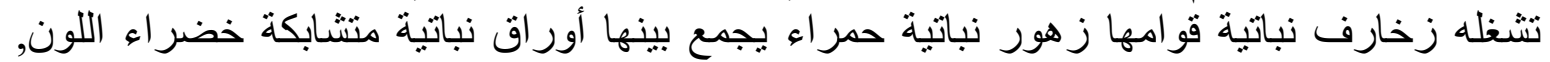

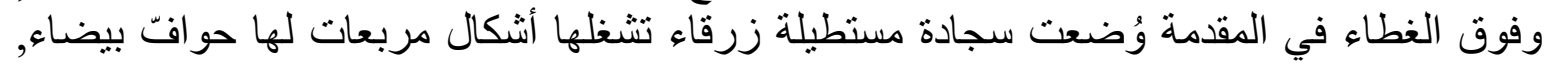

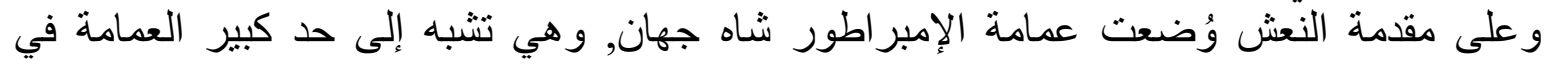


التصويرة السابقة, غير أنها ينقصها اللؤلؤ الذي يتدلى من طرف الريشة المثبتة في العمامة, أما المظلة

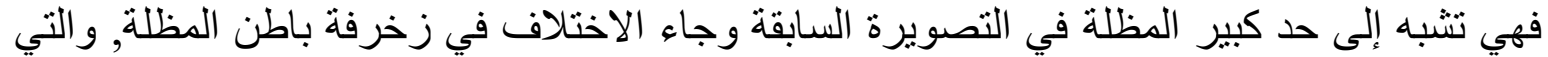

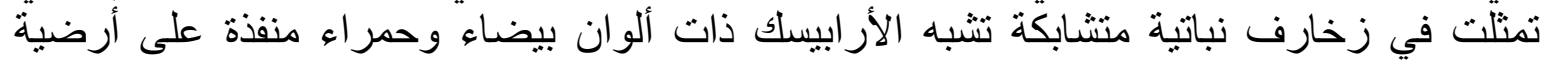
زرقاء, و وزّ الفنان باقي الحضور المشاركين في الجنازة على منتصف ومقدةمة التصويرة, فإلى

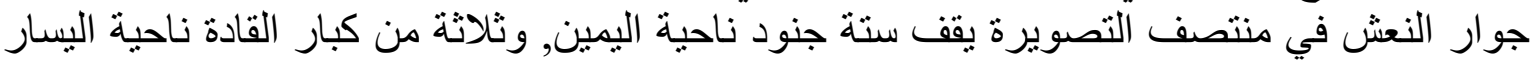

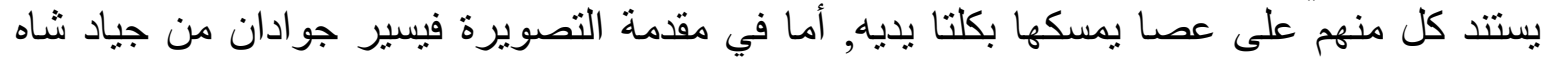

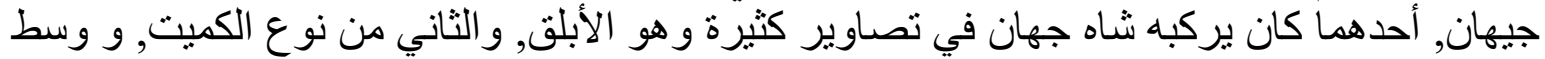

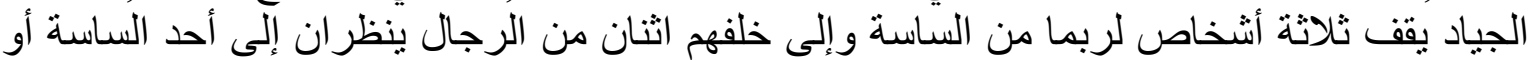

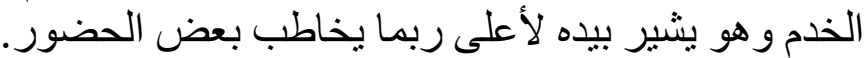

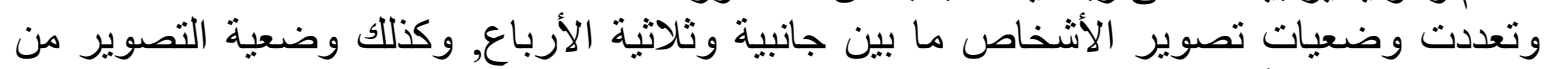

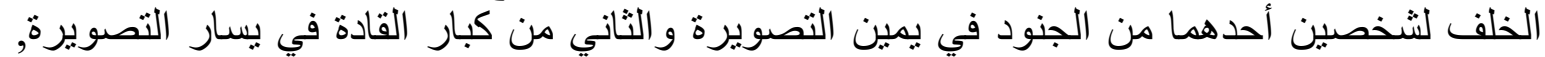

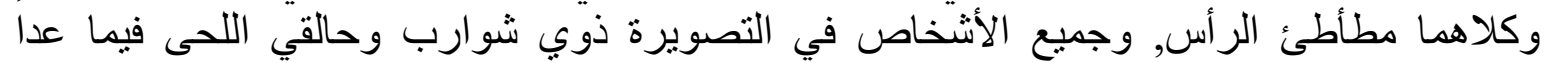

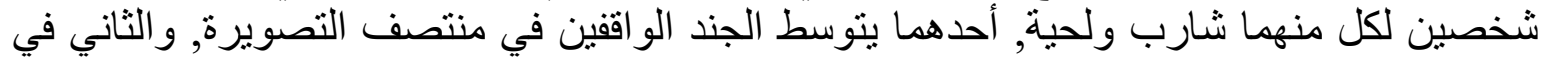

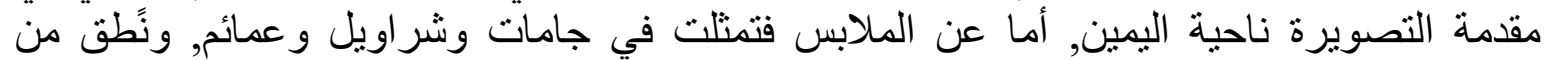

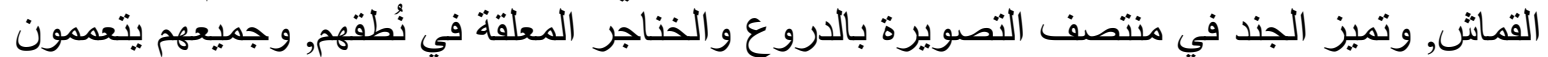

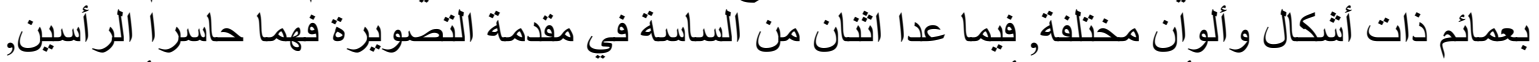

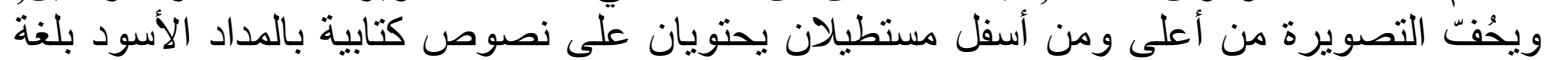

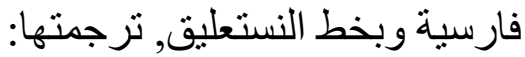
النص العلوي: تم الانتهاء بعد عشرين عام من العمل المتونئن اصل من الصباح إلى اللى الليل بتكلفة مائة

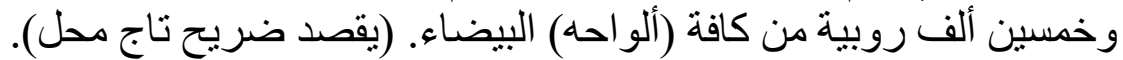

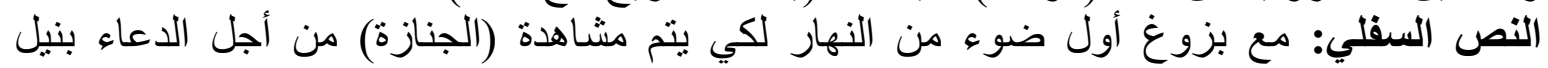
ويحيط بالتصويرة إطار من وحدة زخرفية نباتية مكررة تتمثل في أشكال بخاريات و وريدات رباعية البتلات ذات لون أزرق, ويفصل بين تللك الوحدات الزخرفية الزئة المكررة أشكال وريدات وأورات نباتية صفر اء اللون منشابكة. ونظرًا لأن التصويرة منفذة على صفحة واحدة وليس على صفحتين متقابلتين كالتصويرة السابقة, فإن الن التهاب

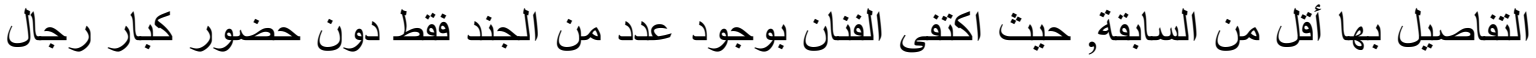

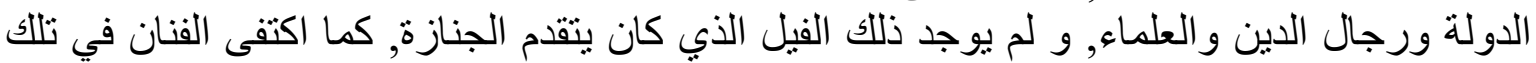
التصويرة بخلفية طبيعية من أثجار خضراء فقط دون وجود لأشكال العمائر, هذا بالإضافة إلى

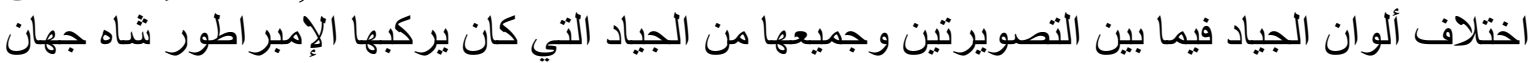
في حياته, كما اختلفت ملامح التعبير عن الحزن في تللك التصويرة عن سابقتها, حيث اكتفى الفنان هنا لإنا

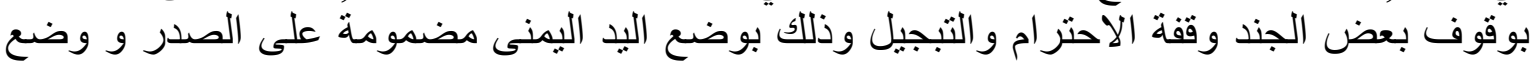

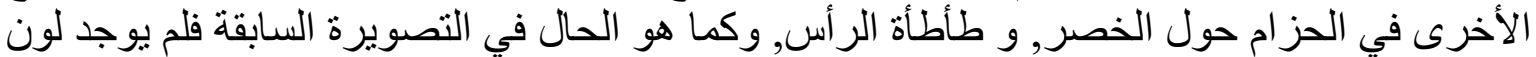
واحد فيما يخص ملابس الحضور حيث تنوعت ألوان أرديتهم ما بين البرتقالي والأخضر الباهن

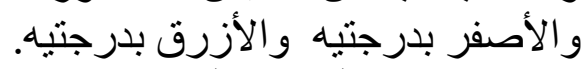

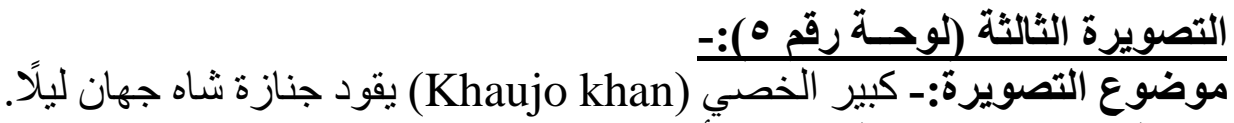

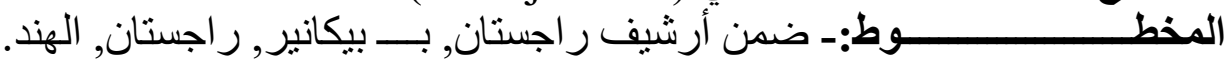

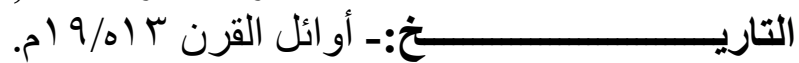

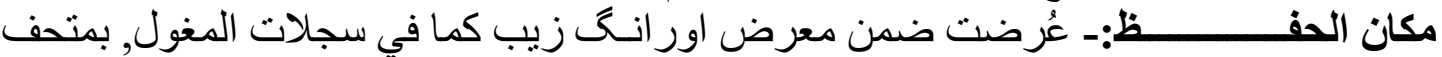




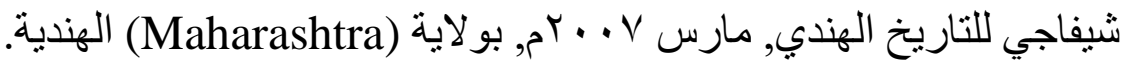

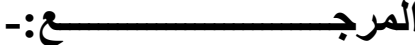

http://preamblequestioned.blogspot.com/2007/07/aurangzeb-as-he-was-according-tomughal.html

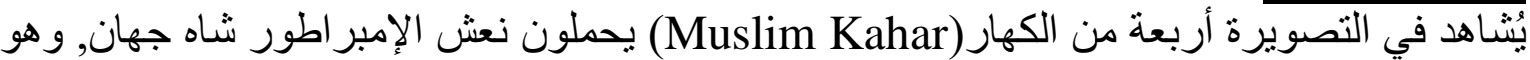

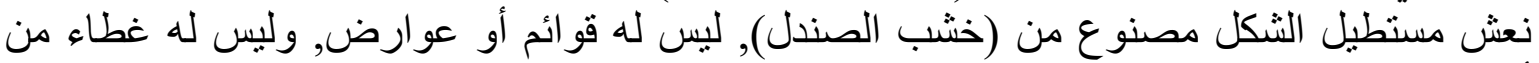

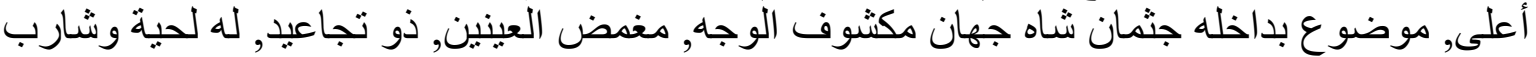

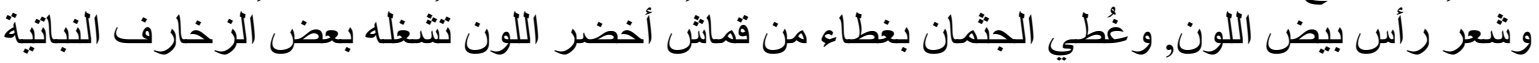

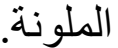

أما عن الكهار, فمثل الفنان وجوههم في وضعيات جانبية وأجسامهم في وضعية ثلاثية الأرباع,

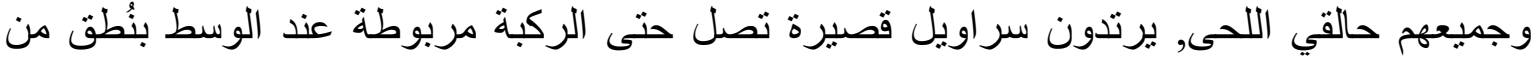

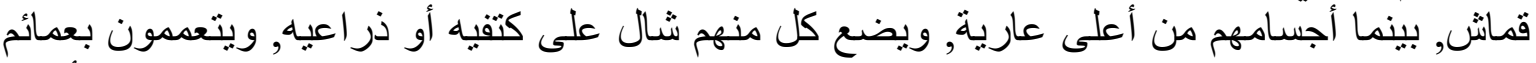

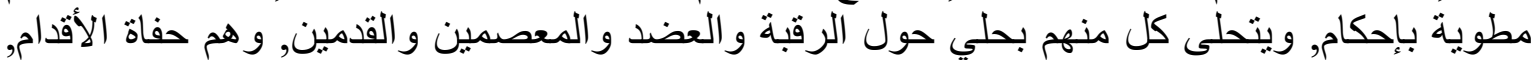

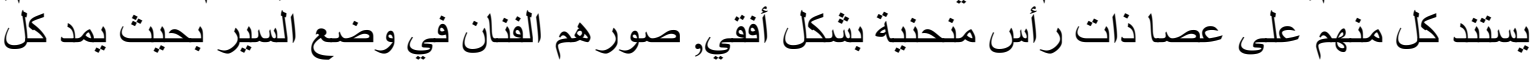

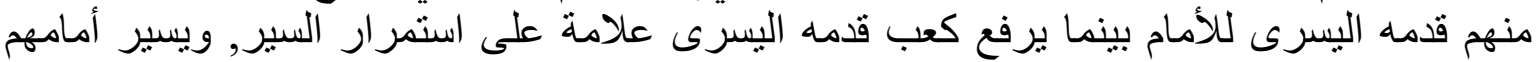

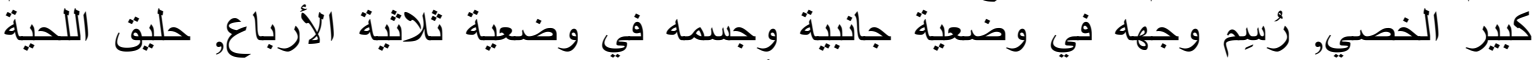

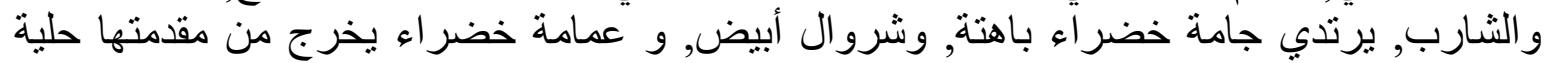

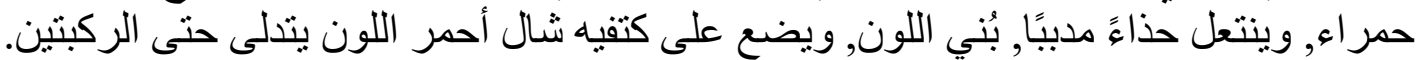

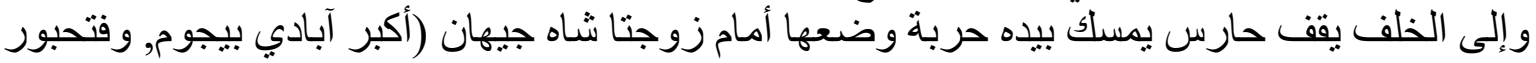

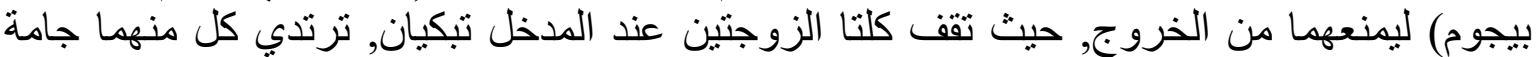

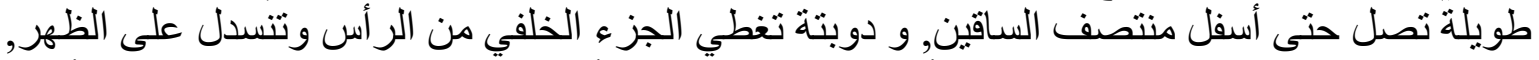

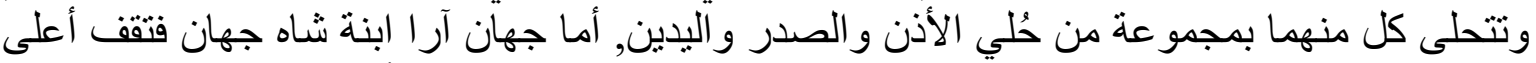

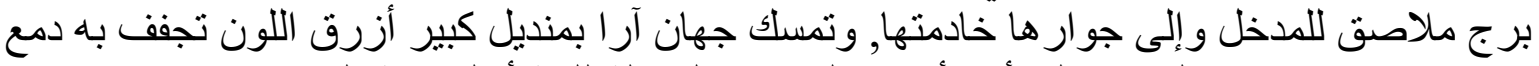

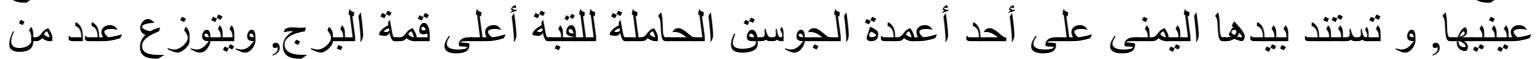

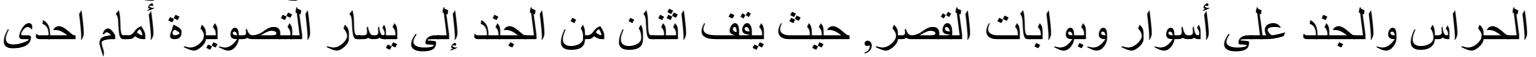

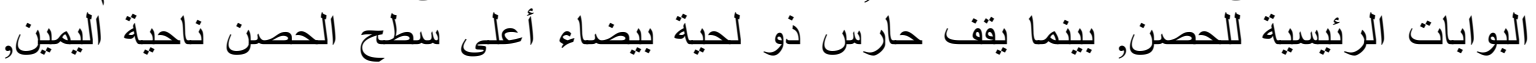

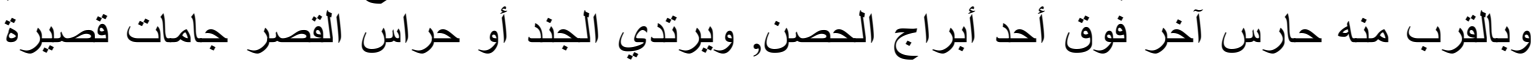

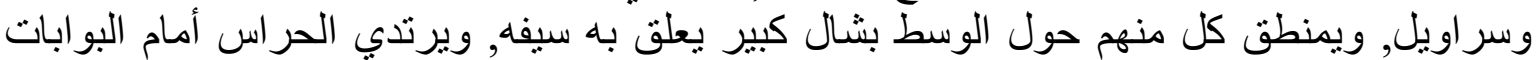

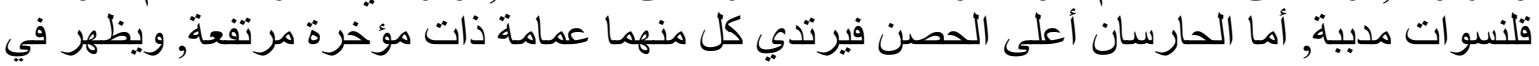

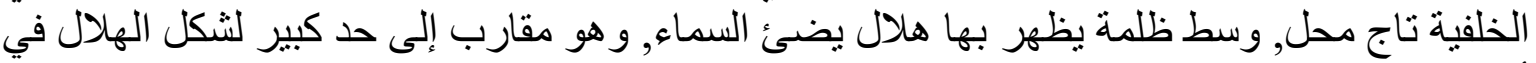

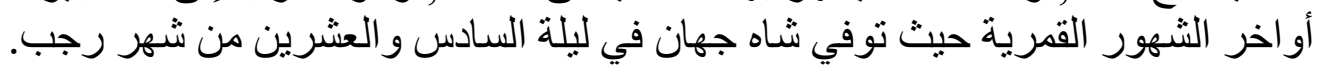

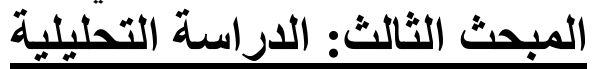

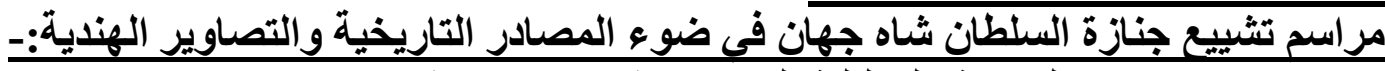

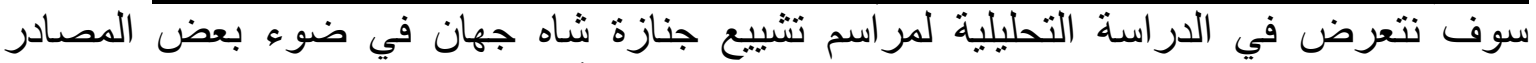

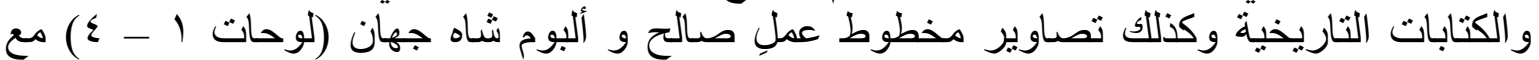

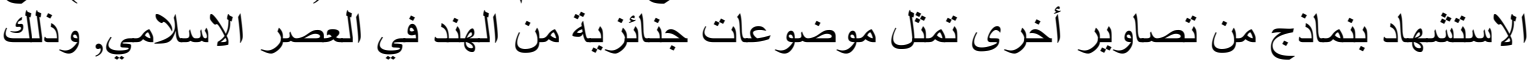

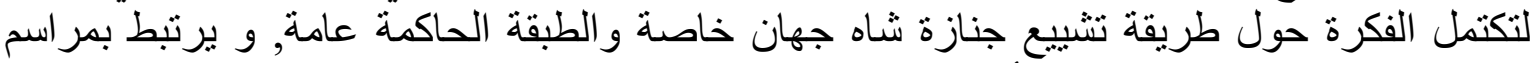

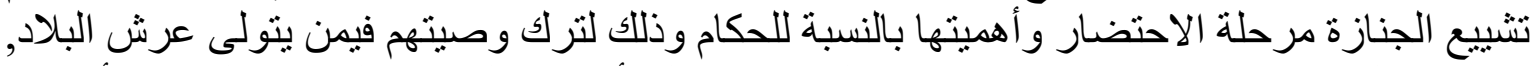

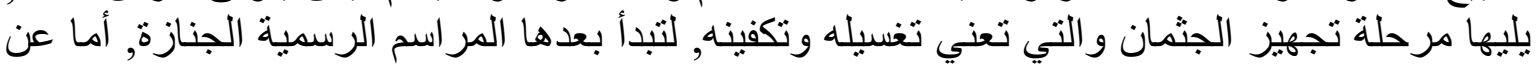


صلاة الجنازة فكانت أحيانًا تتم قبل السير بالجثمان, وأحيانًا تتم في المقابر, وسوف نتناول ذلك

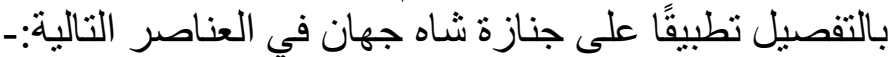

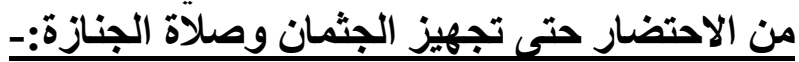

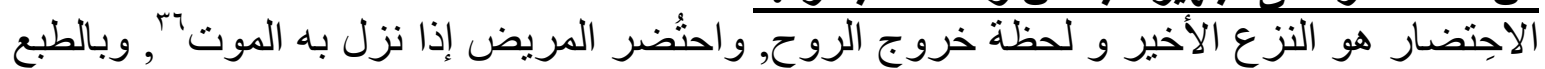

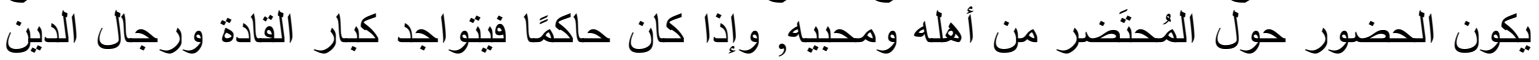

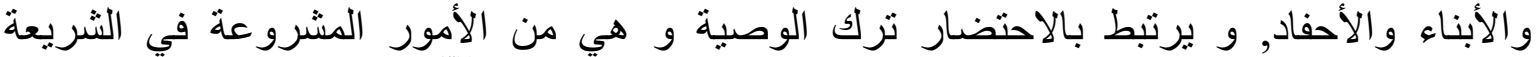

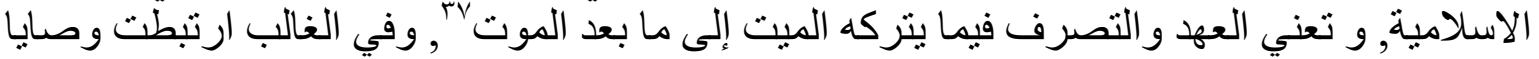

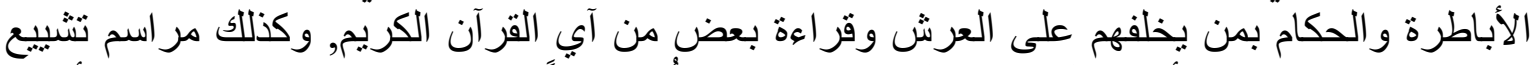

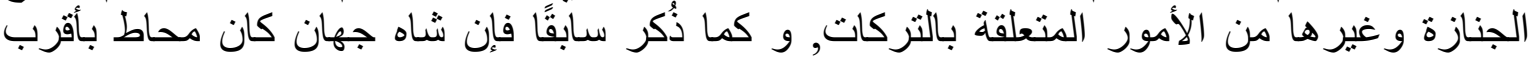

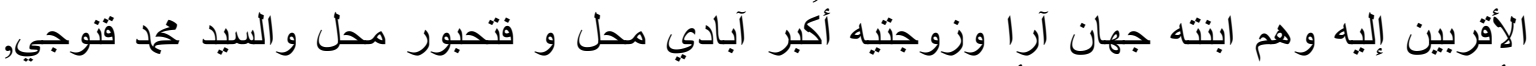

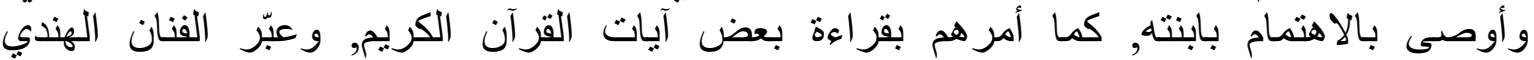

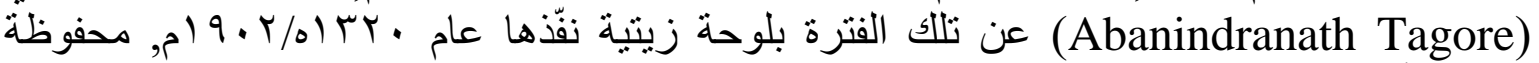

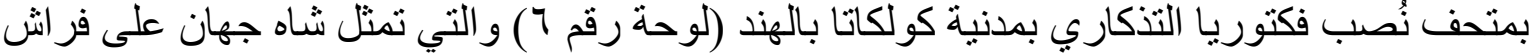

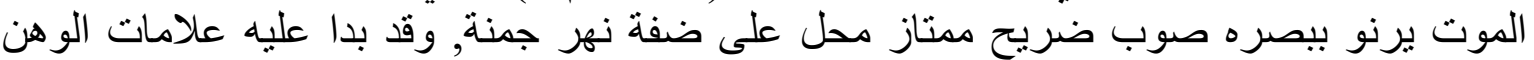

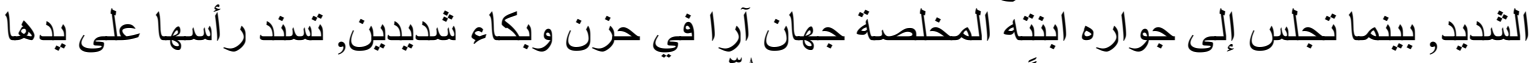

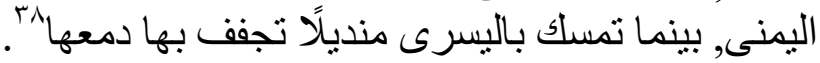

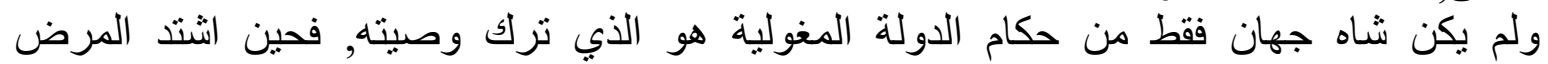

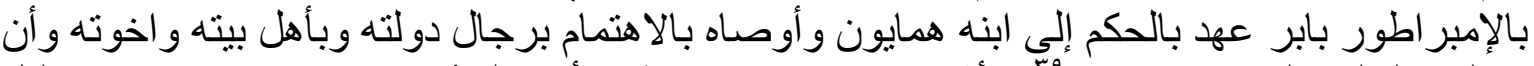

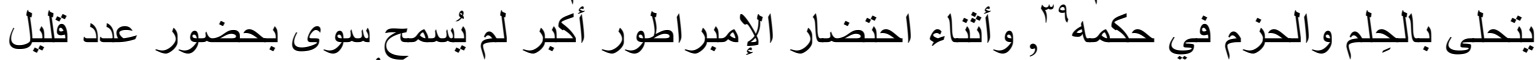

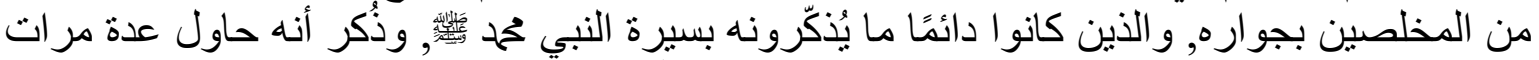

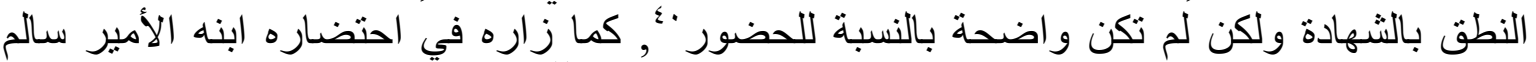

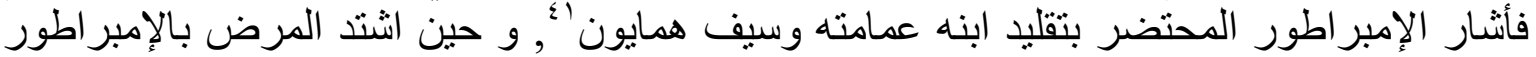

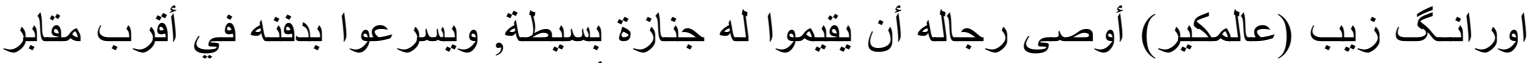
للمسلمين, ولا يزيدوا في ثمن كفنه عن خمس روبيات, وأن يتصدقوا على الفقراء بثلاثمائة من

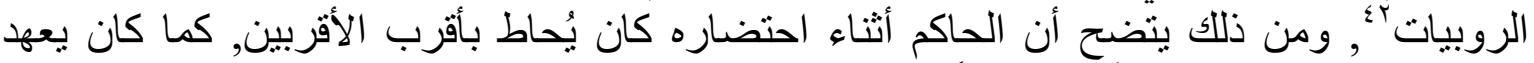

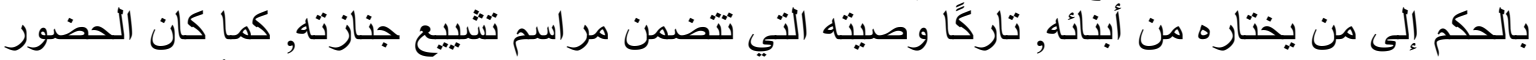

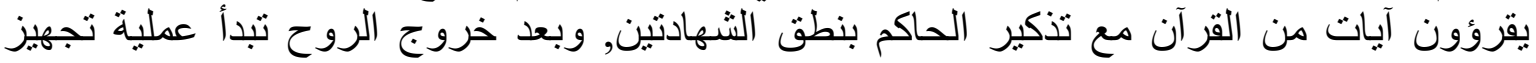

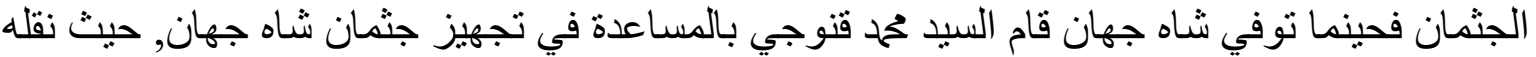

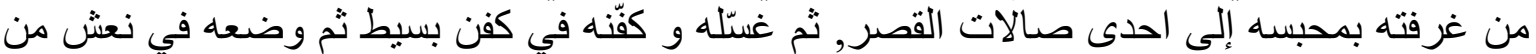

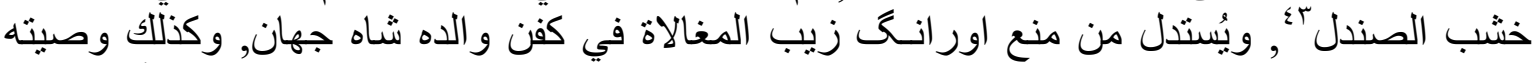

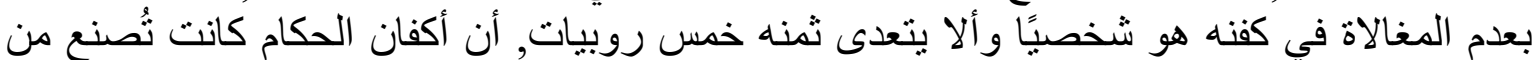

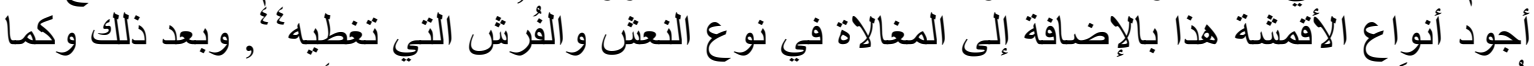

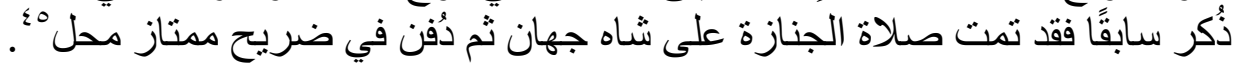

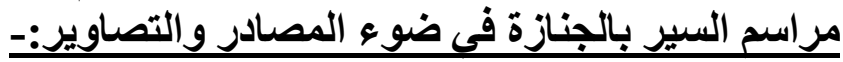

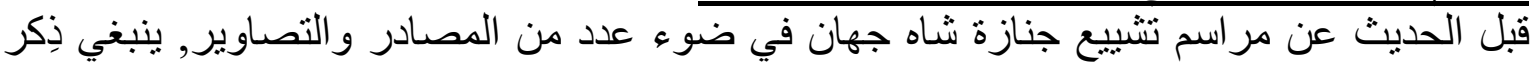

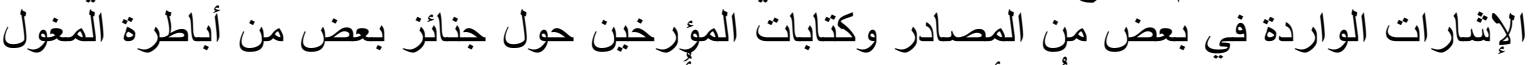

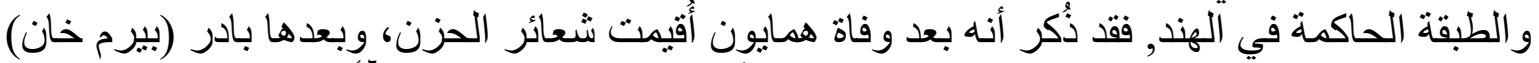

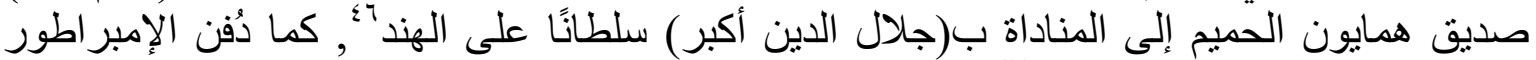

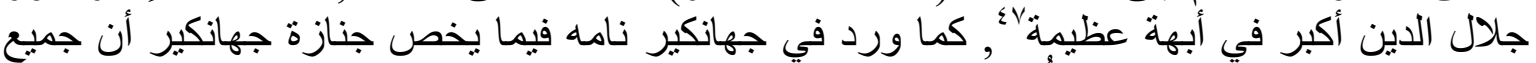

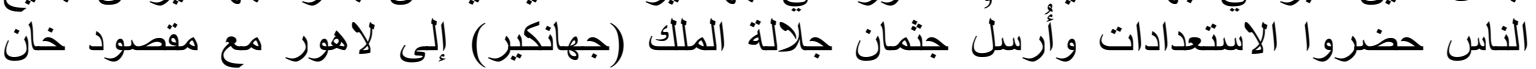


وآخرين وتم دفنه يوم الجمعة في حديقة كانت نورجهان بيجوم قد شيدتها على الجانب الآخر من

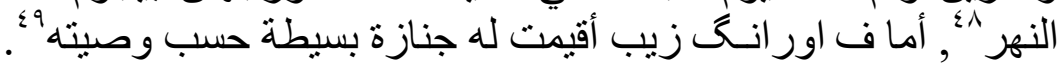

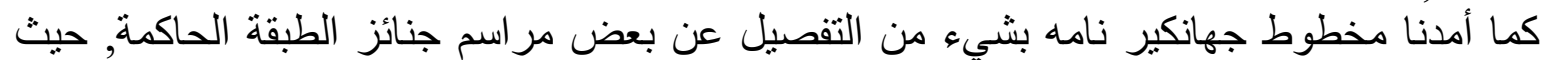

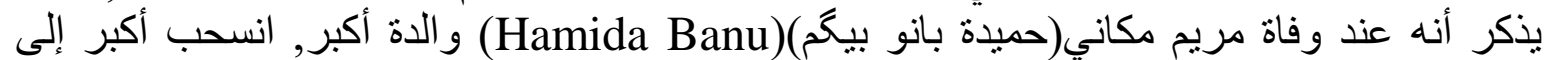

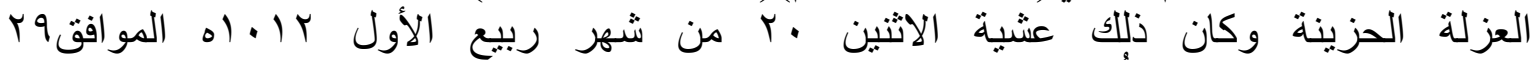

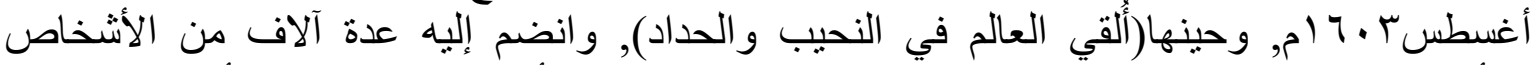

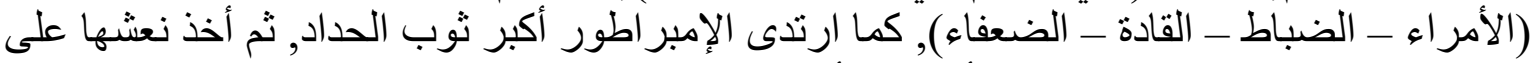

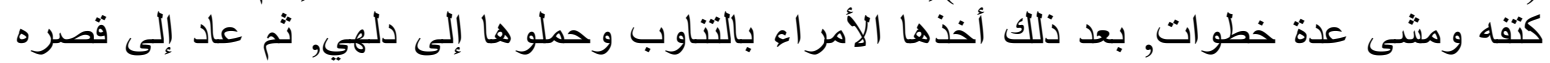

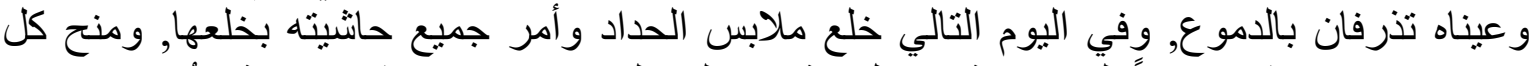

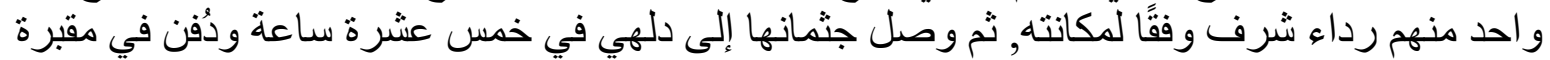

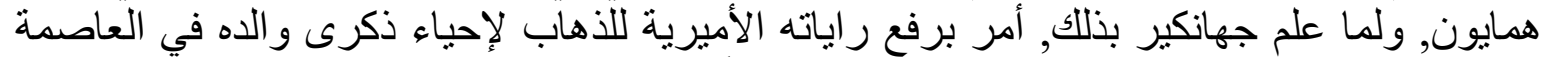

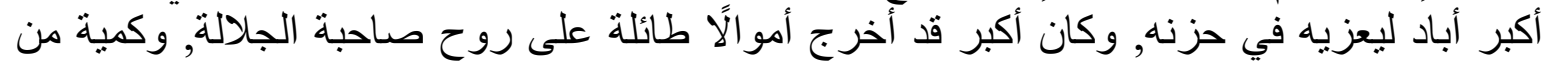

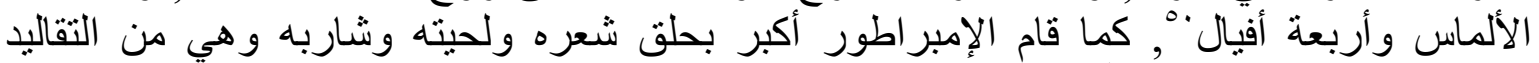

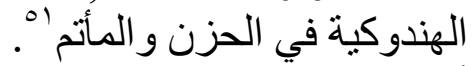

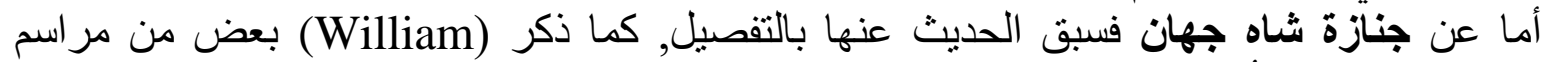

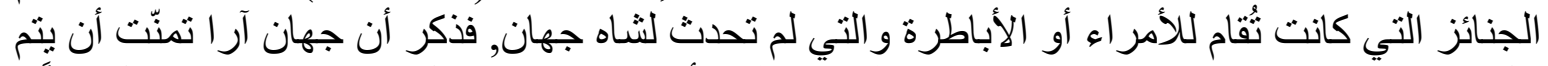

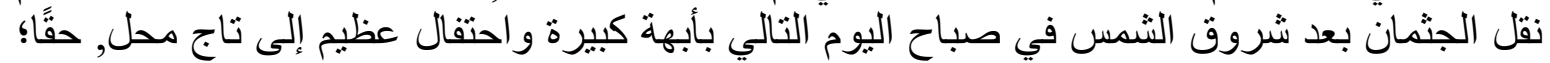

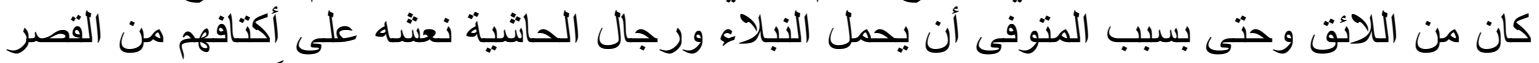

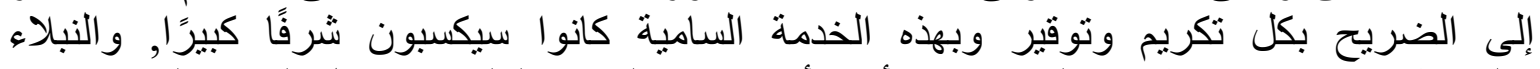

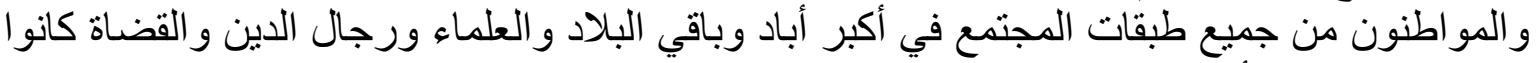

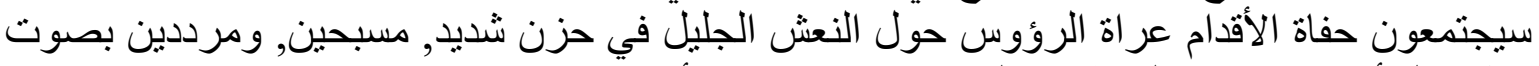

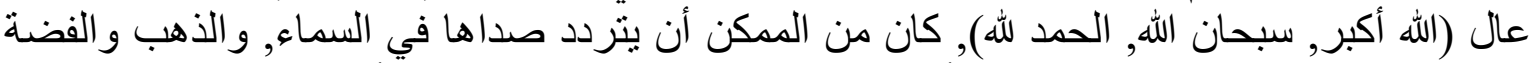

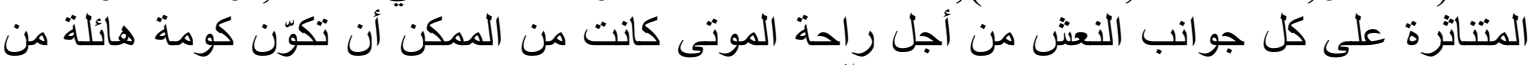

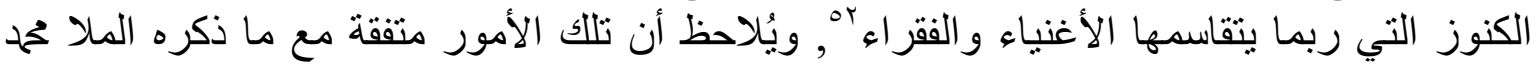
صالح كنبوه حول جنازة شاه جهان.

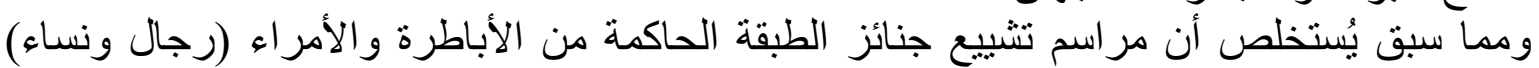

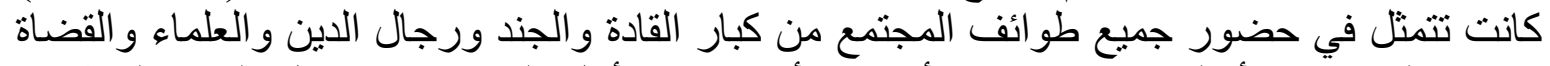

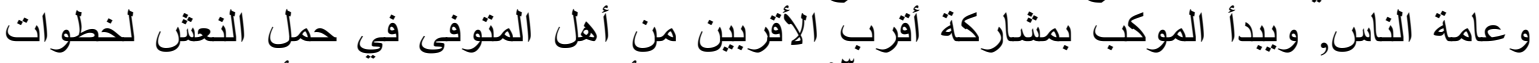

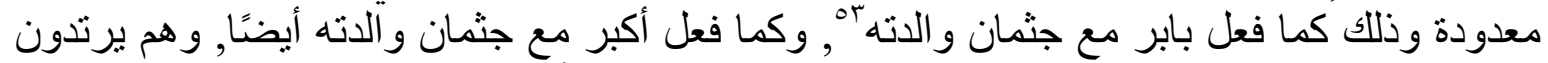

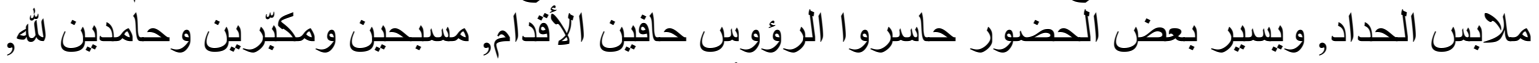

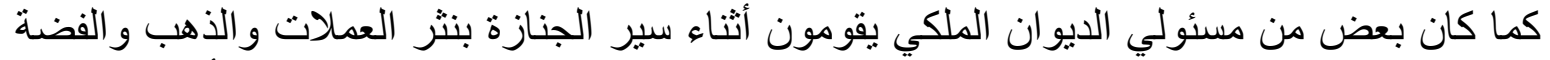

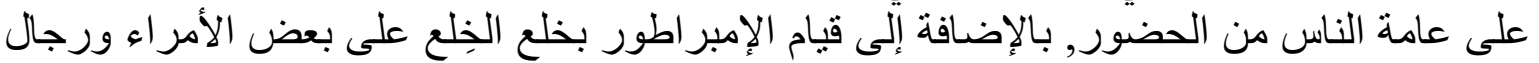

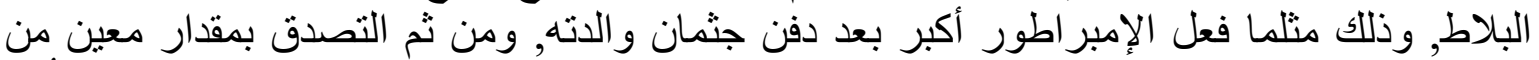

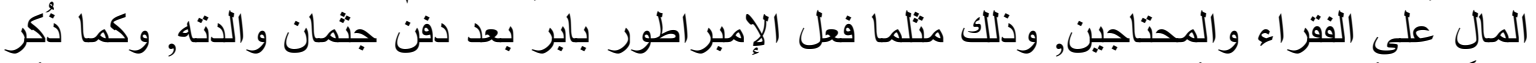

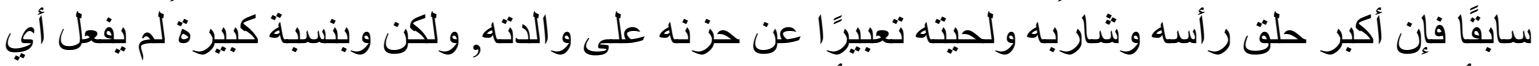

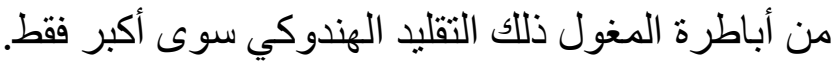

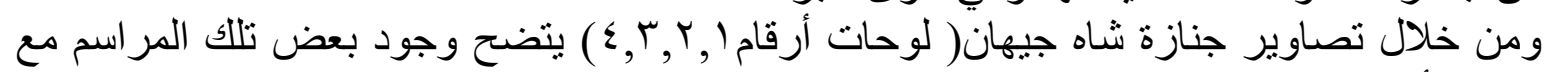

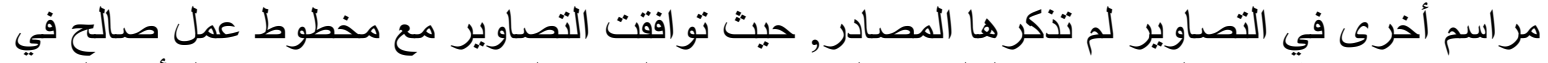

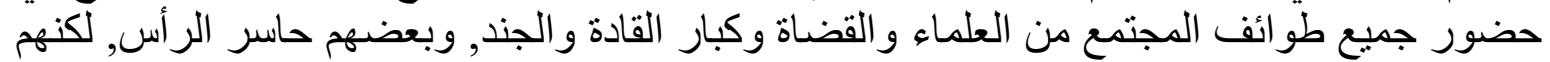

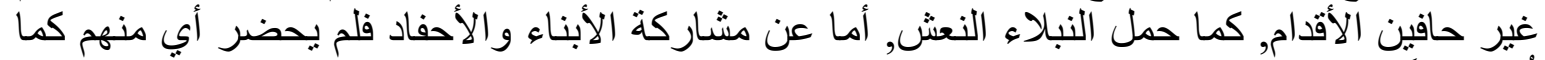

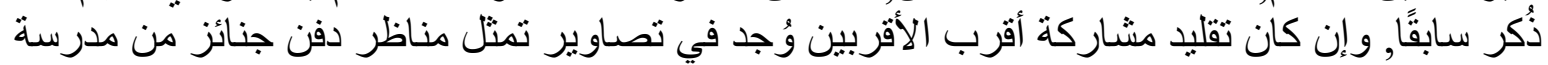


شركة الهند الثرقية (لوحتا ^,9), هذا بالإضافة إلى حالة الحزن التي ظهرت على المشاركين في

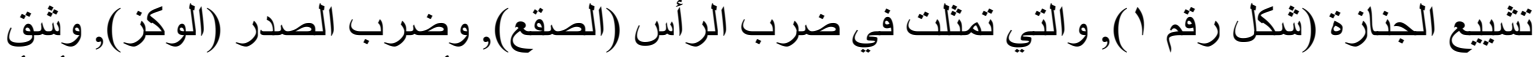
الجيب, والبكاء, كما بمسك عدد من الحضور بـاء بناديل لتجفيف دمع أعينهم, بالإضافة إلى طأطأة
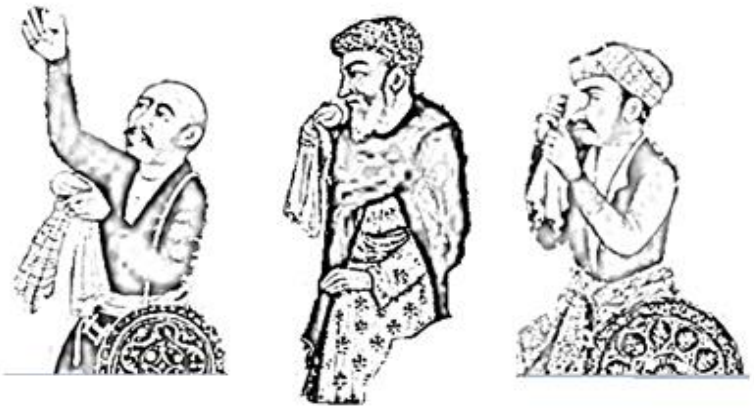

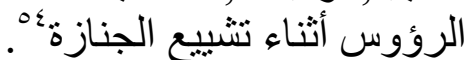

أما عن المراسم والتقاليا الجنائزية التى أمدتنا بها تصاوير جنازة شاه جهان والتي لم ترد في

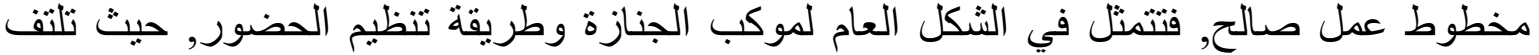

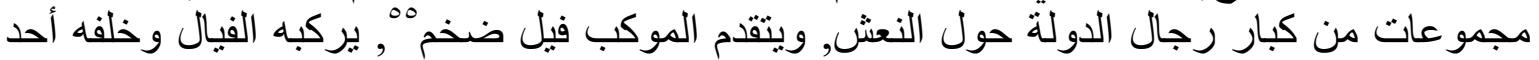
حاملي الر ايات يحمل راية منثلثة الشكل غير منتظمة الأضلاع (شكل رقم ؟).

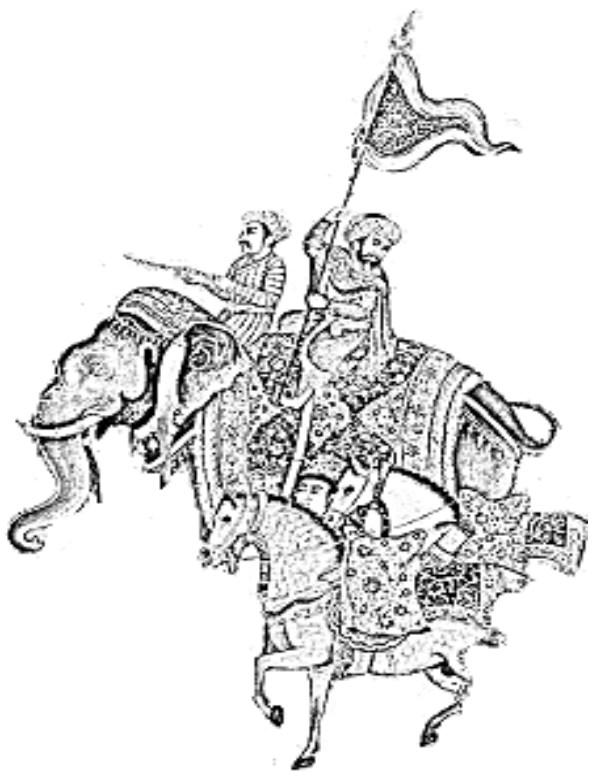

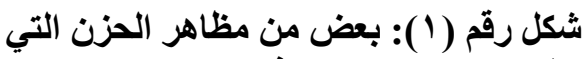

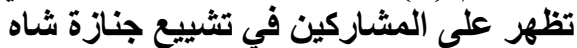

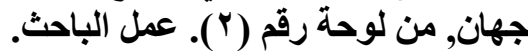

وليس بغريب أن يشارك الفيل (أحد أهم الحيو انات في الهند) في موكب جنازة الإمبر اطور شاه جهان,

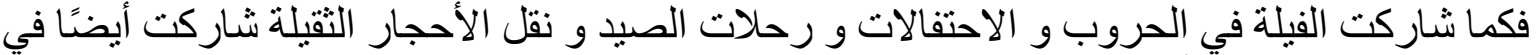

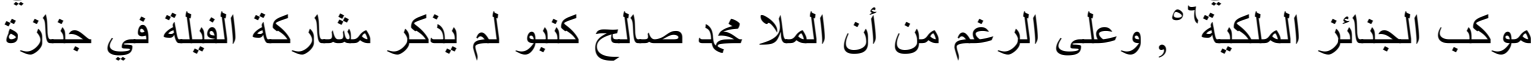

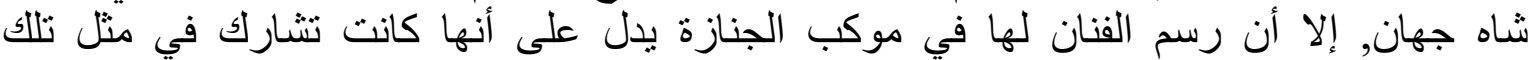

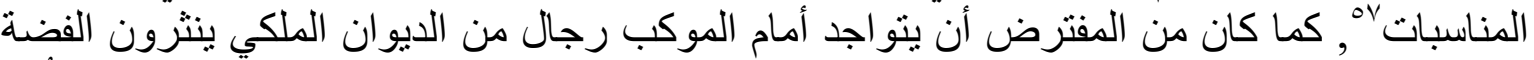

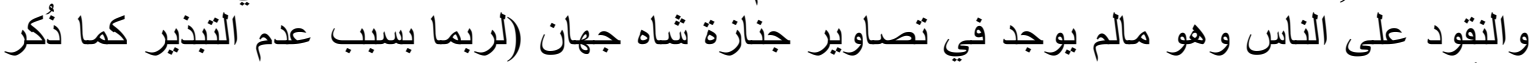

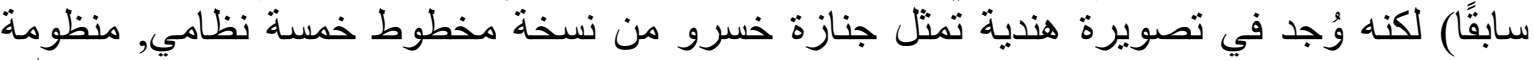

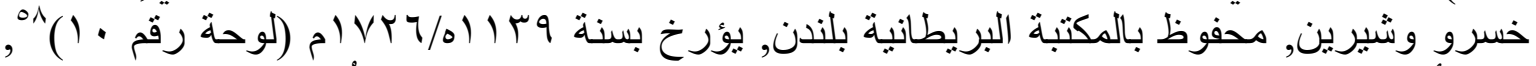

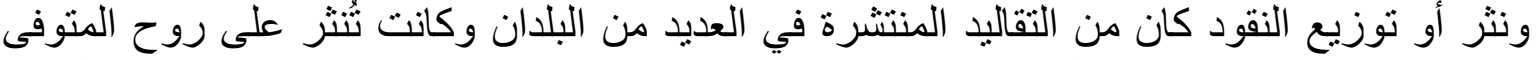

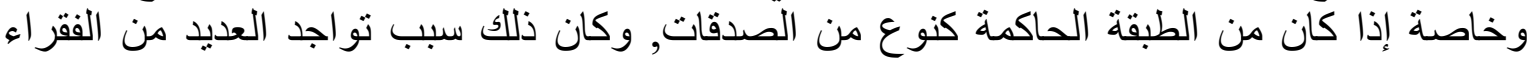

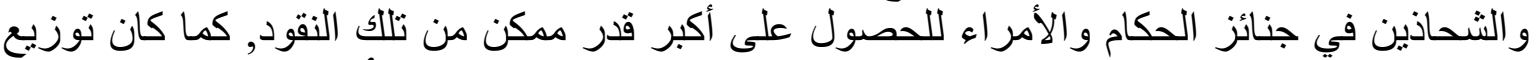

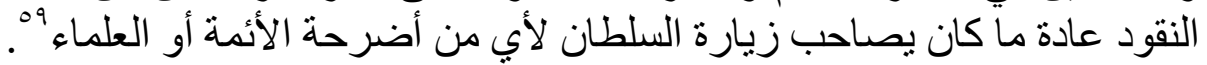


ومن المر اسم الجديدة في جنازة شاه جهان المظلة التي تظلل النعش (شكل رقم بَ), و التي كانت تُصنع

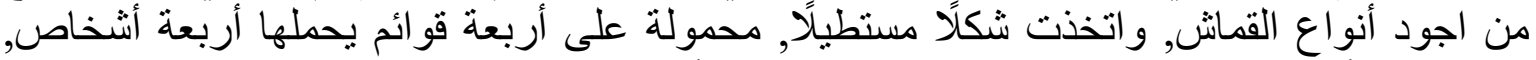

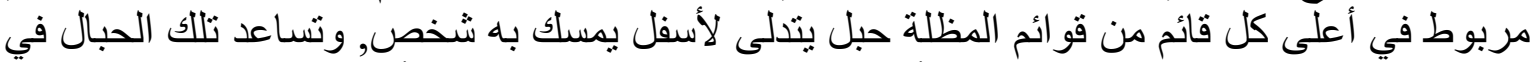

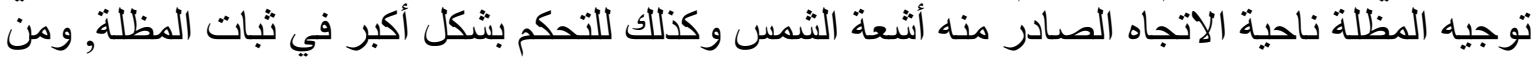

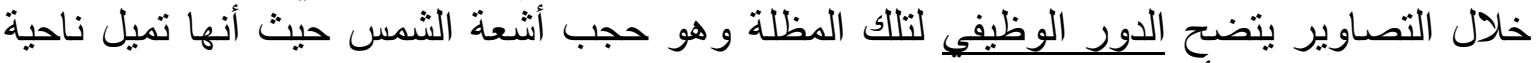

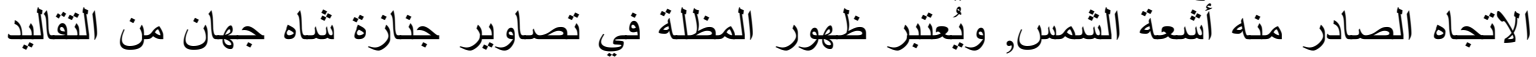

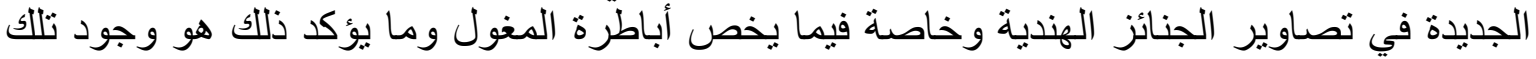

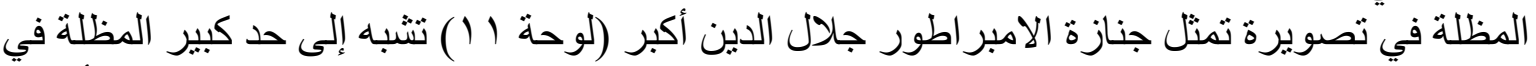

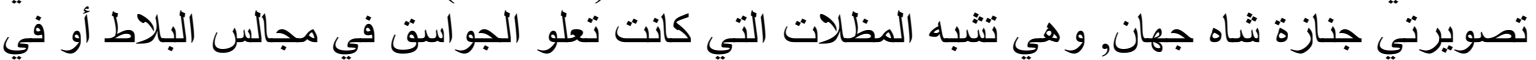

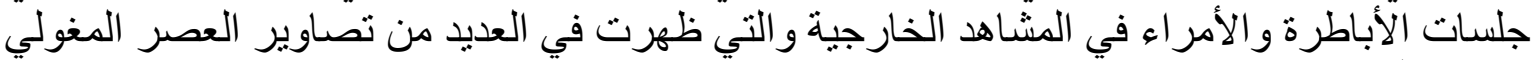

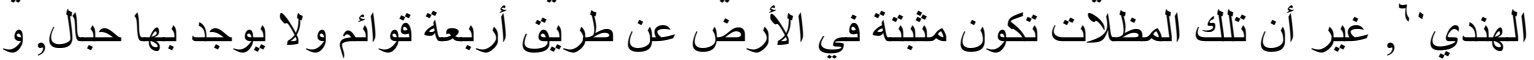

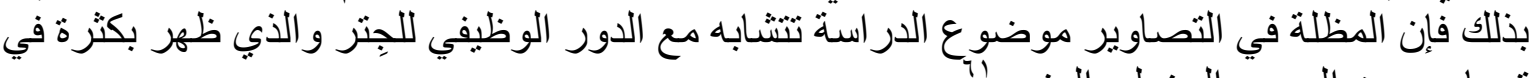

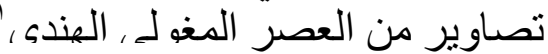

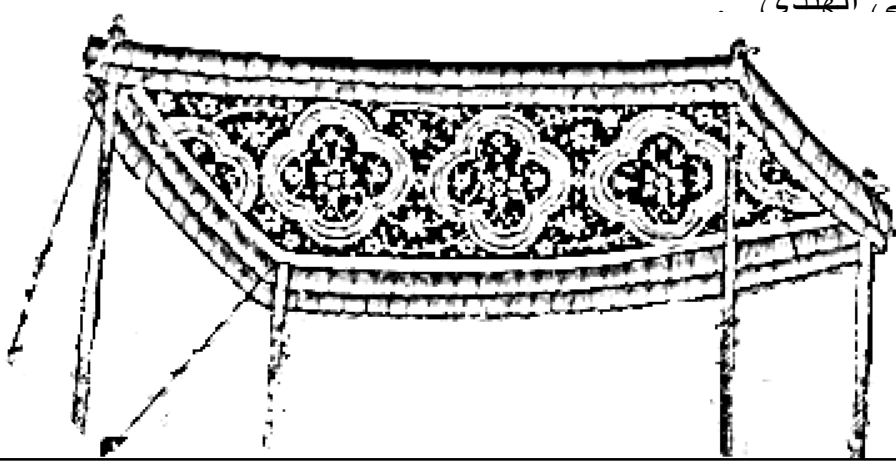

شكل رقم (r) المظلة التي تظلل نعش شاه جهان, من (لوحة رقم ץ). عمل الباحث.

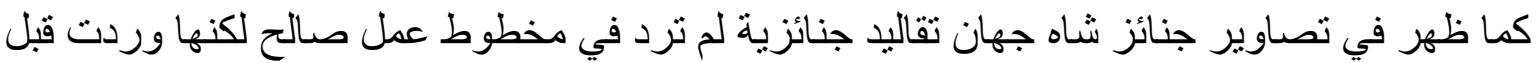

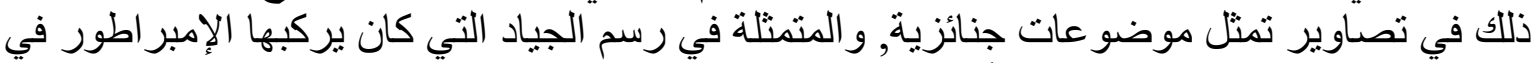

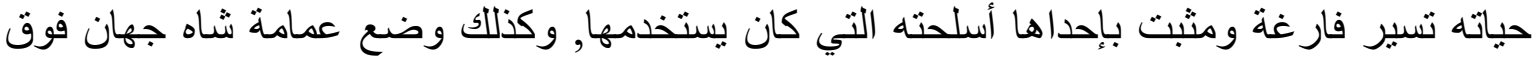

مقدمة النعش, بالإضافة إلى وقفة الاحتر ام و التبجيل, ويمكن تناول تلإلك التقاليد بالتفصيل فيل فيما يلي:-

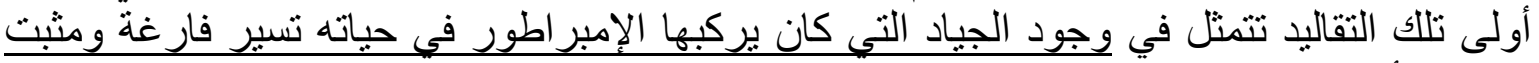

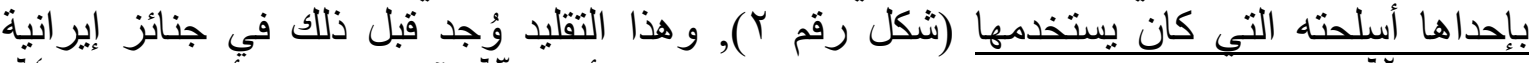

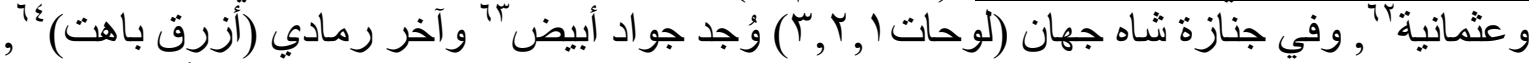

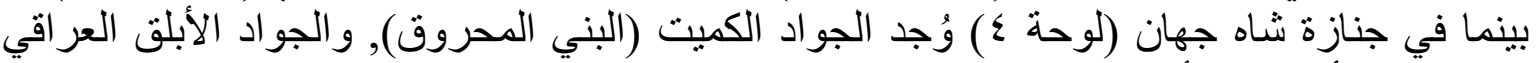

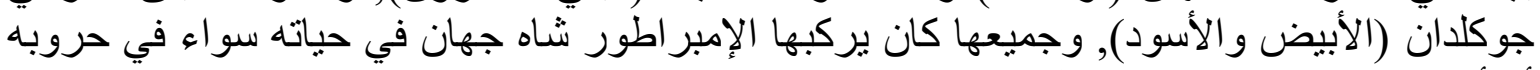

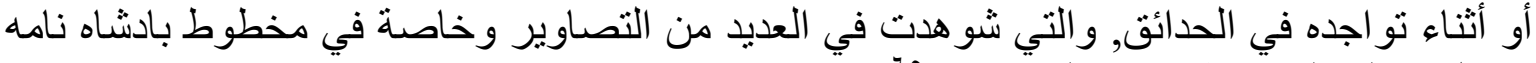

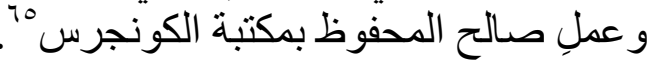

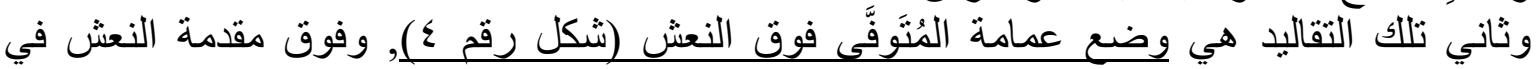

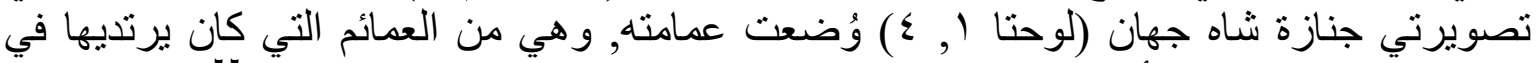

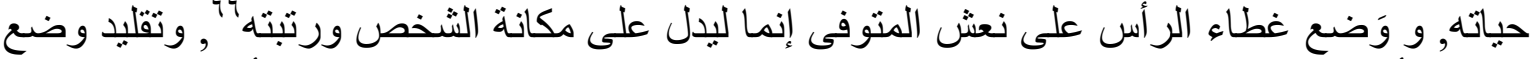

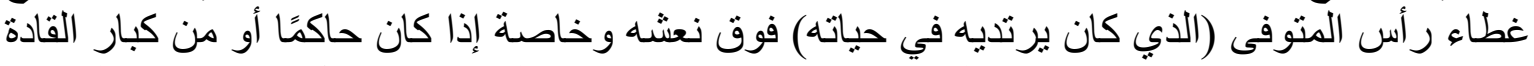

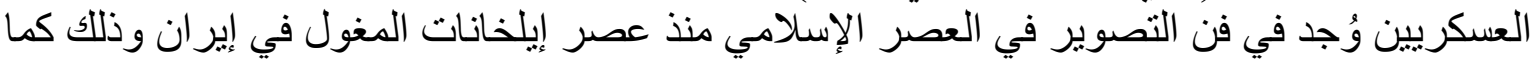

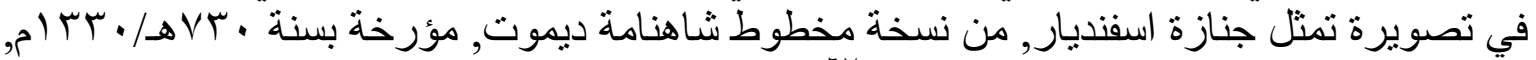

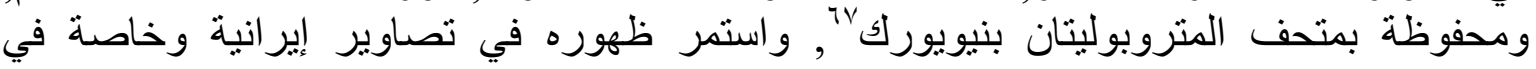


التصاوير التي تمثل جنازة الإسكندر الأكبر, كما انتشر ذللك التقليد في تصاوير عثمانية خاصة في تصاوير جنائز الإسكندر الأكبر وسلاطين وأمراء الدولة العثمانية, وفي العصر المغولي الهندي تم

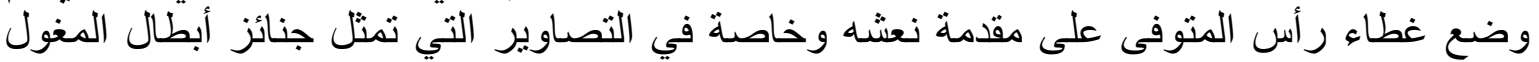

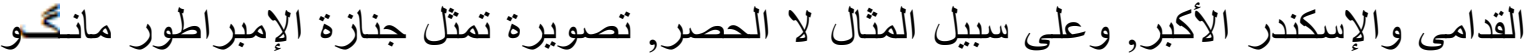
خان(Mangu Khan) حفيد جنكيز خان, من نسخة مخطوط تاريخ المغول, مؤرخة بسنة

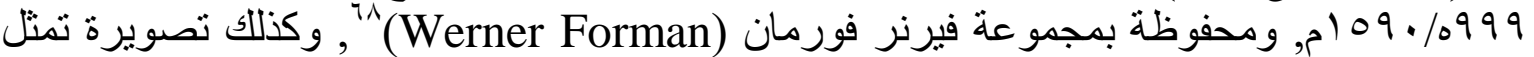

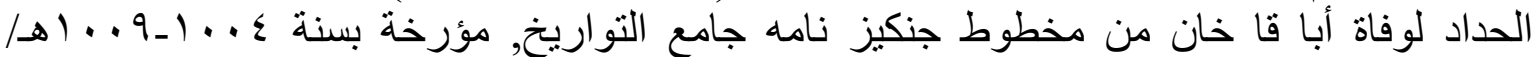

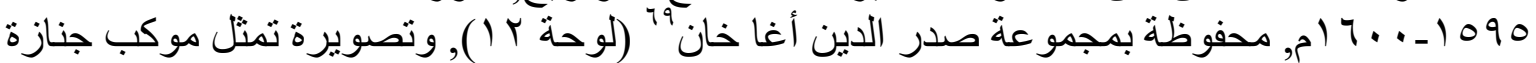

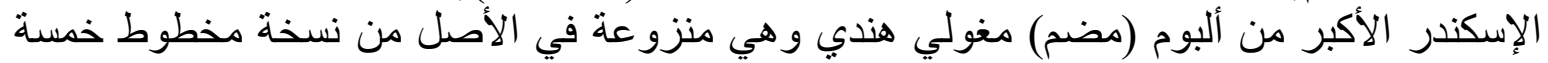

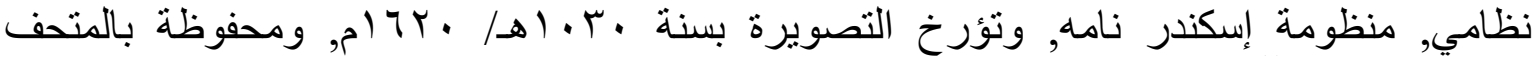

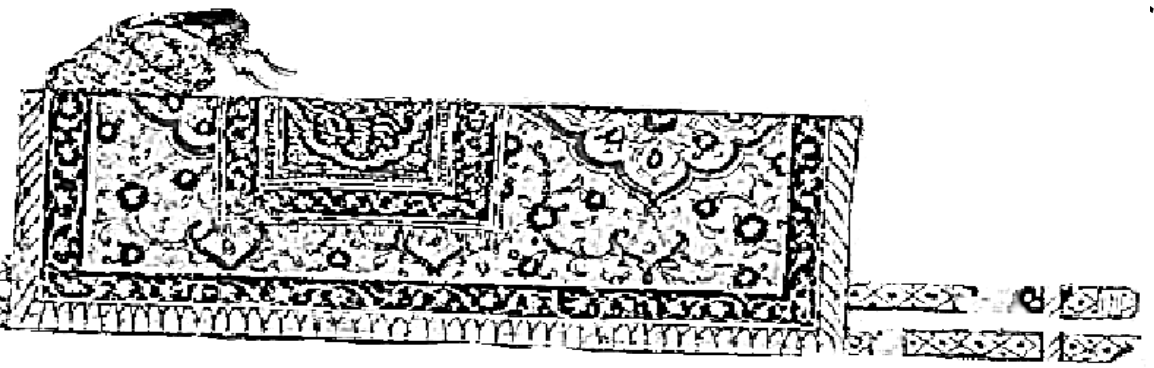

\section{شكل رقم (؛) ): عمامة شاه جهان موضوعة فوق مقدمة النعش, من (لوحة رقم ؟). عمل الباحث.}

و ثالث تلك التقاليد يتمثل في وقوف بعض الجند وقفة الاحتر ام و التبجيل (شكل رقم 0), وتتمثل وقفة

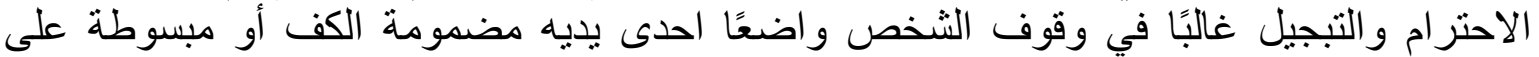

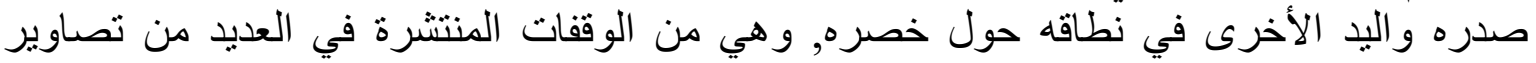

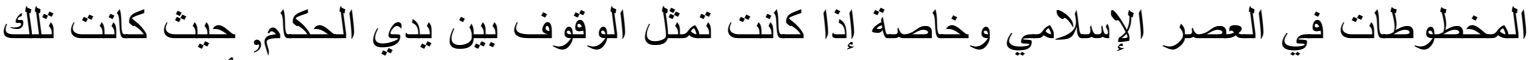

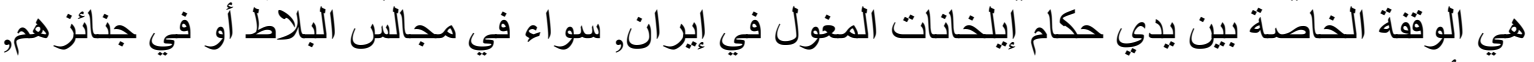

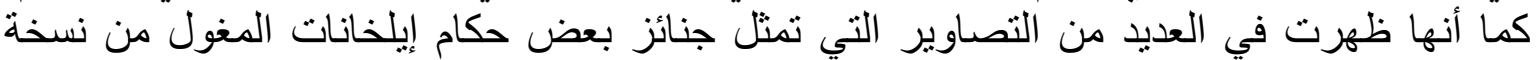

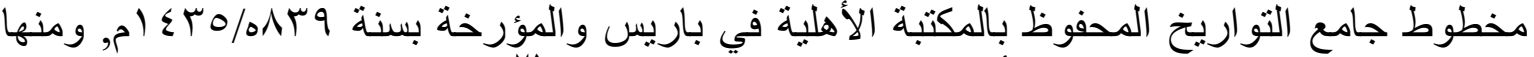

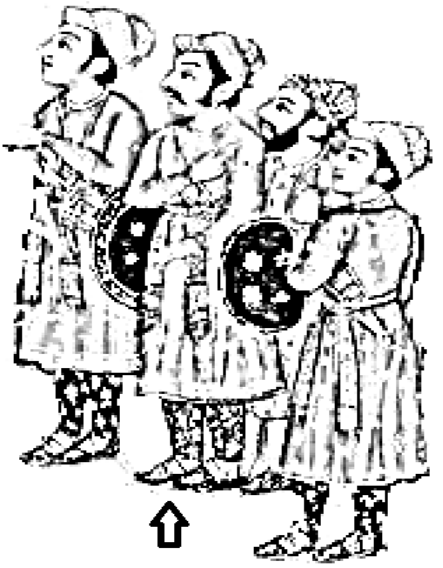

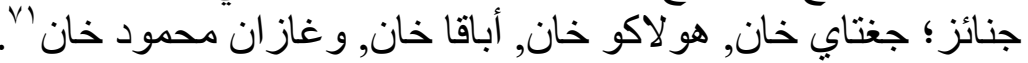
من (لوحة رقم ؟). عمل الباحث

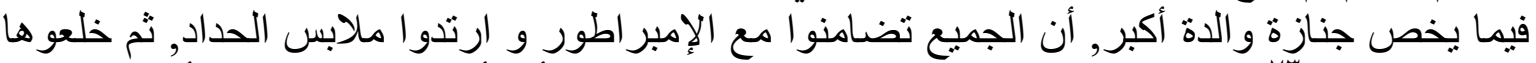

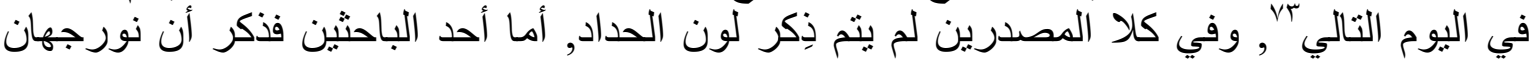

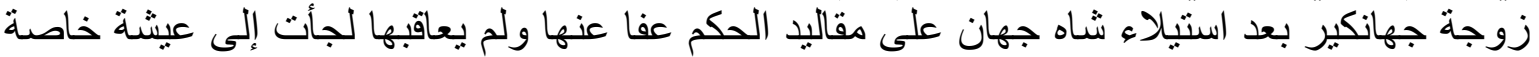

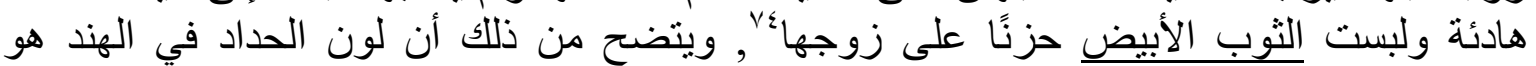


الأبيض •, كما كان اللون الأبيض هو لون الحداد عند الهندوس, حيث كانت نو افذ الهندوس أثناء فترة

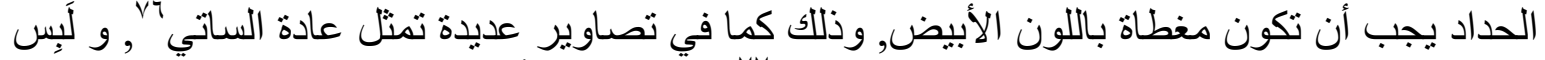

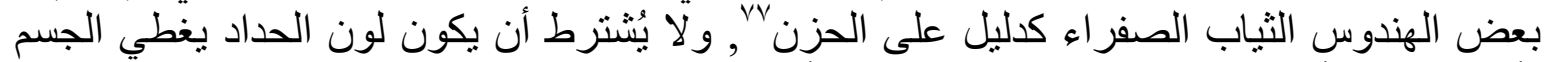

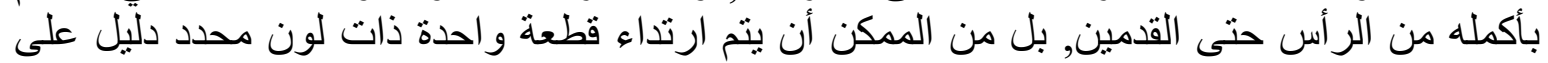

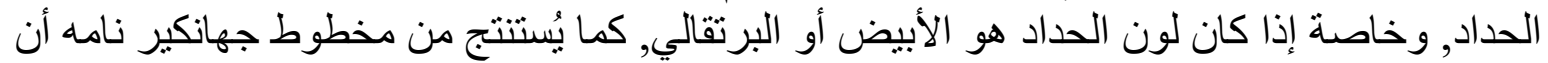

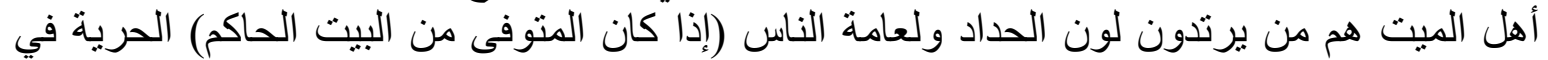

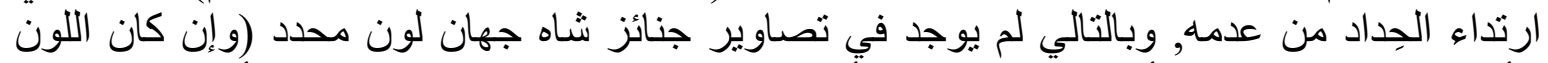

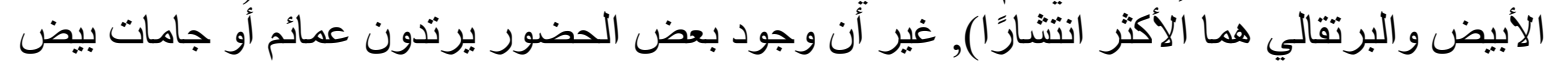

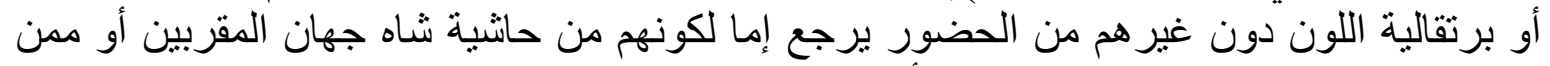

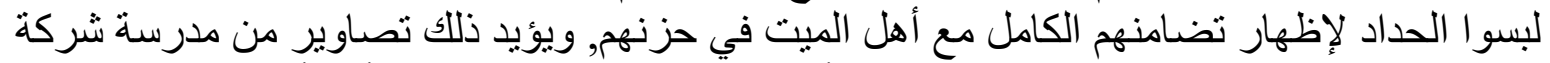

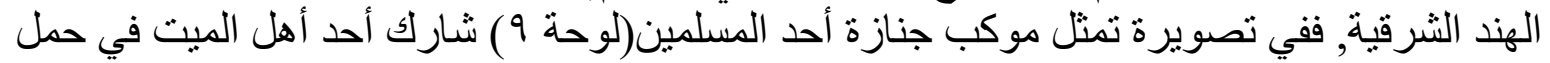

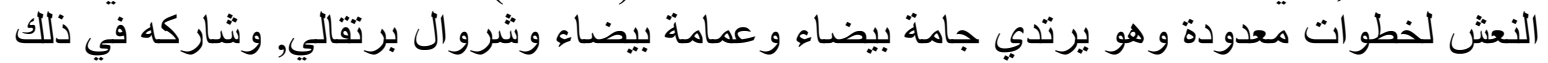

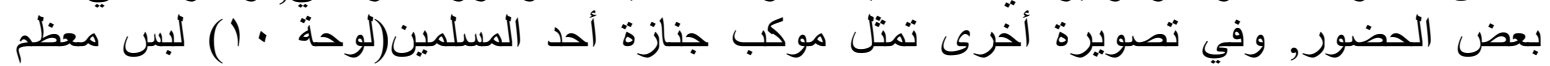

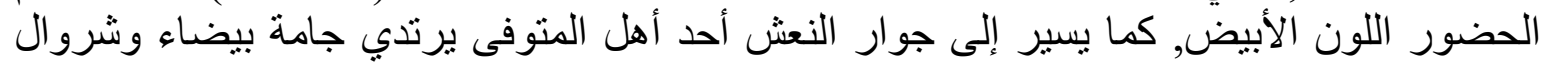

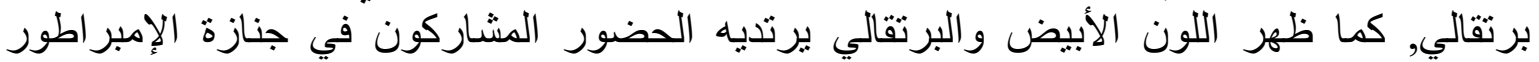

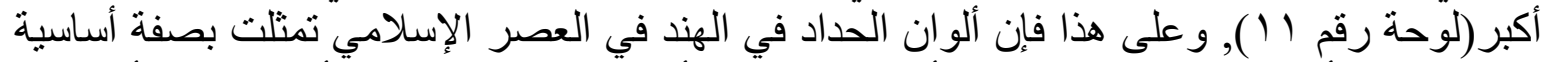

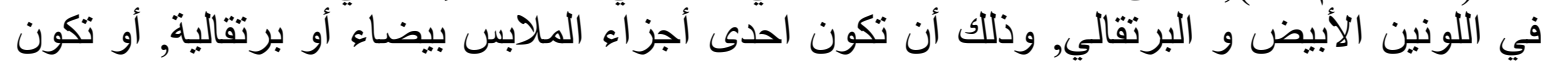

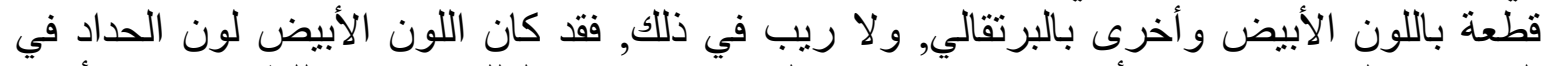

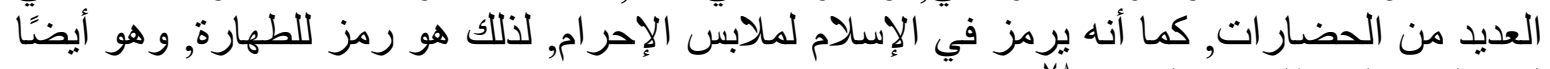

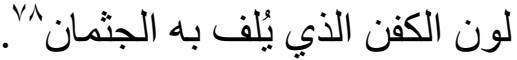

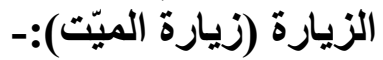

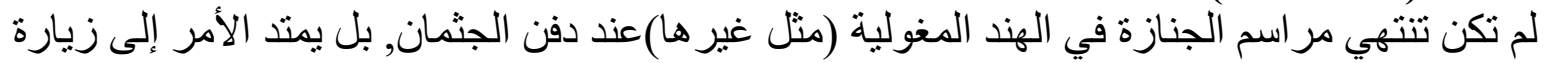

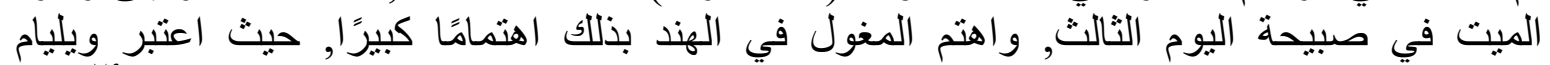

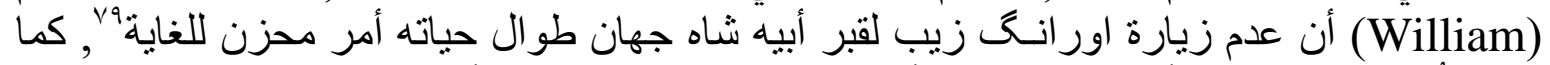

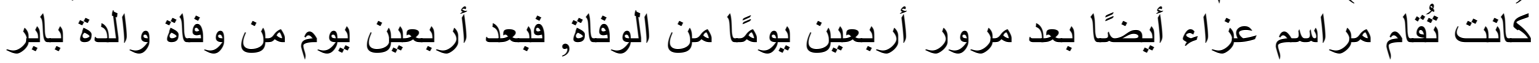

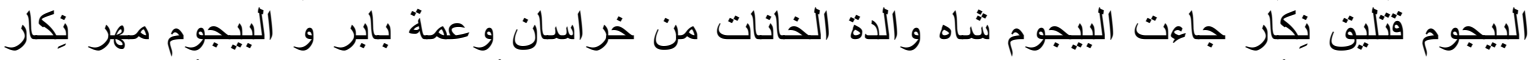

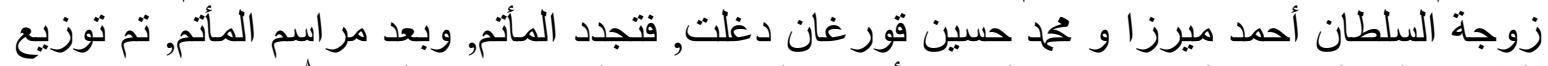

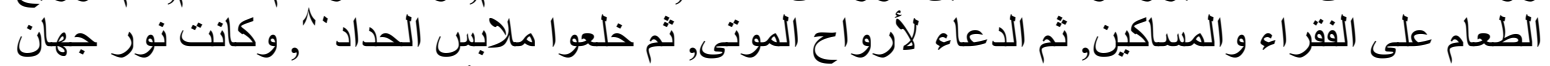

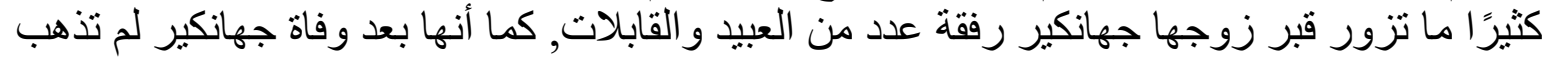

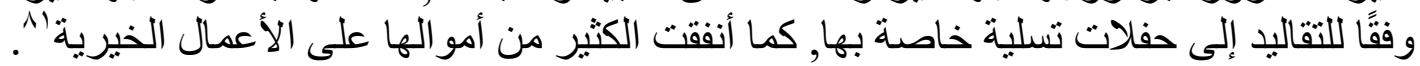

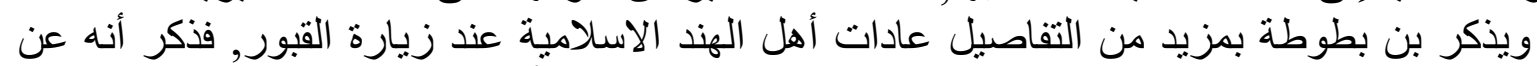

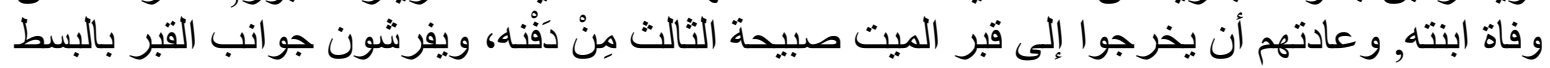

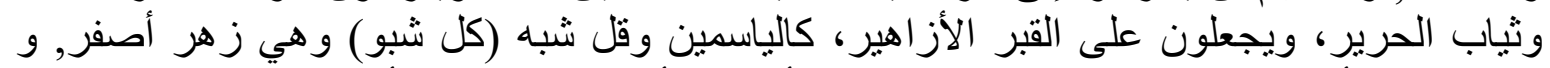

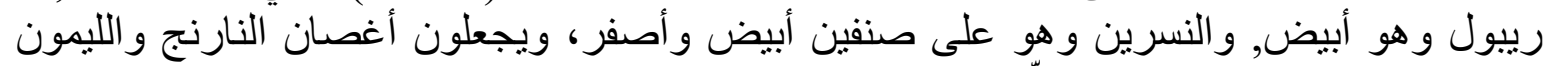

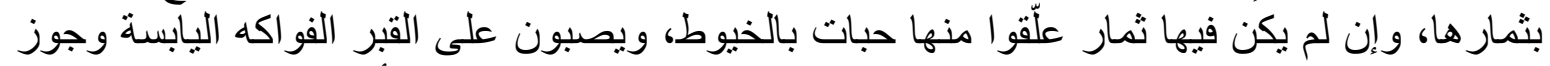

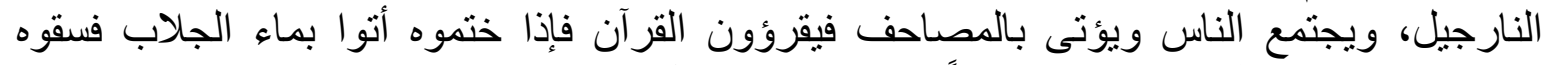

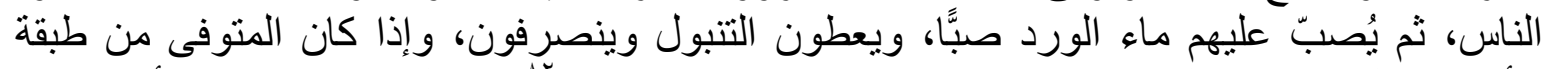

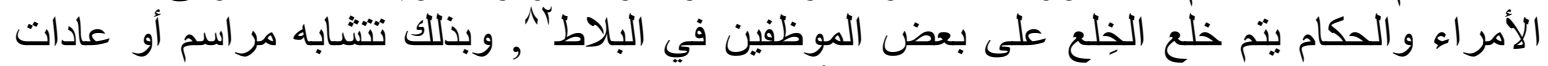

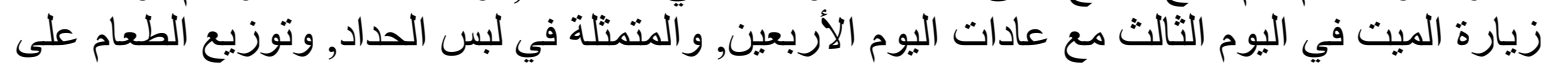

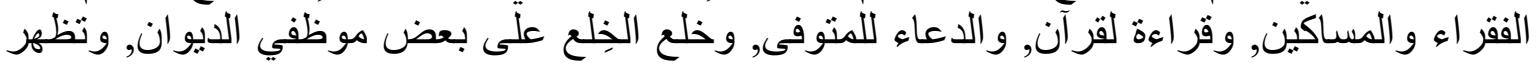




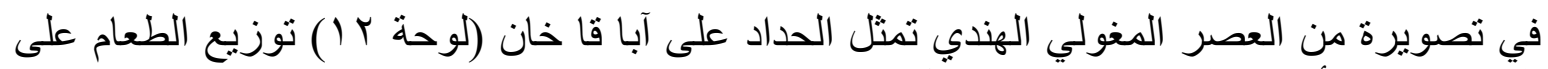

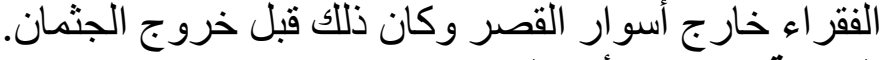

الخاتمة وتتضمن أهم النتائج

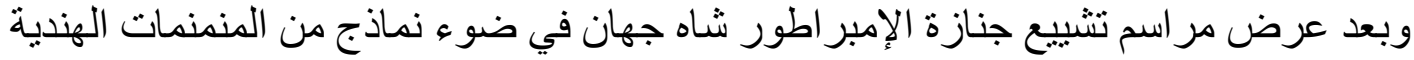

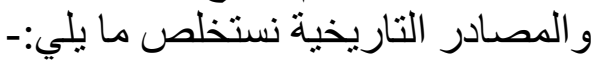

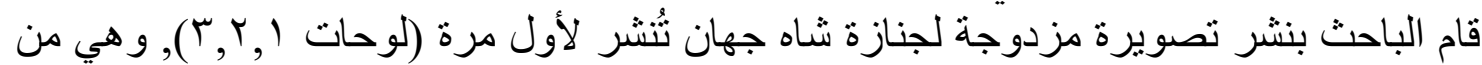

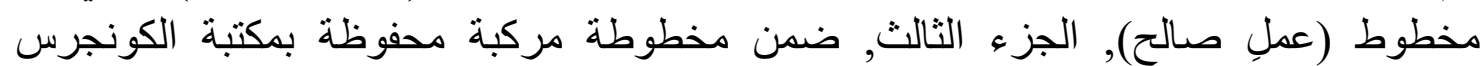
بالو لايات المتحدة الأمريكية. أوضحت الدر اسة أن سبب الاختلاف حول الألايام الأخيرة في حياة شاه جهان وطريقة تتثييع جثمانه

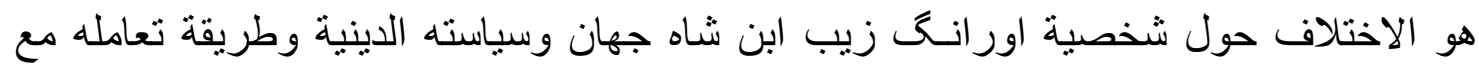

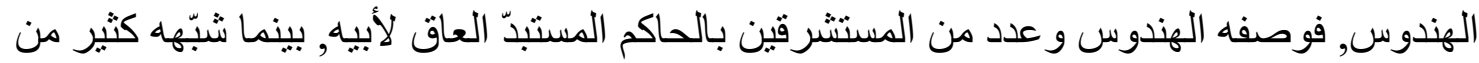
علماء المسلمين ومؤرخيهم بالخلفاء الر اثندين في حياته الثخصية وطريقته في إدارة شئون الثئن البلاد.

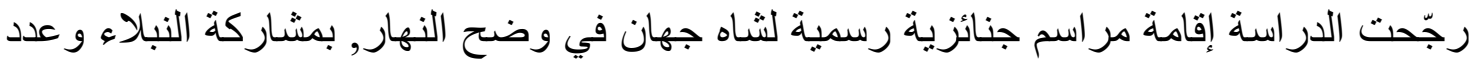

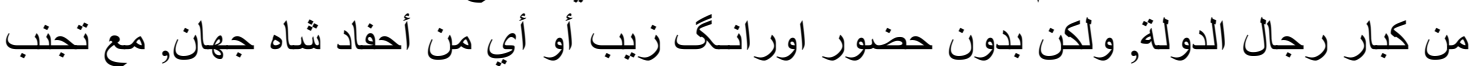

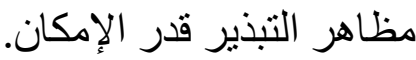

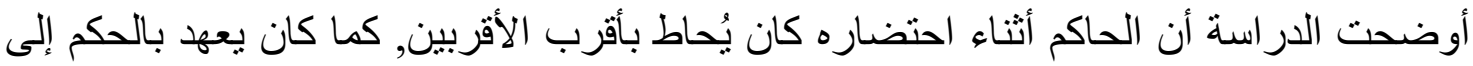

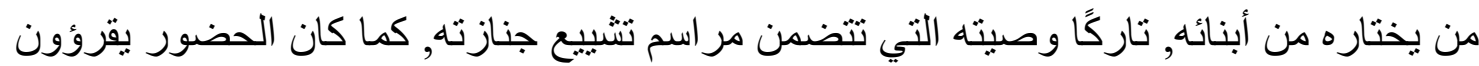

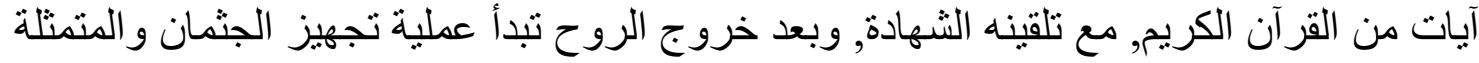

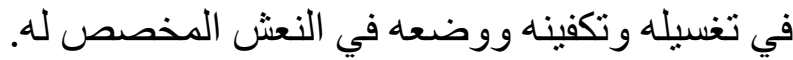
أوضحت الدراسة أن مراسم تثييع جنائز الطبقة الحاكمة من الأباطرة والأمر اءلهاء (رجال ونساء)

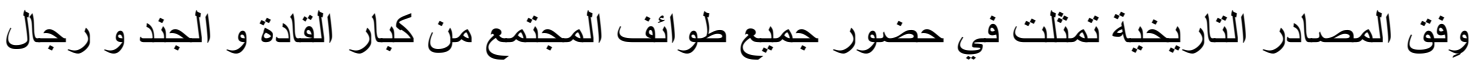

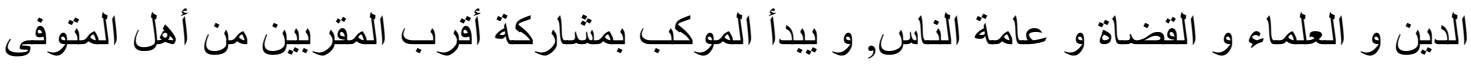

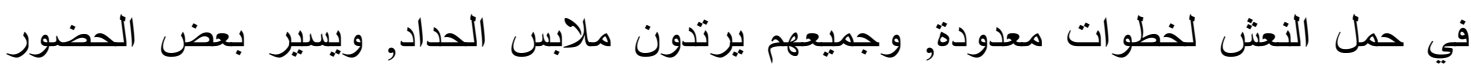

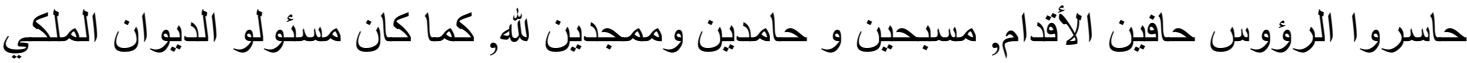

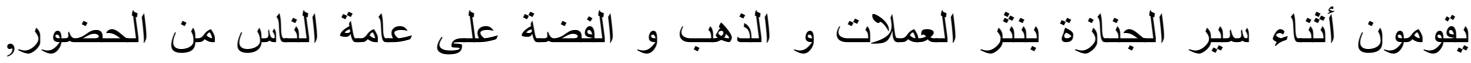

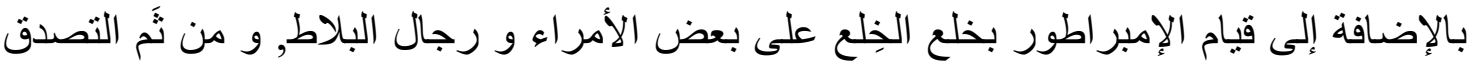

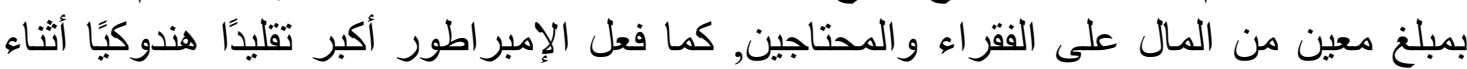

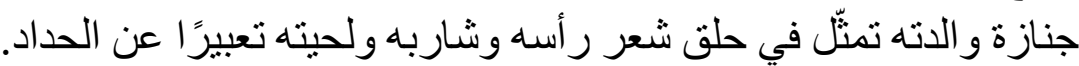

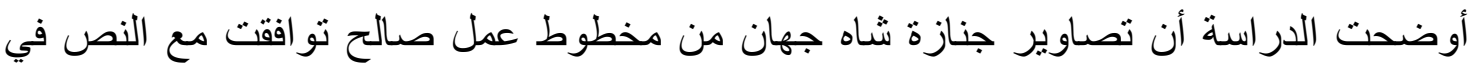

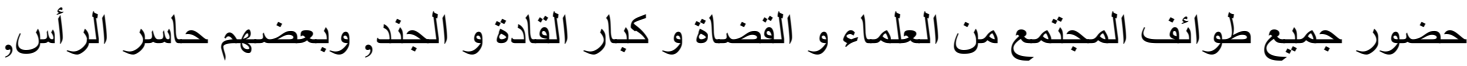

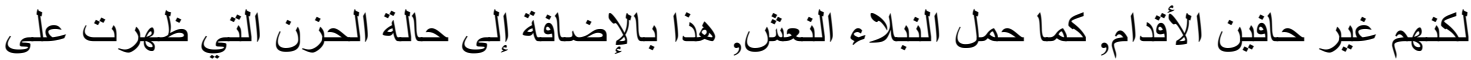

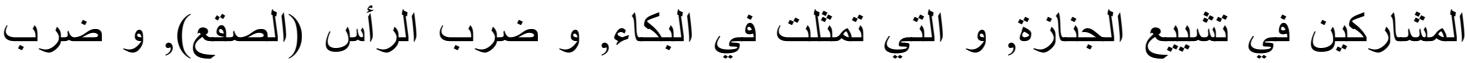

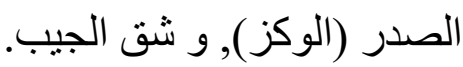

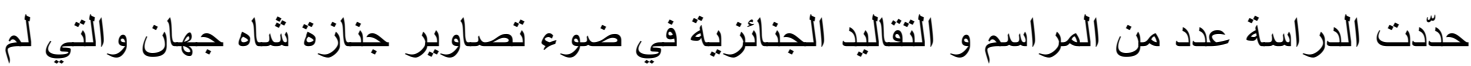

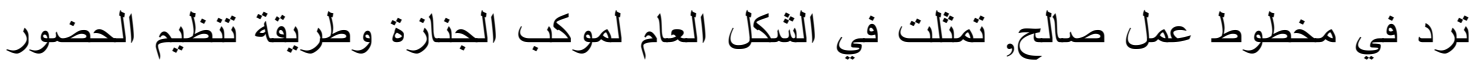

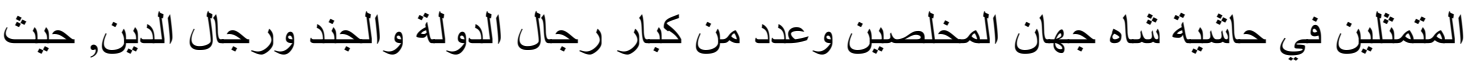


تلتف مجموعات من كبار رجال الدولة حول النعش, ويتقدم الموكب فيل ضخم, يركبه الفيال وخلفه أحد حاملي الرايات.

أوضحت الدر اسة عدد من المر اسم الجديدة في تصاوير جنازة شاه جهان منها: المظلة التي تغطي النعش و التي يشارك في حملها ثمانية اشخاص, و الفيل الذي يتقدم الجنازة.

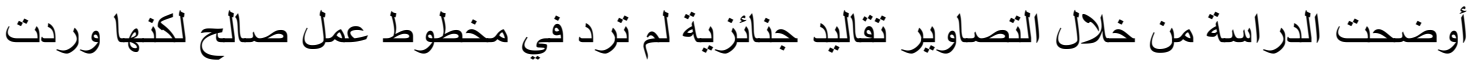

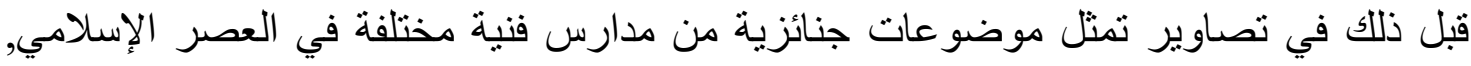

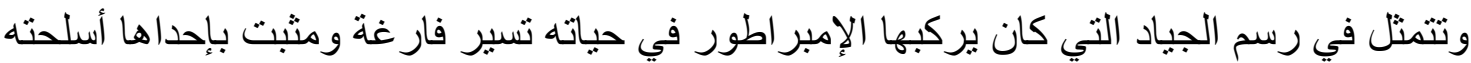
التي كان يستخدمها, وكذلك وضع عمامة شاه جهان فوق مقدمة النعش دليل على مكانته كحاكم

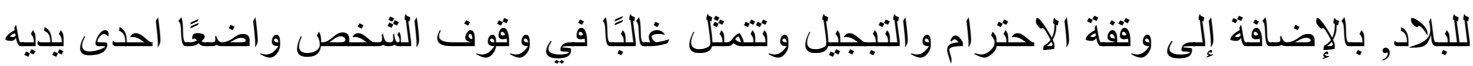

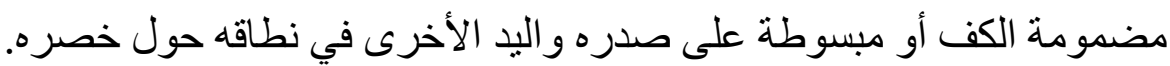

أوضحت الدر اسة أن ألو ان الحداد في الهند في العصر الإسلامي تمثلت بصفة أساسية في اللونين الأبيض و البرتقالي.

أوضحت الدر اسة تشابه مر اسم أو عادات زيارة الميت في اليوم الثالث و اليوم الأربعين, و المتمثلة في لبس الحداد, وتوزيع الطعام والصدقات على الفقراء والمساكين, وقراءة القرآن, والداء الداء للمتوفى, وخلع الخِلع على بعض موظفي الديوان إذا كان المتوفى من الطبقة الحاكمة.

- M. Hidayat Hosain, Contemporary historians during the reign of the emperor Shah Jahan, Islamic culture, Vol. XV, Juanuary, Number 1, 1941, Hyderabad, Deccan, 1941.

https://www.loc.gov/resource/rbc0001.2015rosen1791/?st=gallery.

$$
\text { خامسًا: المواقع الإلكترونية:- }
$$
https://imagesonline.bl.uk/search/?searchQuery=Amal-i+Salih http://preamblequestioned.blogspot.com/2007/07/aurangzeb-as-he-was-according-tomughal.html http://www.columbia.edu/itc/mealac/pritchett/00glossarydata/terms/palanquin/palan quin.html http://collections.vam.ac.uk/item/0434111/bhisma-painting-ali https://www.clevelandart.org/art/1962.279.146.a https://manuscripts.thewalters.org/viewer.php?id=W.650\#page/337/mode/1up https://imagesonline.bl.uk/asset/149579 


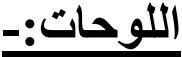

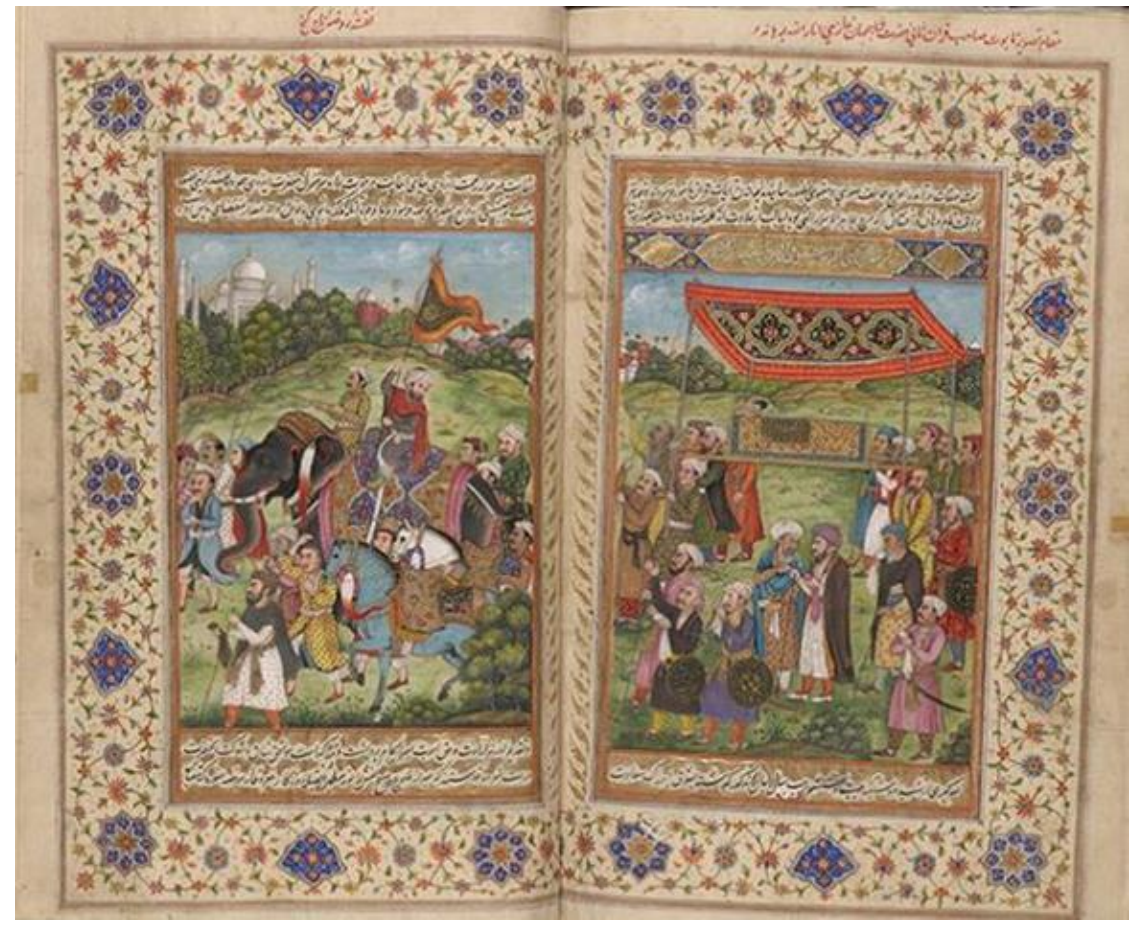

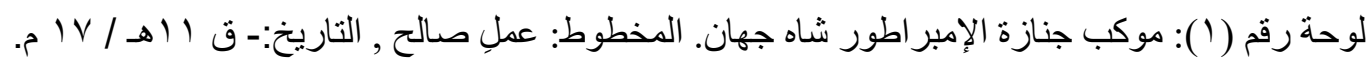

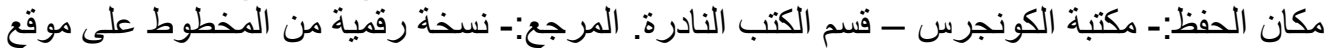
https://www.loc.gov/resource/rbc0001.2015rosen1791/?st=gallery المكتبة المكترة

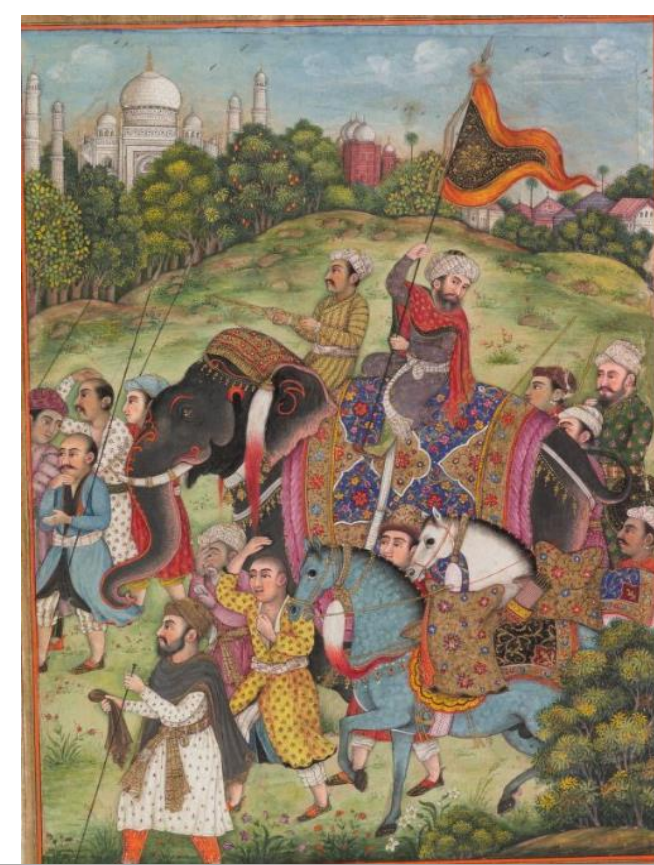

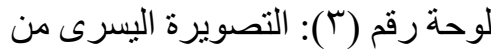
التصويرة السابقة, وتمثل مقدمة الموكبر التبري.

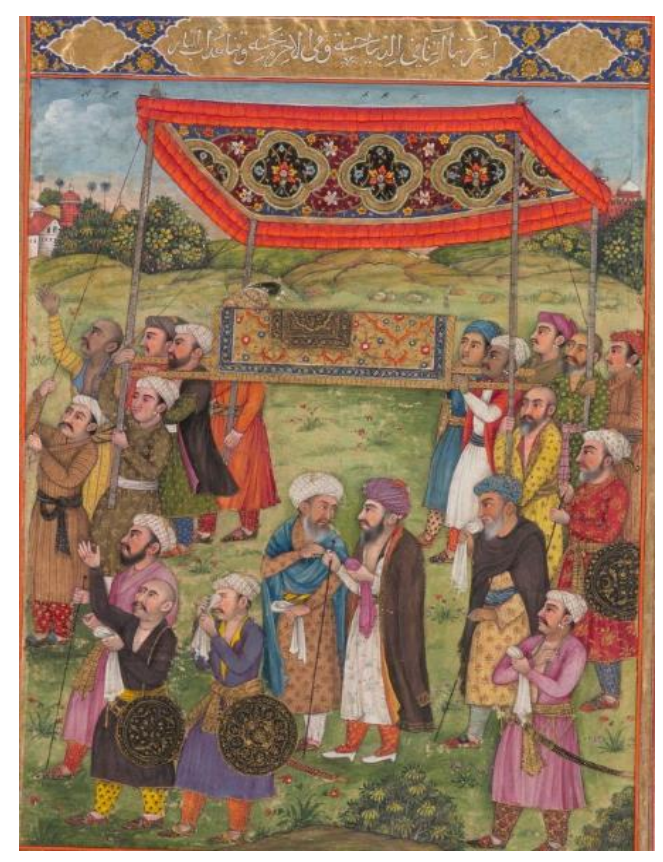

لوحة رقم (r): التصويرة اليمنى من التصويرة

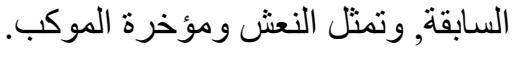



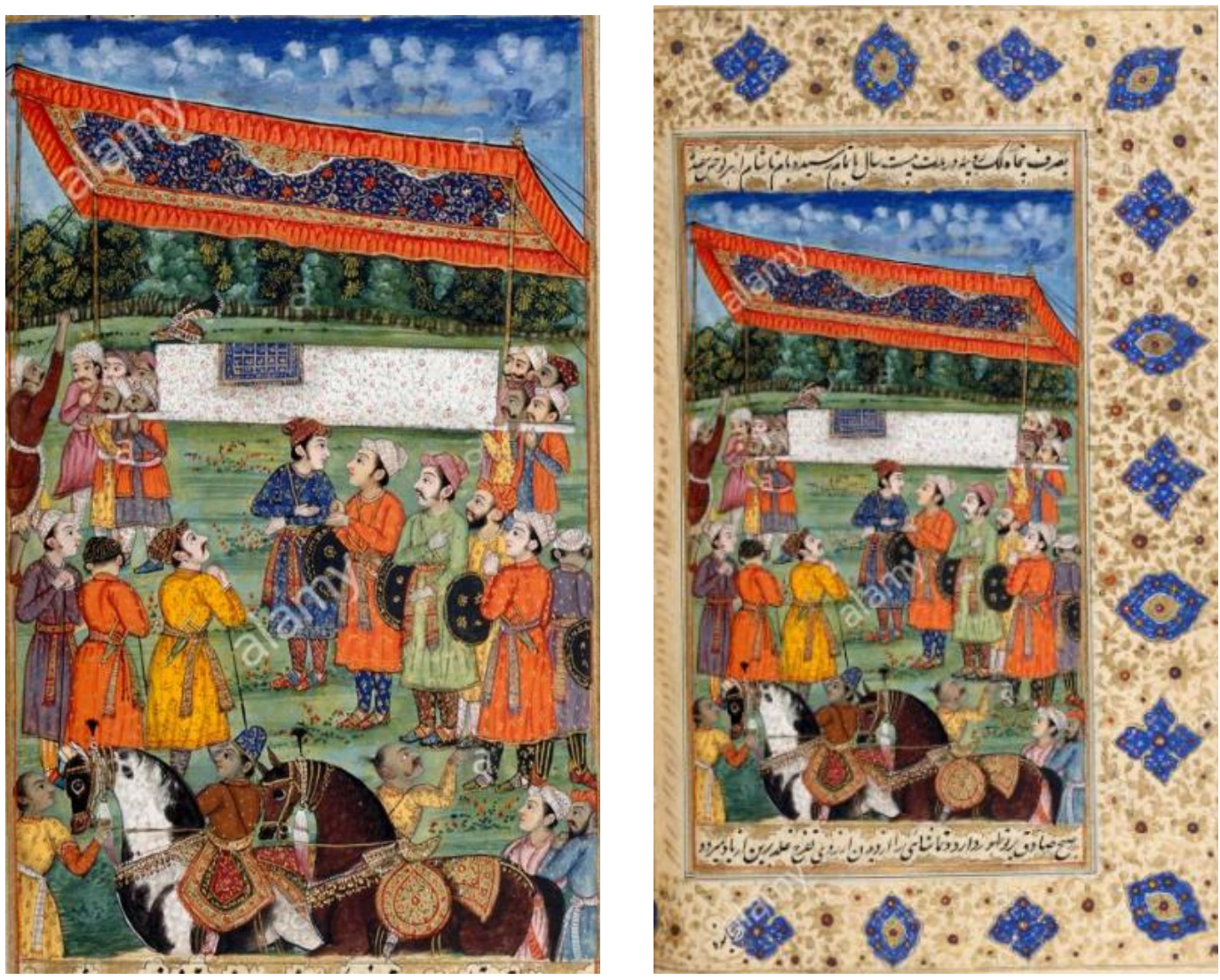

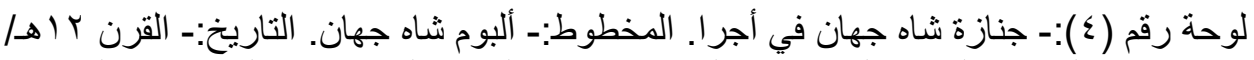
1 ام. مكان الحفظ:- المكتبة البريطانية. المرجع:- موقع المكتبة البريطانبة الإلكتروني ــ لندن. https://imagesonline.bl.uk/asset/10978

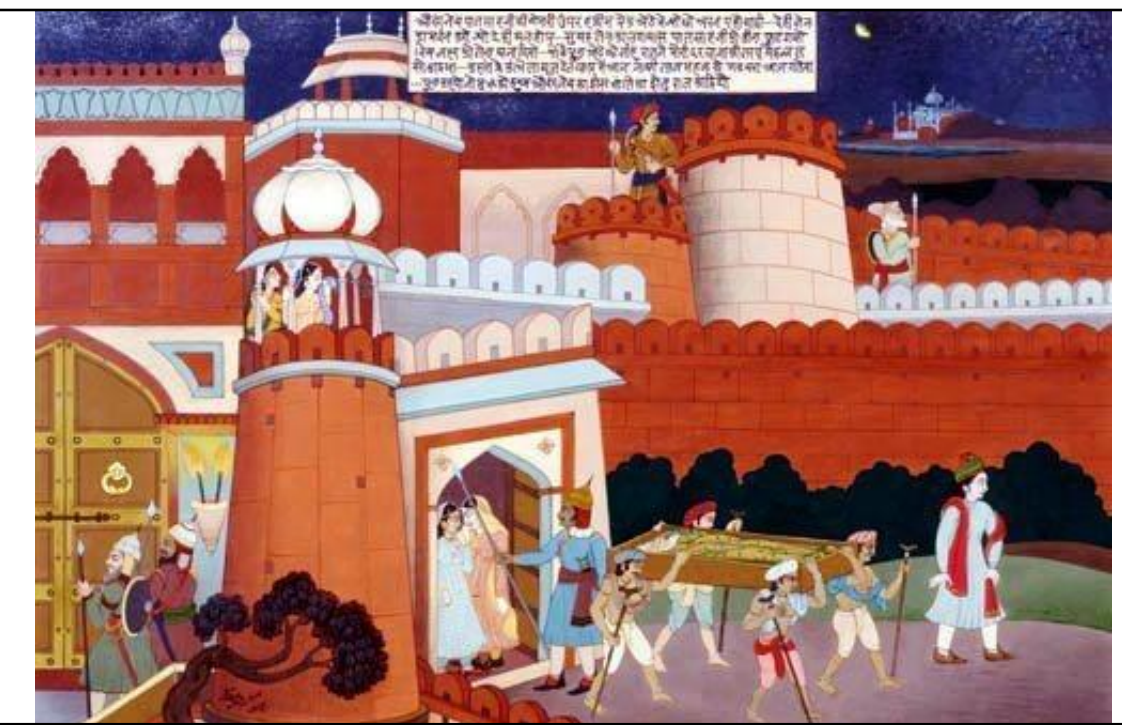

لوحة رقم (0): جنازة شاه جهان أثناء خروجها ليلًا من حصن أجرا. أرشيف راجستان في بيكانير, القرن

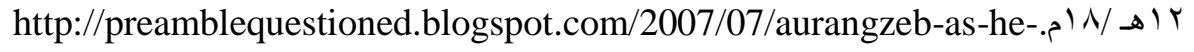
was-according-to-mughal.html 


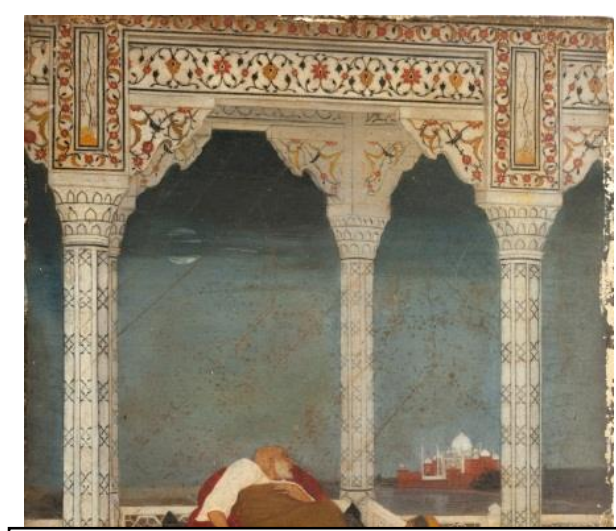

لوحة رقم (7): احتضار شاه جهان. الألبوم: تصويرة زيتية.

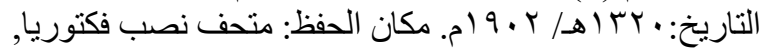

بو لاية كولكاتا الهندية (Victoria Memorial Hall, Kolkata) الفنان: Abanindranath Tagore المرجع: الموقع الرسمي لمتحف نصب http://www.victoriamemorial-فكتورئ cal.org/virtual_exhibition/content/en

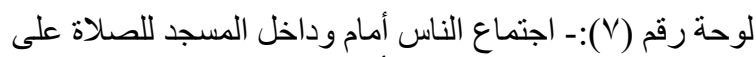

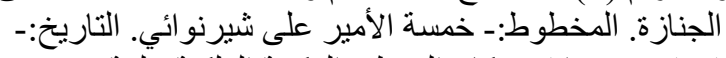

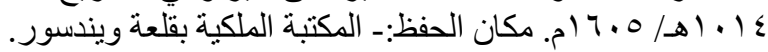
Asok Kumar Das, Mughal Masters, Further Studies, 1st edition, Mumbai: Marg Publications, 1998. P. 136, PL. 2.
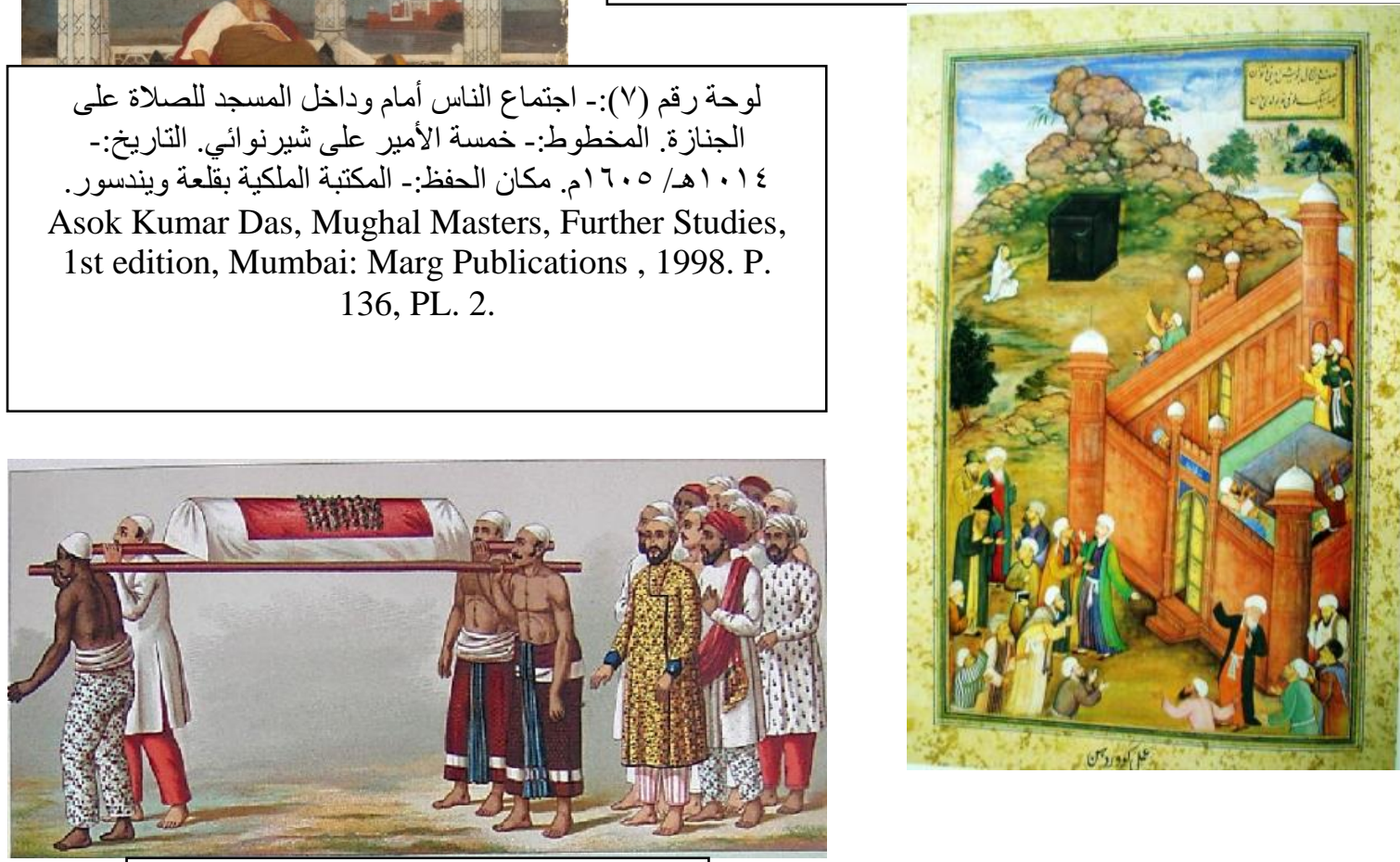

$$
\begin{aligned}
& \text { لوحة (^): مشهد جنازة إسلامية, من مدرسة }
\end{aligned}
$$

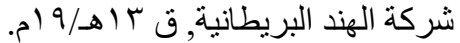
http://www.columbia.edu/itc/mealac/ pritchett/00routesdata/1800_1899/dai lylife_drawings/racinet/xfuneralcostu

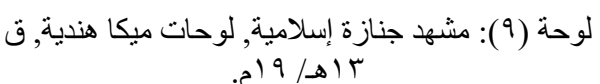

somersetandwood.com/collections/asianart/indian-mica-paintings/company-school-

19th-century-indian-mica-painting-ingouache-funeral-procession-jm-119

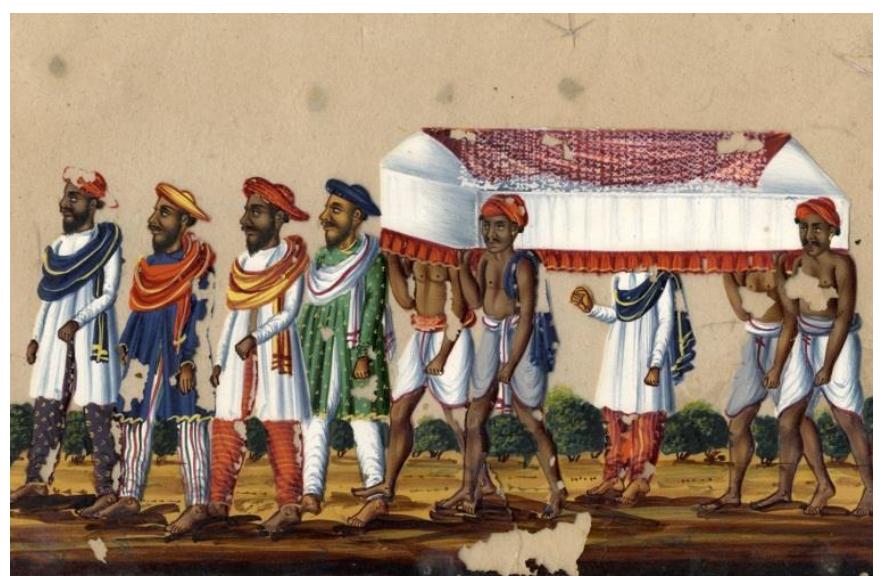




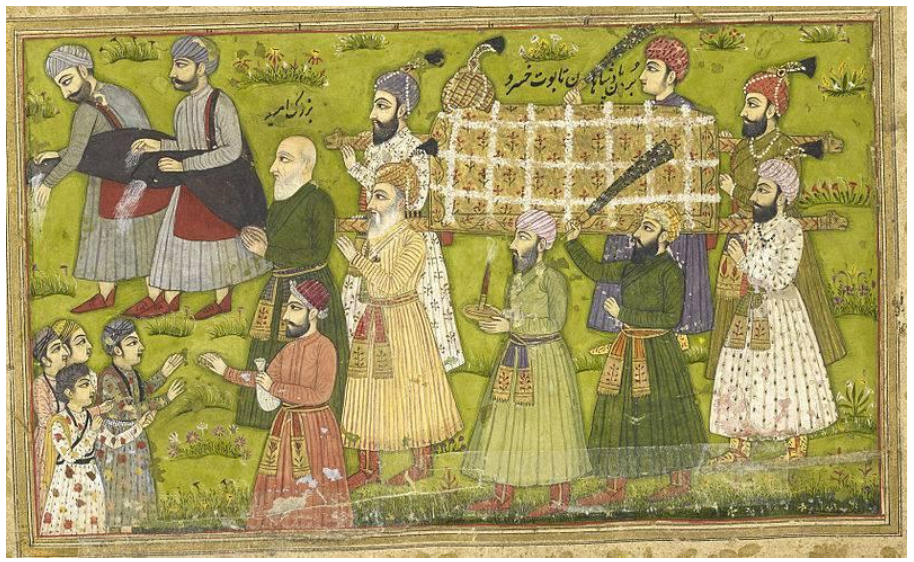

لوحة رقم (• (): جنازة خسرو, من

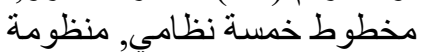

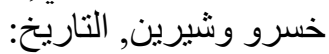
| المكتبة البريطانية, لندان.

المرجع:-موقع المكتبة البريطانية. https://imagesonline.bl.uk/a sset/149579
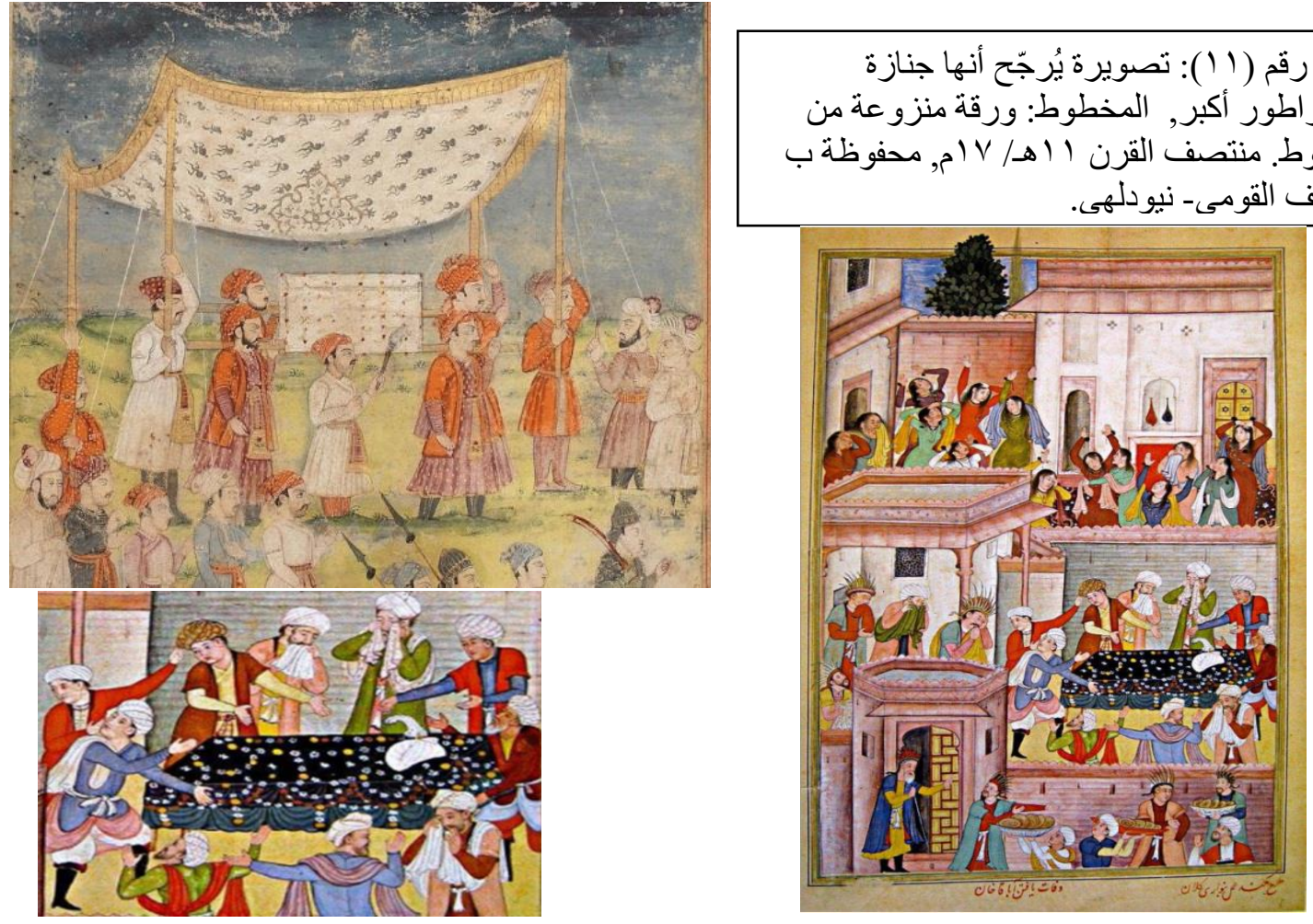

تفصيل من اللوحة (r ( ) يوضح وضع العمامة فوق النعش.

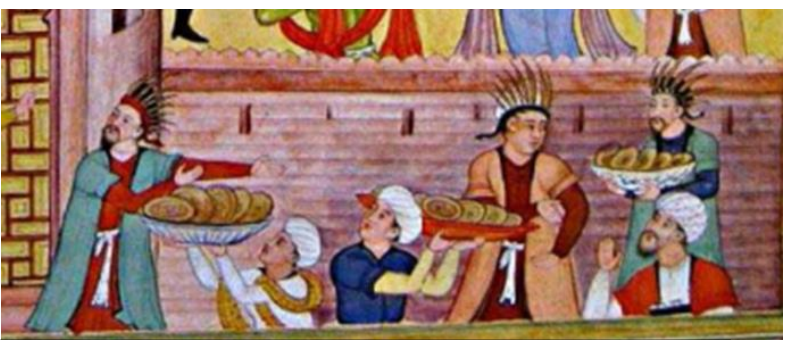

لوحة رقم (r ا ): الحداد لوفاة آبا قا خان من مخطوط جنكيز

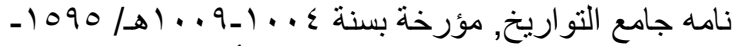

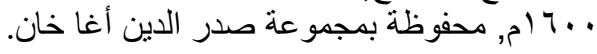
Sheila R. Canby, Princes, Poets and Paladins, Islamic and Indian Paintings. pl. 90.

تفصيل من اللوحة (r ( ) يوضح نوزيع الطعام

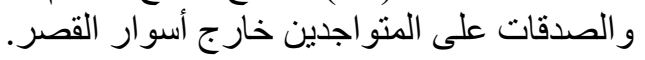




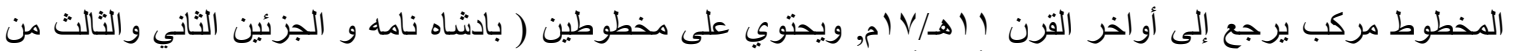

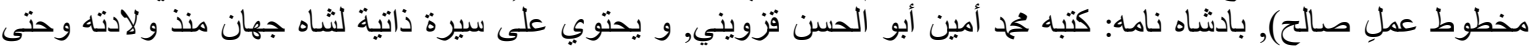

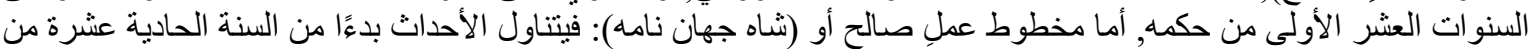

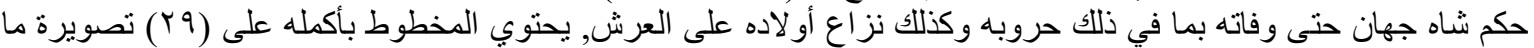

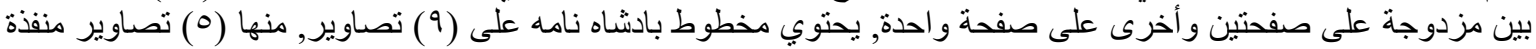

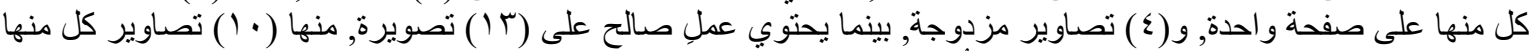

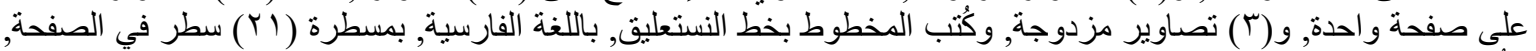

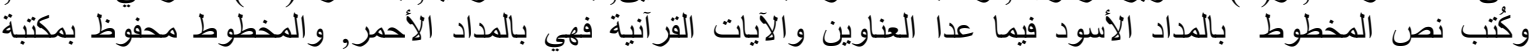
الكونجرس, تحت رقم, (DS461.6 M75 1700z) مجموعة (Lessing J. Rosenwald), وكان قد ند نم بيعه في مزاد الاد

(Sotheby's London)

للمزيد راجع نسخة مزوقة بالتصاوير من المخطوط على موقع مكتبة الكونجرس بالو لايات المتحدة الأمريكية. https://www.loc.gov/resource/rbc0001.2015rosen1791/?st=gallery(Last visit 20/5/2021).

' الألبوم (المضم) يحوي (^) تصاوير متفرقة من مخطوط عمل صالح, محفوظ بالمكتبة تحت رقم (Or. 2157) و توجد منه صور ضوئية على موقع المكتبة البريطانية

https://imagesonline.bl.uk/search/?searchQuery=Amal-i+Salih (Last visit 20/5/2021)

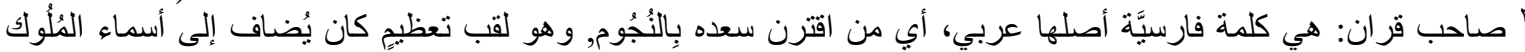

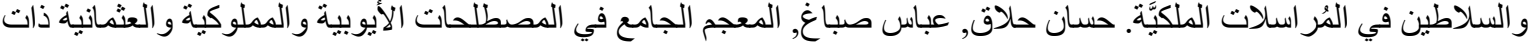

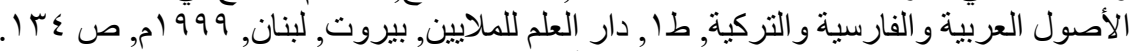

${ }^{4}$ Ashirbadi Lal Srivastava, The Mughul empire 1526-1803 A.D, $7^{\text {th }}$ edition, Shiva Lal agrwala company, Agra-3, India, 1960, P.293.

• أحمد محمود الساداتي, تاريخ المسلمين في شبه القارة الهندية وحضارتهم, جزآن, جr (الدولة المغولية), المطبعة النموذجية,

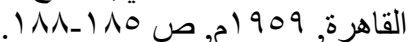
' آصاف خان, هو أخا نور جهان زوجة جهانكير, ووالد أرجمند بانو (ممتاز محل), وهو قائد الجيوش في فترة حكم أكبر وجهانكير, وكان له الدور الأكبر في تولي (زوج ابنته) شاه جهان لعرش المغول. أحمد محمود الساداتي, تاريخ المسلمين في شئ شئ

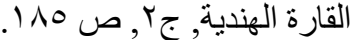
" جمال الدين الثبال, تاريخ دولة أباطرة المغول في الهند, طا, مكتبة الثقافة الدينية, بورسعيد, جمهورية مصر العربية, ا..بrم,

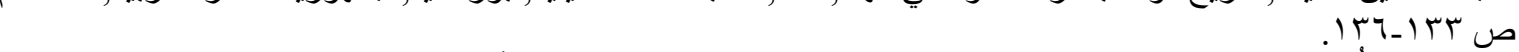

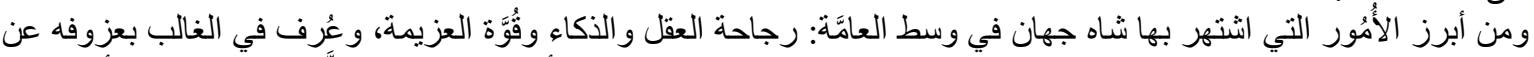

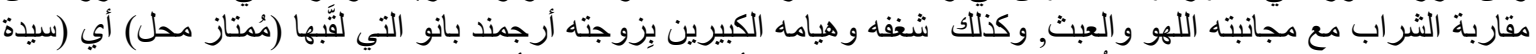

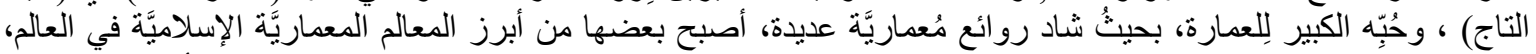

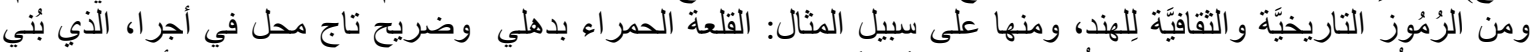

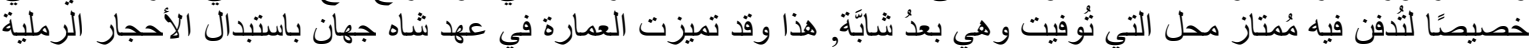

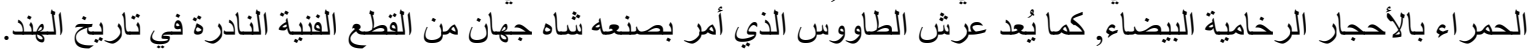

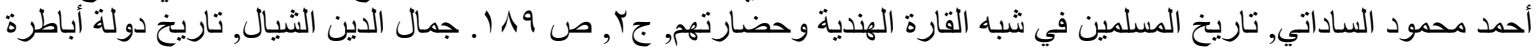

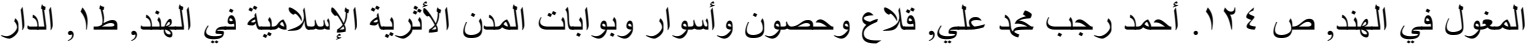

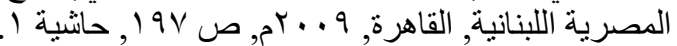

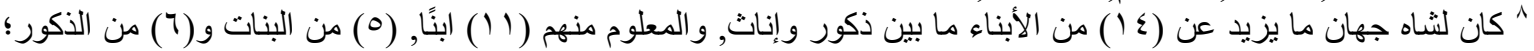

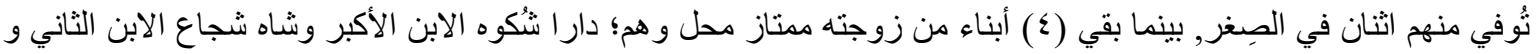

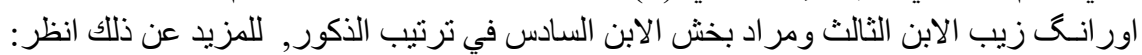
William Hoey and others, Memoirs of Delhi and Faizábád : being a translation of the Táríkh Farahbaḳhsh of Muhammad Faiz Baḳsh from the original Persian, Vol. 1 (memoirs of Delhi), Govt. Press, North-western Provinces and Oudh, Allahabad, India, 1988, P. 136.

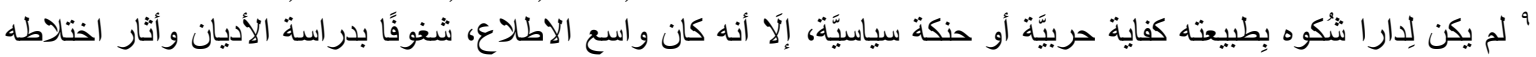

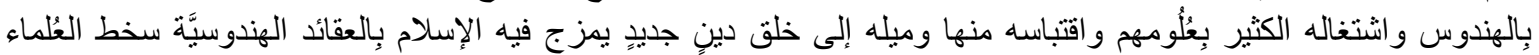

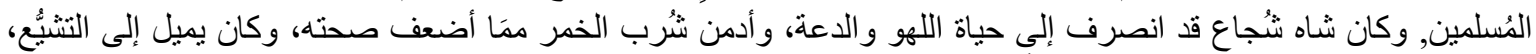

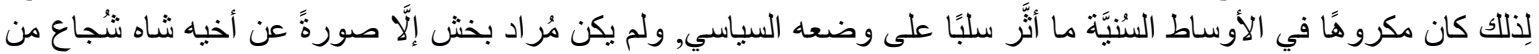

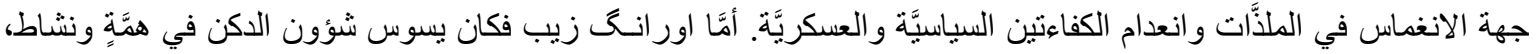




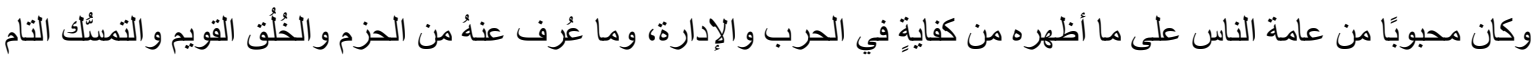

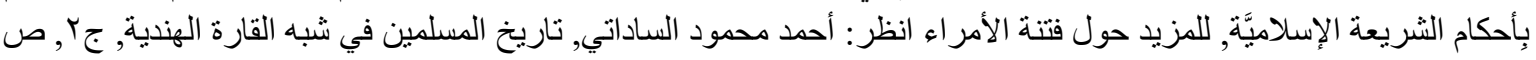
r.

Ashirbadi Lal Srivastava, The Mughul empire 1526-1803 A.D, P. 315- 321.

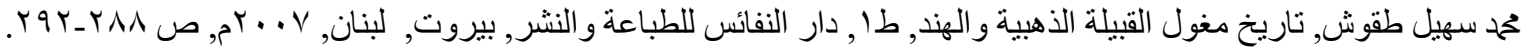

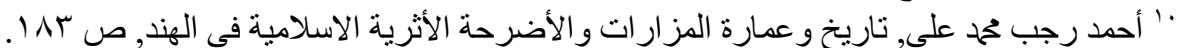

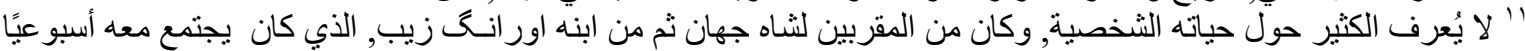

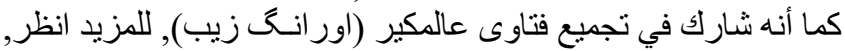

Munis D. Faruqui, The Princes of the Mughal Empire, 1504-1719, Cambridge University Press, 2012, P. 81. Iftikhar Ahmad Ghauri, War of Succession Between the Sons of Shah Jahan, 1657-1658, Publishers United, Lahore, 1964, P. 39.

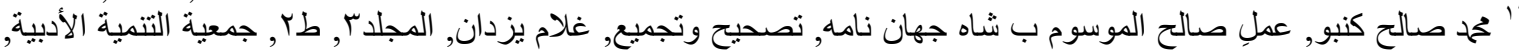

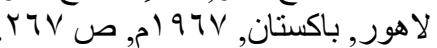

${ }^{13}$ Abraham Eraly, Emperors of the Peacock Throne: The Saga of the Great Moghuls, penguim books, India, 2000, P. 379.

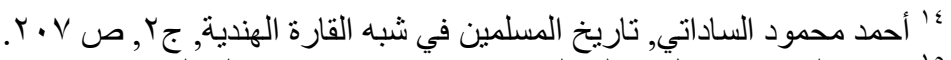

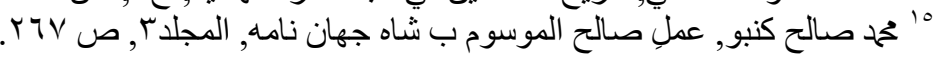

${ }^{16}$ William Hoey and others, Memoirs of Delhi and Faizábád, P.131-132.

${ }^{17}$ Abraham Eraly, Emperors of the Peacock Throne: The Saga of the Great Moghuls, P. 379.

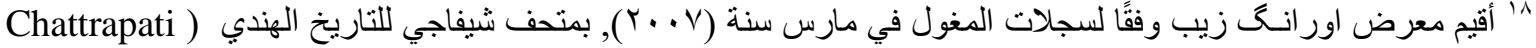
(Mhivaji Maharaj Museum of Indian History Aurangzeb -- As he was according to Mughal Records- Part II.

http://preamblequestioned.blogspot.com/2007/07/aurangzeb-as-he-was-according-to-mughal.html (Last visit 20/5/2021).

${ }^{19}$ Jadunath sarkar, M. A., History of Aurangzib mainly based on Persian sources, Vol. 2, Calcutta, India, 1912, P. 81-82.

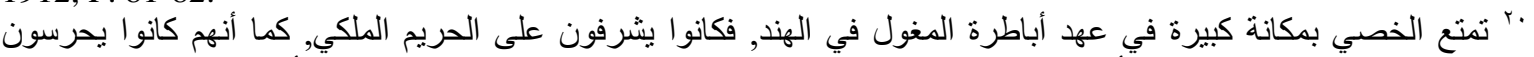

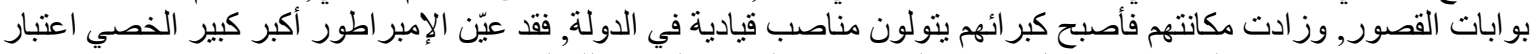

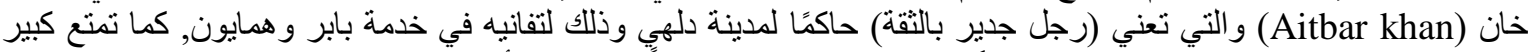

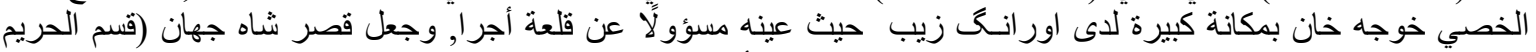

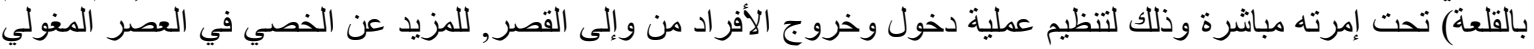

K.S. Lal, Muslim slave system in medieval India, Delhi, India, 1994, P. 99 - 104.

المندي انظر,

${ }^{21}$ William Hoey and others, Memoirs of Delhi and Faizábád, P.131-132.

${ }^{22}$ Abraham Eraly, Emperors of the Peacock Throne: The Saga of the Great Moghuls, P. 379.

Purushottam Singh, Shikashta-Nastaliq Persian farmans in court of Aurangzeb Almgir: a case syudy of

"Tarikh-i-dargah-i-mualla" preserved in Blanker archives, Journal of Brahmavart, Year Six, January -

December, India, 2019, P. 10-13.

احتل خشب الصندل مكانة كبيرة لاى الحرفيين الهنود لاسيما في مجال الحفر, ويحتل الككانة الثانية بعد العاج, لما له من رائحة

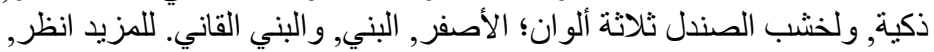

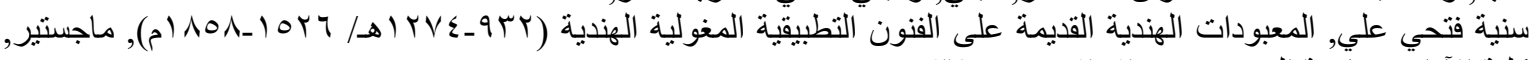

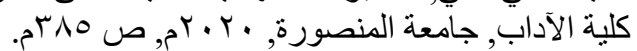

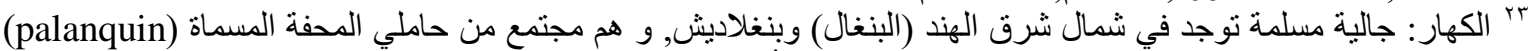

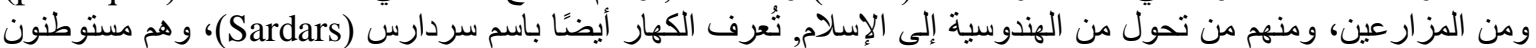

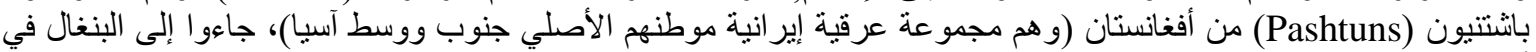

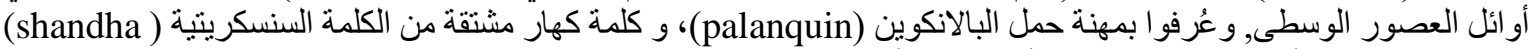

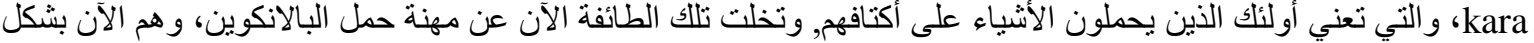

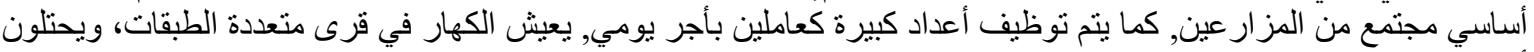

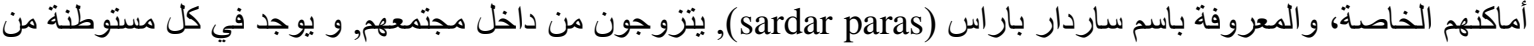

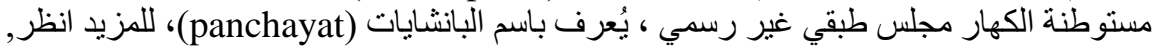

M.K.A Siddiqui, Marginal Muslim Communities in India, Institute of Objective Studies, New Delhi, India, 2004, P. 331-344. 
وللمزيد عن تصاوير الكهار في المجتمع الهندي انظر: http://www.columbia.edu/itc/mealac/pritchett/00glossarydata/terms/palanquin/palanquin.html.

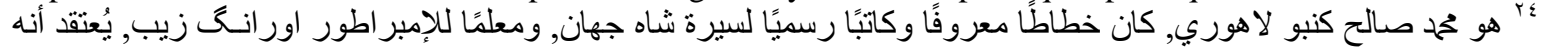

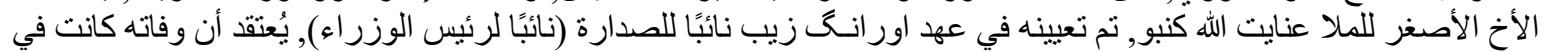

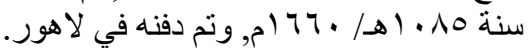

M. Hidayat Hosain, Contemporary historians during the reign of the emperor Shah Jahan, Islamic culture, Vol. XV, Juanuary, Number 1, 1941, Hyderabad, Deccan, 1941, P. 64-78.

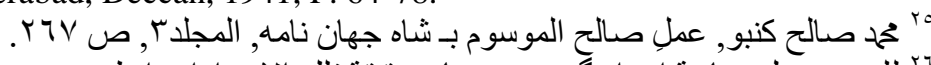

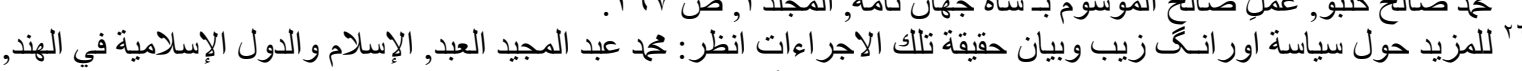

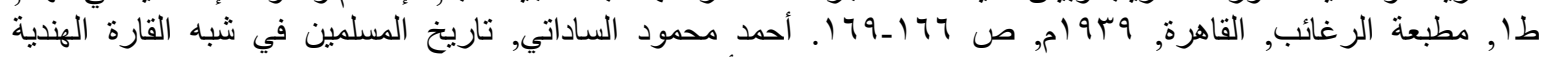

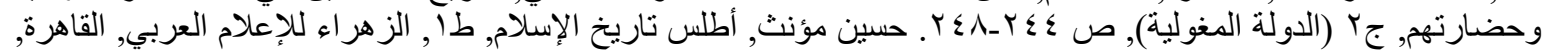

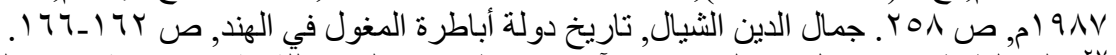

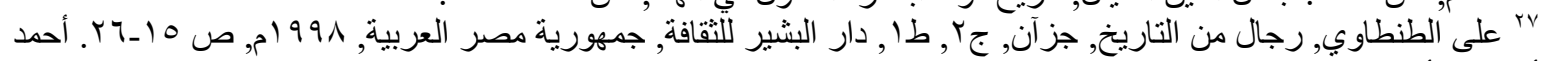

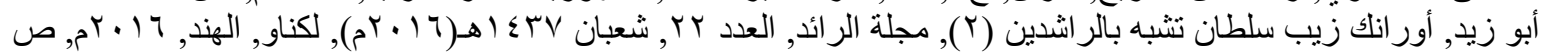

. 17

${ }^{28}$ William Hoey and others, Memoirs of Delhi and Faizábád, P. 134.

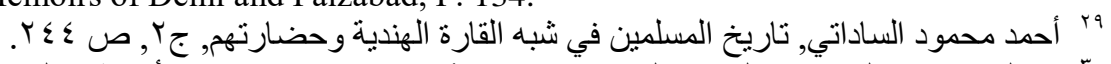

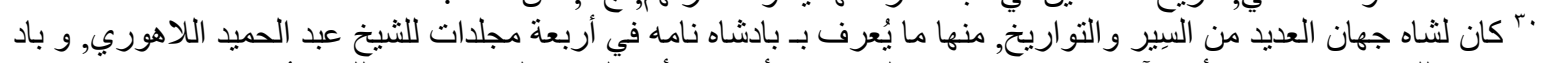

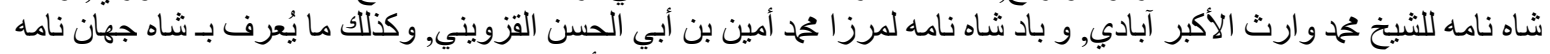

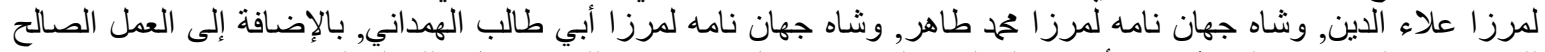

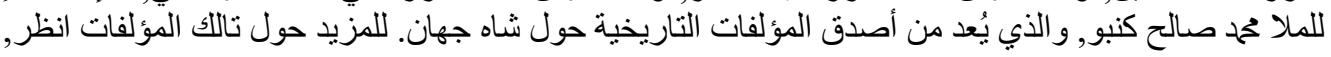
Elliot, H. M. (Henry Miers), Sir, Shah Jahan, Lahore, 1875.

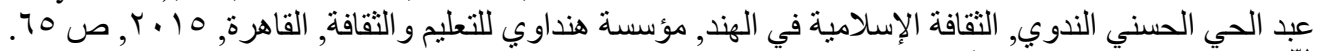

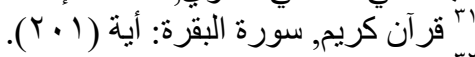

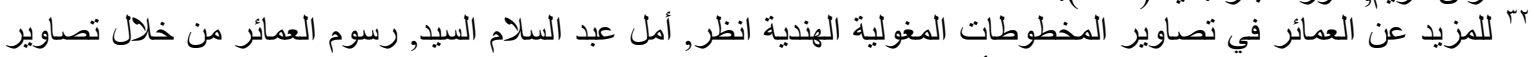

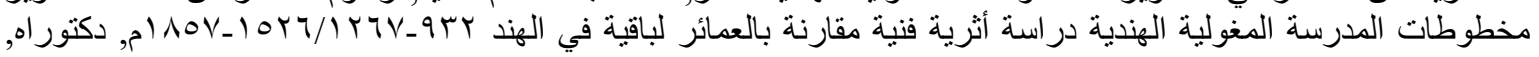

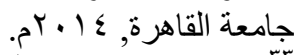

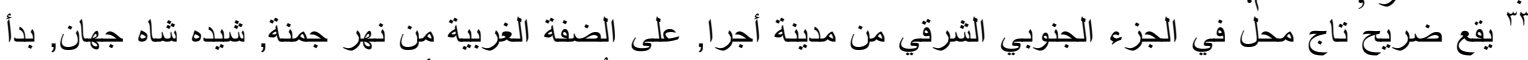

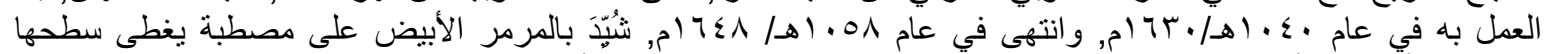

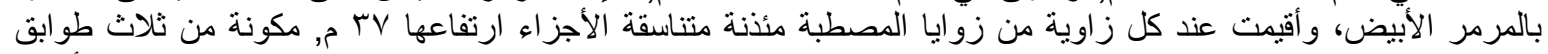

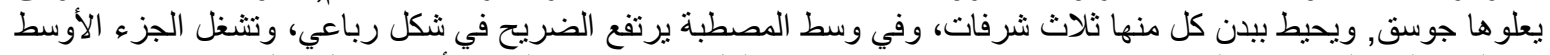

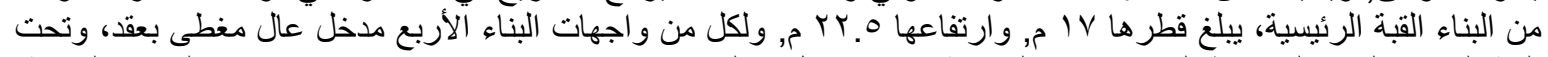

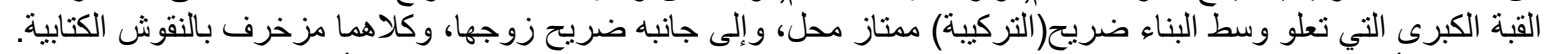

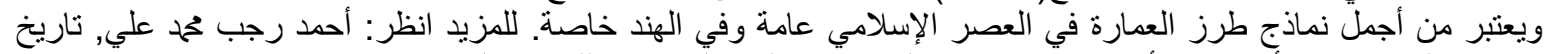

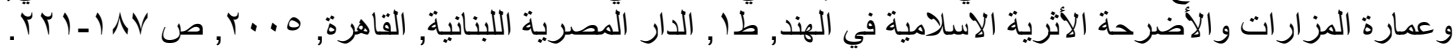

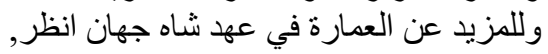

Percy brown, Indian architecture(The Islamic period), 3th edition,Treasure house of books,

Bombay, India, 1942, P. 110-119.

Group of authors, Great monuments of India, Dorling Kindersley Limited, New York, U. S. A., 2009, P.239-254.

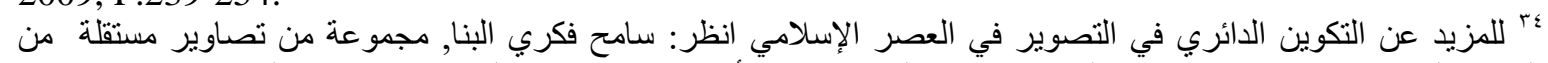

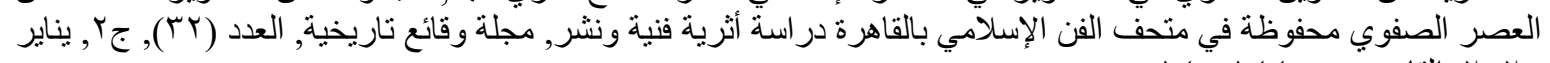

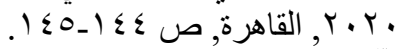

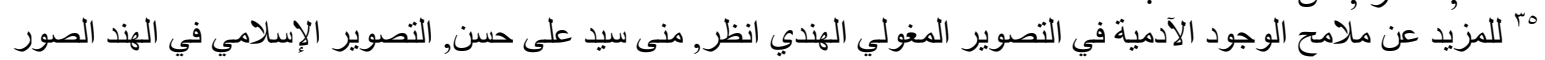

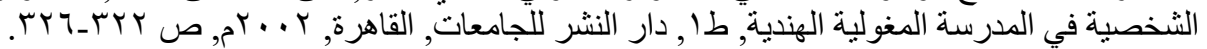

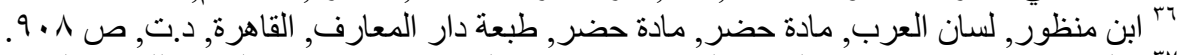

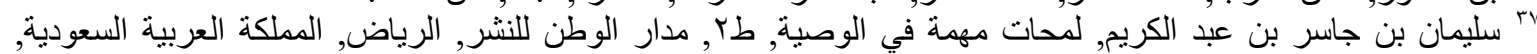

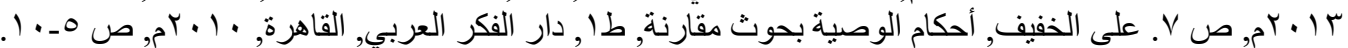

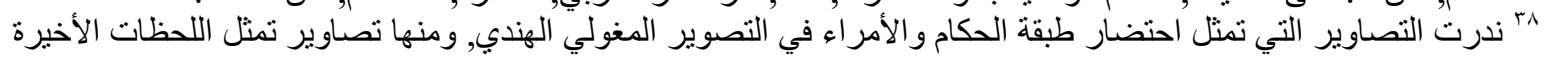

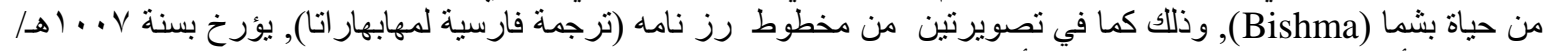
هو 1091 ام, الأولى محفوظة بمتحف فكتورياً و ألبرت بيرلين 
http://collections.vam.ac.uk/item/O434111/bhisma-painting-ali-(Last visit 20/5/2021)

و الثانية محفوظة بالمتحف البريطاني بلندن

https://www.britishmuseum.org/collection/object/W_1930-(Last visit 20/5/2021)

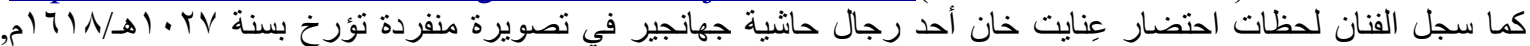

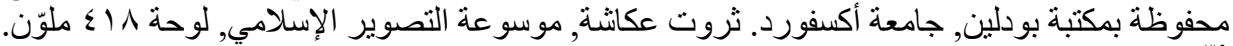

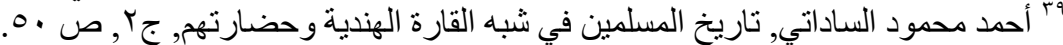

${ }^{40}$ Vincent A. smith, Akbar the great mogul 1542-1605, at the clarenadun press, Oxford, England, 1917, P. 223-224.

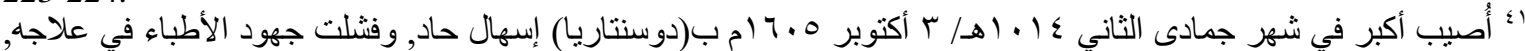

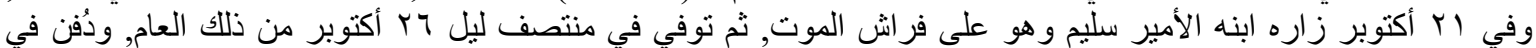

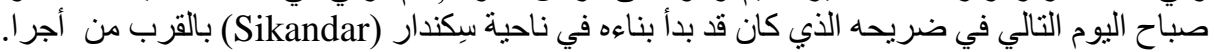
R. C. Majumdar, The History and Culture of the Indian People, Volume 11 The Mughal Empire, first published, Bharatiavidya bhavan, Bombay, India, 1917, P. 169.

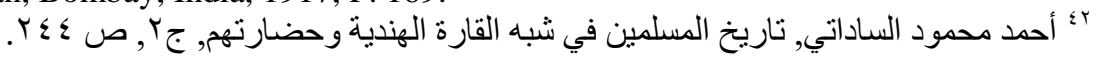

${ }^{43}$ Abraham Eraly, Emperors of the Peacock Throne: The Saga of the Great Moghuls, P. 379.

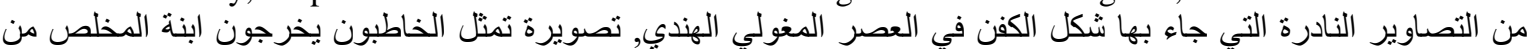

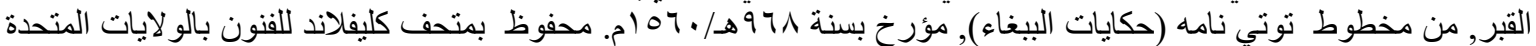

https://www.clevelandart.org/art/1962.279.146.a .(Last visit 20/5/2021)

الأمريكية.

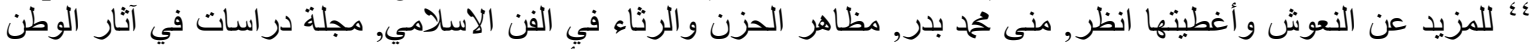

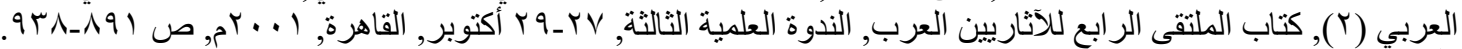

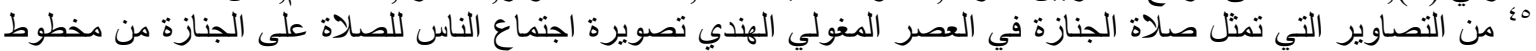

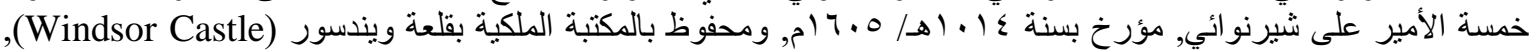
بالمملكة المتحدة انظر:

Asok Kumar Das, Mughal Masters, Further Studies, 1st edition, Mumbai: Marg Publications , 1998. P. 136, PL. 2.

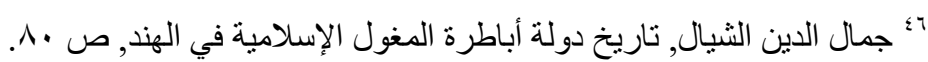

${ }^{47}$ Francis Gladwin, The history of Jahangir, edited with notes by Rao Bahadur, India, 1930, P. 19.

${ }^{48}$ The Jahangirnama (memoris of Jahangir, Empiror of India), translated edited by Wbeeler M. Tbackston,

Oxford university press, 1999, PP. 18, 456.

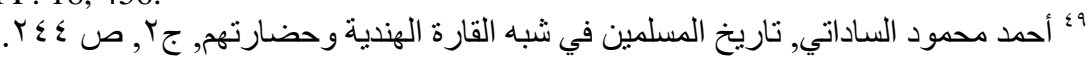

${ }^{50}$ The Jahangirnama (memoris of Jahangir, Empiror of India), p. 14.

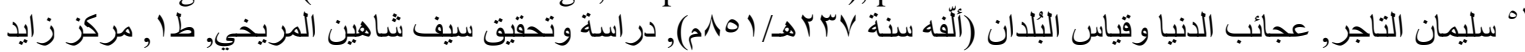

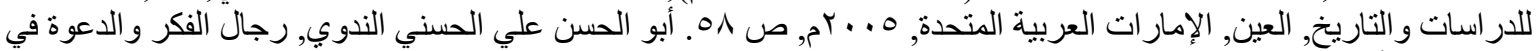

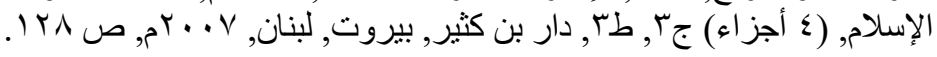

${ }^{52}$ William Hoey and others, Memoirs of Delhi and Faizábád, Vol. 1, P. 133.

به ظهير الدين مححد بابر, تاريخ بابر (بابر نامه) وقائع فرغانة ـ كابل - الهند, ترجمة وتقديم وتعليق, ماجدة مخلوف, طا, دار

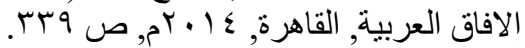

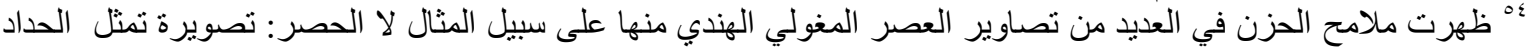

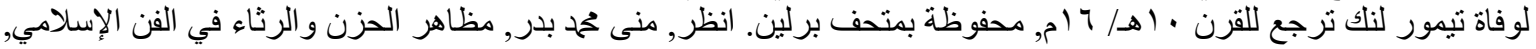
ص و

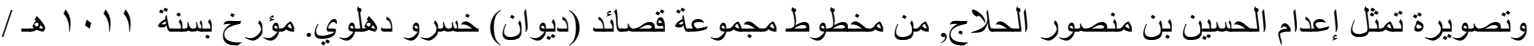

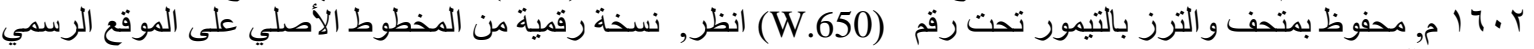

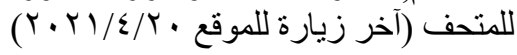

https://manuscripts.thewalters.org/viewer.php?id=W.650\#page/337/mode/1up

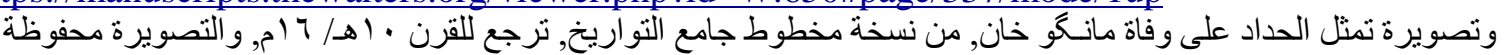
بمكتبة رامبور راز ارة الهند. انظر الهر

Dipanwita Donde, The Grieving Figure in Scenes of Loss and Mourning in Mughal Manuscript Painting. https://bilderfahrzeuge.hypotheses.org/5230, ( Last visit 20/12/2020)

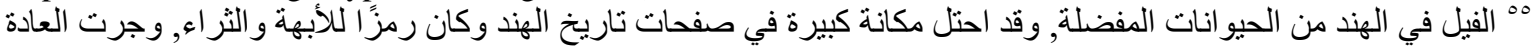

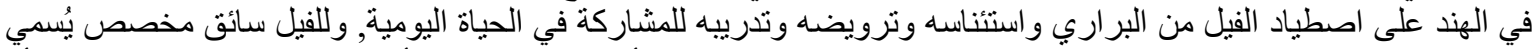

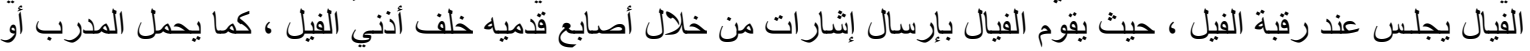


الفيال عصا للتحكم في الفيل تسمي المهماز. إسر اء صلاح الدئ الدين محمود, مناظر الصيد و القنص من خلال تصاوير مخطوطات

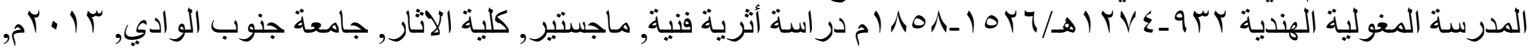

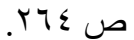

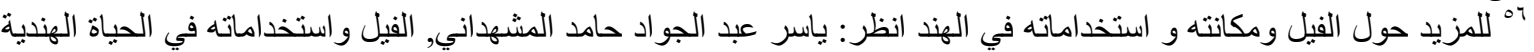

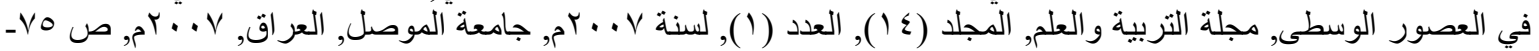

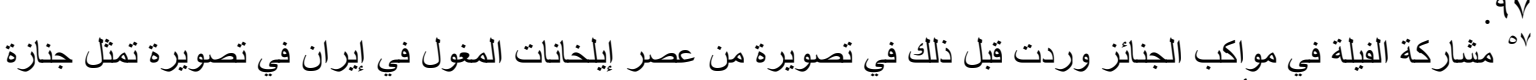

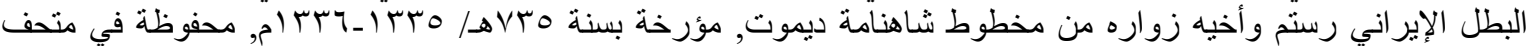

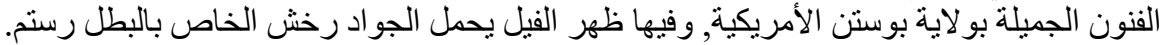

L. Komaroff, S. carboni, The legacy of Gengis Khan, the Metropolitan Museum of art, New York, 2002, Fig. 124.

${ }^{58}$ https://imagesonline.bl.uk/asset/149579(Last visit 20/5/2021). 9. وذلك كما حدث عند زيارة أكبر لضريح خو اجه معين الدين شيشتي تبركًا بميلاد ابنه جهانكير. The Jahangirnama, memoris of Jahangir, p. 5.

ويظهر ذلك جليًا في تصويرة تمثل زيارة أكبر لضريح الثيخ معين الدين شيشتي, من نسخة من مخطوط أكبر نامه, تؤرخ بسنة

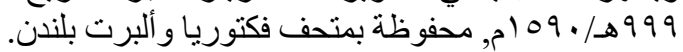

Susan Strong, painting for the Mughal Emperor: The Art of the Book 1560-1660, First edition, Victoria \& Albert Museum, 2002, pl. 1.

"7 ظهرت المظلة محمولة على أربعة قو ائم مثبتة في الأرض ويجلس أسفلها الإمبر اطور أكبر في تصويرة تمثل الإمبراطور أكبر

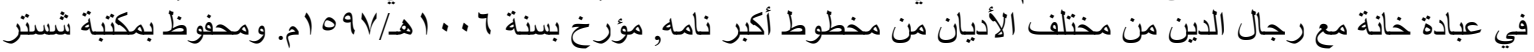
بيتي - مبلن.

John Guy\& Jorrit Britschgi, Wonder of Age Master painters India 1100-1900, The Metropolitan Museum of art, New Yourk, U.S.A., 2011, Fig. 15, P. 50.

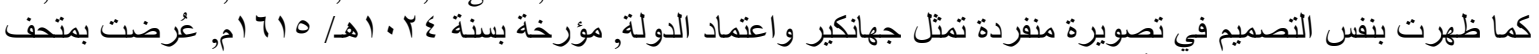

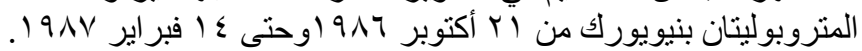

Sturat Cary welch and others, The emperor's album images of Mughal India, the metropolitan museum of art, Now York, 1987, PL. 16, P. 110.

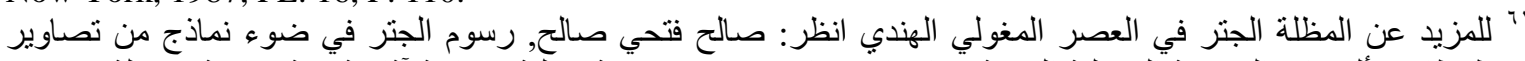

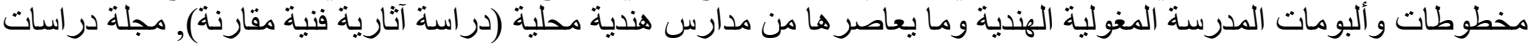

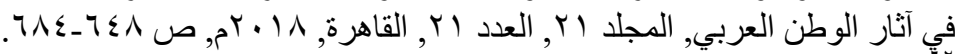

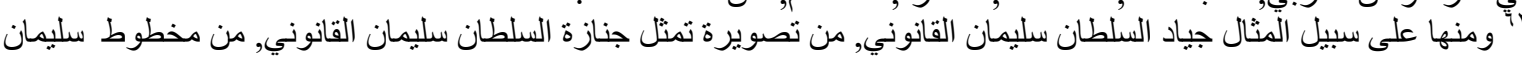

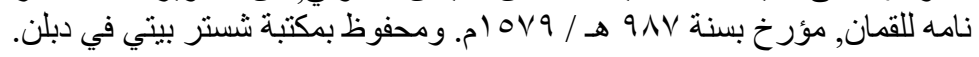
Serpil bagci, and others, Ottoman painting , Istanbul , Turkey, 2010, p.123

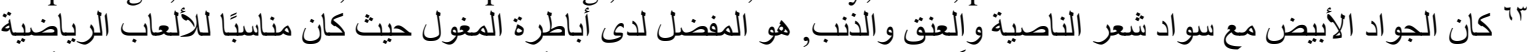

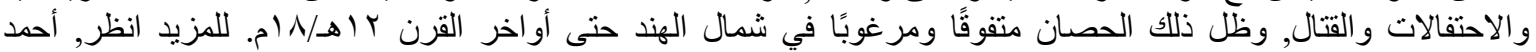

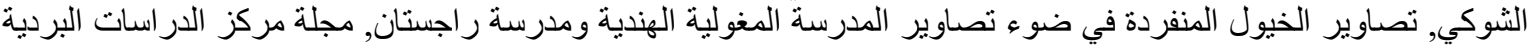

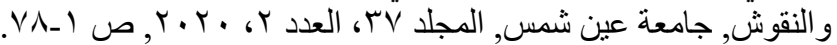

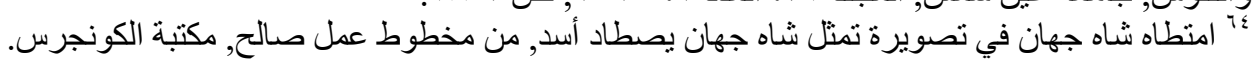
https://www.loc.gov/resource/rbc0001.2015rosen1791/?sp=76(Last visit 20/5/2021)

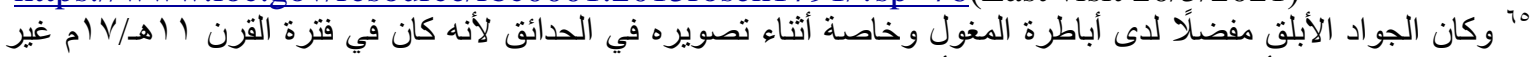

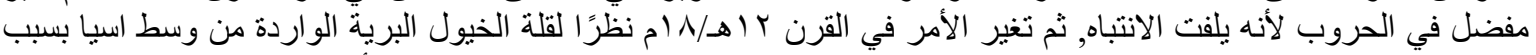

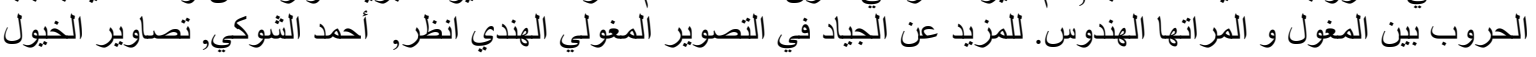

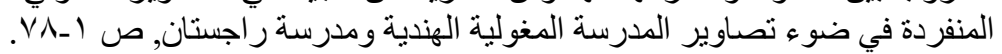

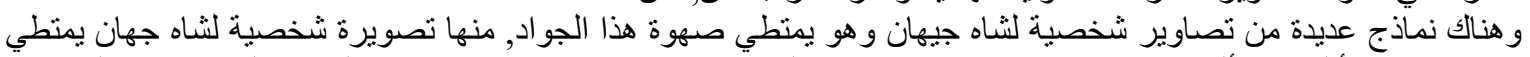

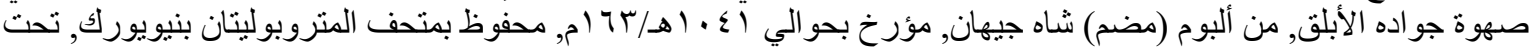

https://www.metmuseum.org/art/collection/search/451267 (Last visit 20/5/2021)

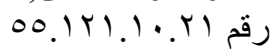
وكذلك تصويرتين من نسخة مخطوط عمل صالح, محفوظة بمكتبة الكونجرس بالو لايات المتحدة الأمريكية تمثل الأولى شاه جهان على جو اده الأبلق وسط جنون من نهن. https://www.loc.gov/resource/rbc0001.2015rosen1791/?sp=873\&r=-1.203,-0.002,3.405,1.726,0 و الثانية تمثل شاه جهان في حديقة قلعة شاه جهان آباد. https://www.loc.gov/resource/rbc0001.2015rosen1791/?sp=812 (Last visit 20/5/2021) 


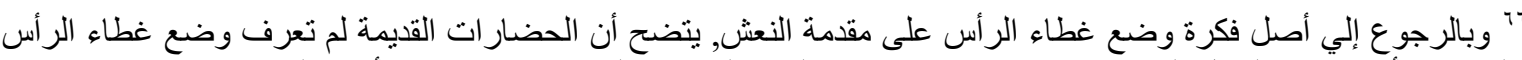

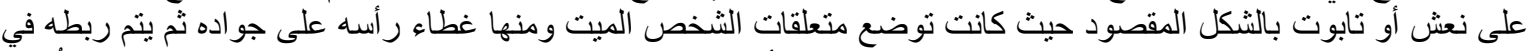

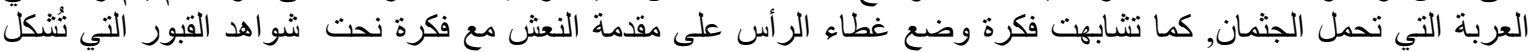

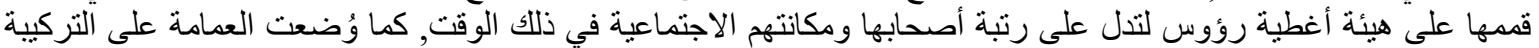

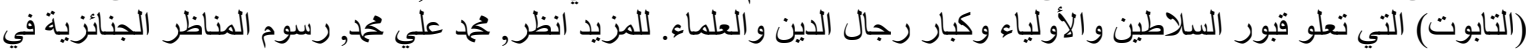

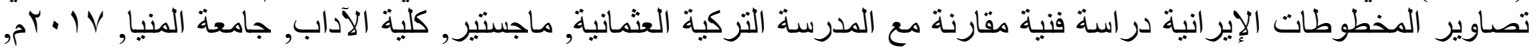

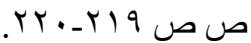

${ }^{67}$ Richard Ettinghausen, Islamic Art, The Metropolitan Museum of art Bulletin, New series, Vol .33, N.1, Islamic Art, 1975, PP.2-52, P. 24.

${ }^{68} \mathrm{https} / / / \mathrm{www}$.akgimages.de/CS.aspx?VP3=SearchResult\&VBID=2UMESQ5AK6LZYE\&SMLS=1\&RW=8 53(Last visit 20/5/2021)

${ }^{69}$ Sheila R. Canby, Princes, Poets and Paladins, Islamic and Indian Paintings from the Collection of Prince and Princess Sadruddin Aga Khan, 1st edition, British Museum Press, 1998, pl. 90.

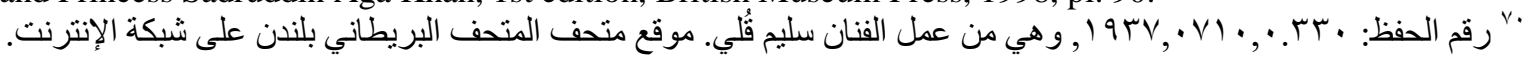
https://www.britishmuseum.org/collection/object/W 1937-0710-0-330

(Last visit 20/5/2021)

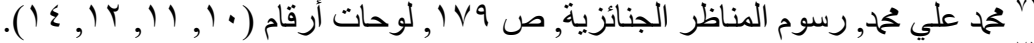

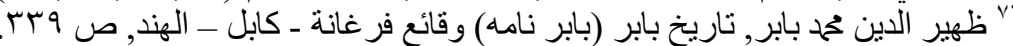

${ }^{73}$ The Jahangirnama (memoris of Jahangir, Empiror of India), p. 14.

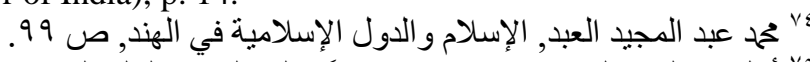

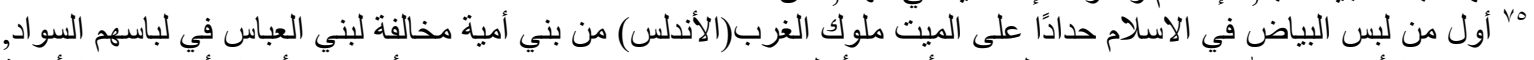

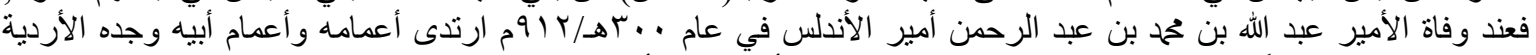

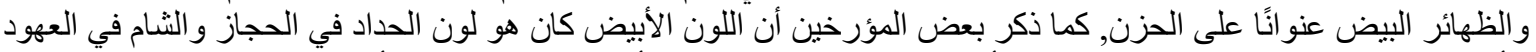

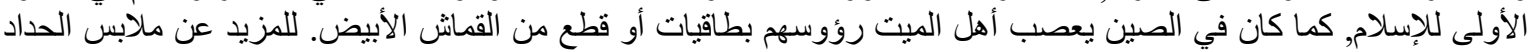

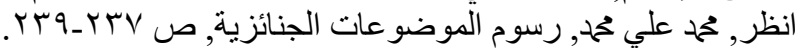

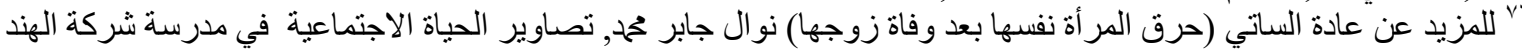

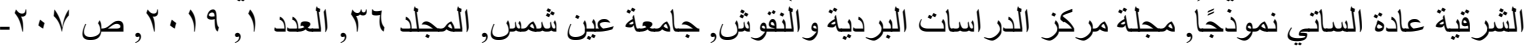
VYV عبد الله مبشر الطرازي, موسوعة التاريخ الإسلامي والحضارة الإسلامية لبلاد السند والبنجاب (باكستان الحالية) في عهر

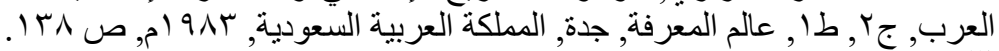

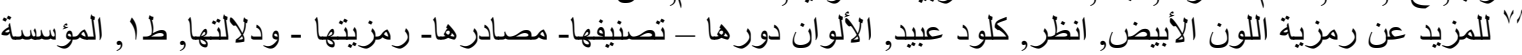

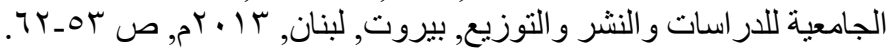

${ }^{79}$ William Hoey and others, Memoirs of Delhi and Faizábád, P. 134.

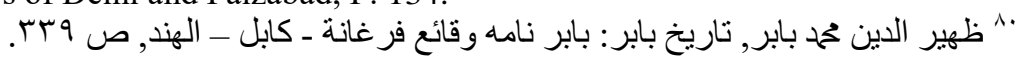

${ }^{81}$ Ellison Banks Findly, Nur Jahan empress of Mughal India, Oxford university press, 1993, P. 285-287.

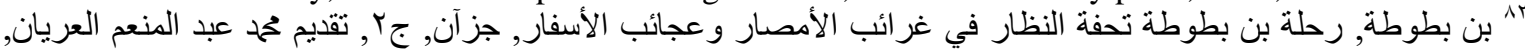

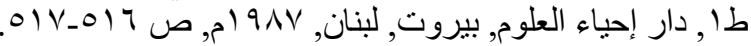

